University of Louisville

ThinkIR: The University of Louisville's Institutional Repository

Electronic Theses and Dissertations

$5-2014$

\title{
Lost in transition : a grade nine transition program using articulation activities and their effect on student attitudes.
}

Michael J. Hibbett

University of Louisville

Follow this and additional works at: https://ir.library.louisville.edu/etd

Part of the Education Commons

\section{Recommended Citation}

Hibbett, Michael J., "Lost in transition : a grade nine transition program using articulation activities and their effect on student attitudes." (2014). Electronic Theses and Dissertations. Paper 613.

https://doi.org/10.18297/etd/613

This Doctoral Dissertation is brought to you for free and open access by ThinkIR: The University of Louisville's Institutional Repository. It has been accepted for inclusion in Electronic Theses and Dissertations by an authorized administrator of ThinkIR: The University of Louisville's Institutional Repository. This title appears here courtesy of the author, who has retained all other copyrights. For more information, please contact thinkir@louisville.edu. 


\begin{abstract}
LOST IN TRANSITION: A GRADE NINE TRANSITION PROGRAM USING ARTICULATION ACTIVITIES AND THEIR EFFECT ON STUDENT ATTITUDES
\end{abstract}

\author{
By \\ Michael J. Hibbett \\ B.A., Northeastern Illinois University. 1977 \\ M.A., Tennessee State University, 1979

\begin{abstract}
A Dissertation
Submitted to the Faculty of the College of Education and Human Development of the University of Louisville in Partial Fulfillment of the Requirements for the degree of
\end{abstract}

Doctor of Education

Education Leadership and Organizational Development University of Louisville Louisville, Kentucky

May 2014 

LOST IN TRANSITION: A GRADE NINE TRANSITION PROGRAM USING ARTICULATION ACTIVITIES AND THEIR EFFECT ON STUDENT ATTITUDES

By

Michael J. Hibbett

B.A., Northeastern Illinois University. 1977

M.A., Tennessee State University, 1979

A Dissertation Approved on

April 15, 2014

by the following Dissertation Committee

Dr. Bradley Carpenter

Dissertation Director

Dr. Robert Ronau

Dr. William Bush

Dr. Tom Tretter

Dr. Sam Stringfield 


\section{DEDICATION}

This dissertation is dedicated to my late mother, Patricia Sharp Hibbett, who was a great reader and always in the motion of a continuous learner. I would also like to dedicate this work to my wife, Maribeth Eckert Hibbett, who has been a source of support, encouragement, and patience through this event of research and implementation for the past three years. It is with her guidance and support through these years that this process has been a rewarding experience.

I would also like to dedicate this dissertation to my sister, Diane Lynn Hibbett, for her technical assistance in completing this very complicated process. Finally, I would like to dedicate this dissertation to the students, administration, and faculty of Grant County Middle School and Grant County High School for their tremendous effort in making this research so valuable in understanding the importance of working together to help students make their educational experience valuable and rewarding. 


\section{ACKNOWLEDGEMENTS}

A special thanks to Dr. Robert Ronau, my committee chairman for his guidance, reading, encouraging, support and most of all patience throughout the entire process in developing this dissertation. I wish also to thank my committee members Dr. Molly Sullivan for her continued guidance towards the "prize," Dr. Tom Tretter for establishing the importance of understanding that you must earn the right to be a "guardian of the profession," Dr. Bill Bush who made sure the student and teacher attitudes were not left out of this research, and Dr. Sam Stringfield who opened up a whole new world of evaluating and understanding the importance of "high reliability organizations" in the field of educational structure. Thank you for your support and contribution to effectiveness of this research. 


\section{ABSTRACT \\ LOST IN TRANSITION: A GRADE NINE TRANSITION PROGRAM USING STRUCTURED ARTICULATION ACTIVITIES}

April 15, 2014

The purpose of this study was to investigate the impact of a set of structured articulation activities on the transition of students from grade eight to grade nine. In addition to this study, there are two linking studies, Allen (2011) and Christian (2012). Both studies examined the implications of the intervention of the articulation activities on the academic performance and behavioral conduct (Allen) and the development of Grant County Middle School and Grant County High School organize and progress into a learning organization (Christian). All three studies used the same conceptual framework to develop and construct their individual studies and create a vision that was implemented by teachers, administrators and students. Data were collected by retrieval from three student surveys; the Susan Harter Self-Perception Profile For Adolescents, the Susan Anderson Student Group, and the Focus Group Student Surveys). This was a post treatment one time study with a treatment (implementation) group and one comparison group. The study relies on the literature review of three vital concepts: organizational learning, high reliability organizations, and effective schools. This study was a quasi mixed-method design using both quantitative and qualitative methods. Likert-type survey instruments were used to address personality profiles and the academic, 
procedural, and social transition from the student's perspective of the transition from grade eight to grade nine. Data were analyzed to determine if the set of structured articulation activities influenced student attitudes about the transition process the student experienced moving to the high school. Recommendation for best practices for grade eight to grade nine are included as well as recommendations for further studies in the area of transitioning from middle to high school. 


\section{TABLE OF CONTENTS}

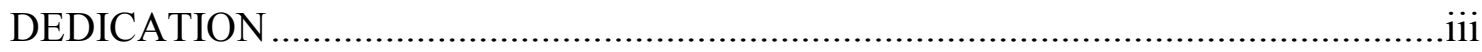

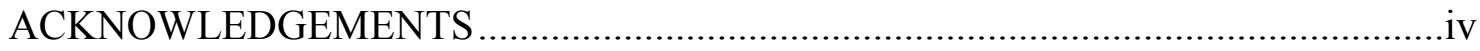

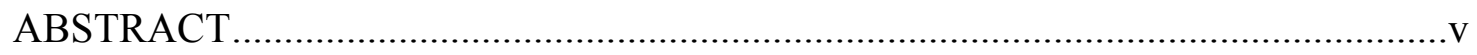

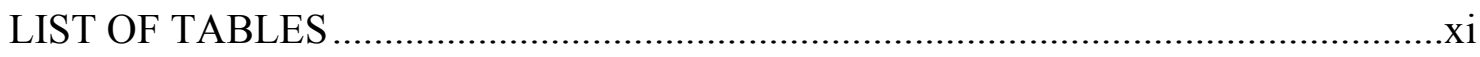

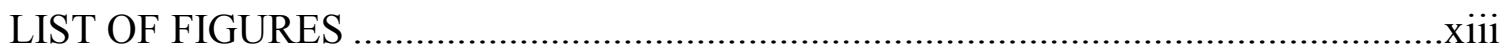

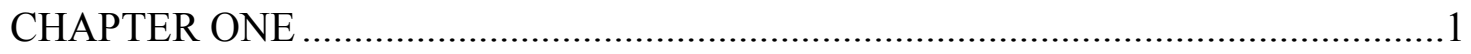

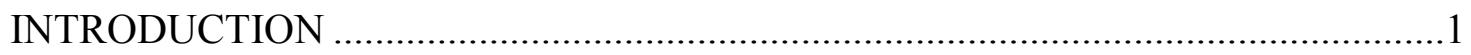

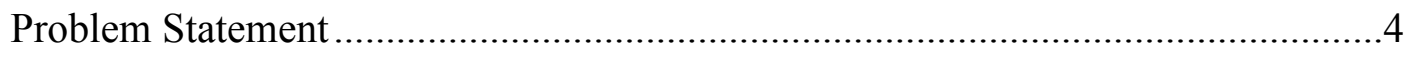

Purpose of the Study ………………….............................................................

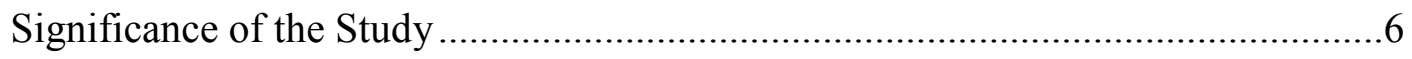

Context-Inception of Grant County Transition Initiative .......................................

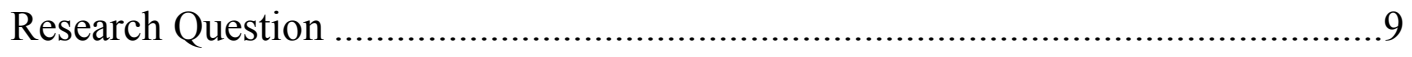

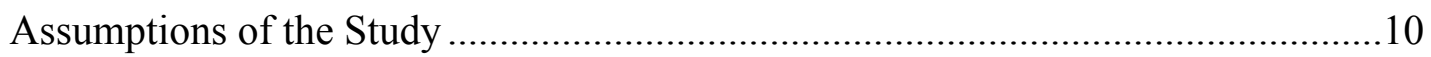

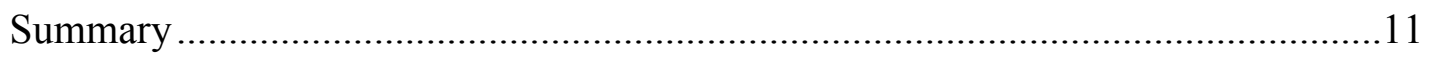

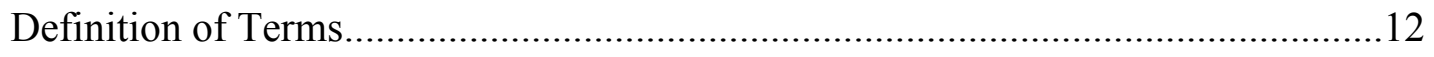

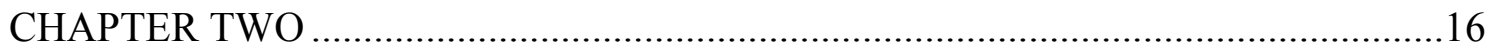

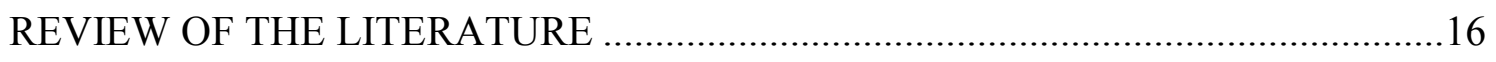

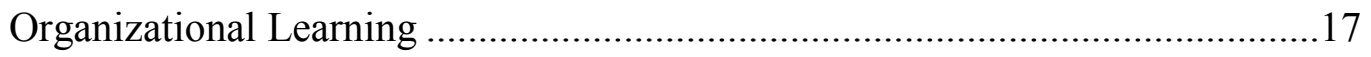

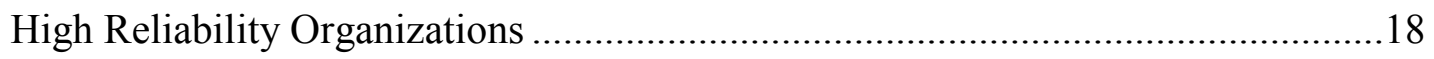

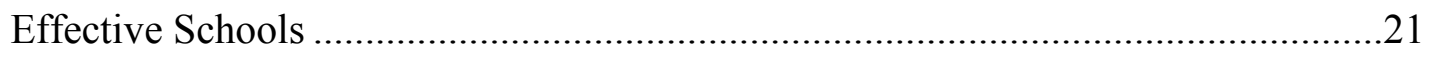


Organizational Learning, High Reliability Organizations, and Effective Schools ....27

Conceptual Framework Foundation.............................................................22

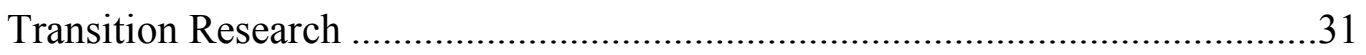

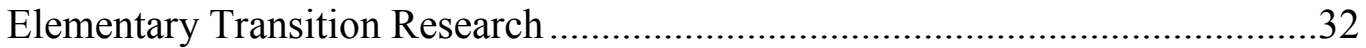

Middle School to High School Transition Research..........................................34

High School to College Transition Research...................................................39

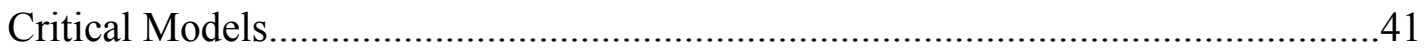

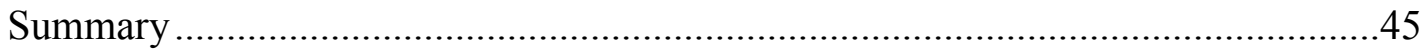

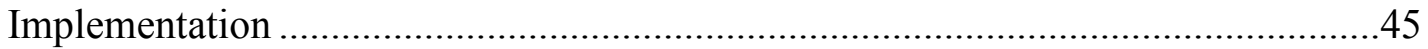

Fidelity and Implementation of Organizational Change................................47

Summary of Implementation of Organizational Change ....................................49

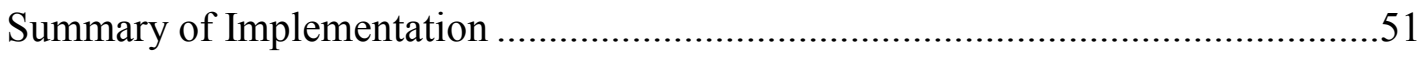

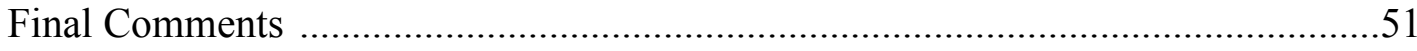

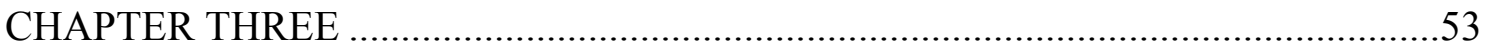

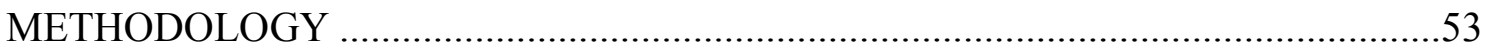

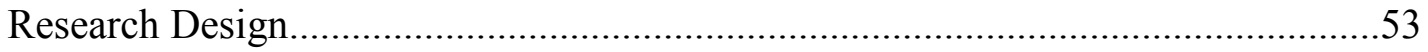

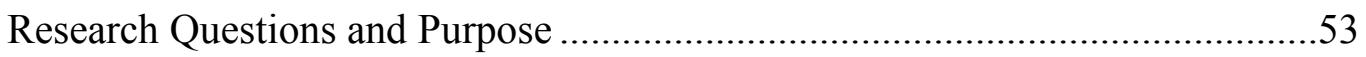

Implementation of Grant County Transition Initiative (GCTI) .............................54

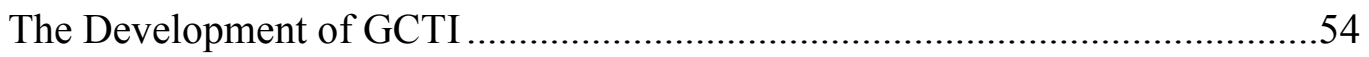

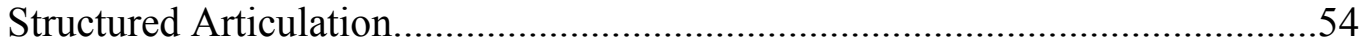

Monitoring GCTI Implementation........................................................60

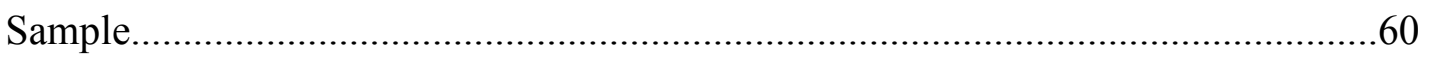

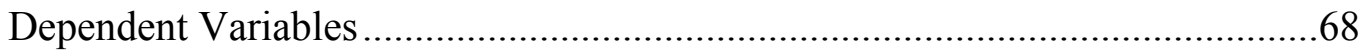




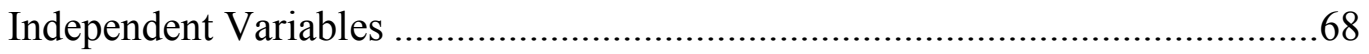

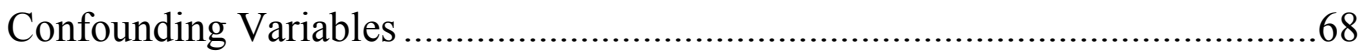

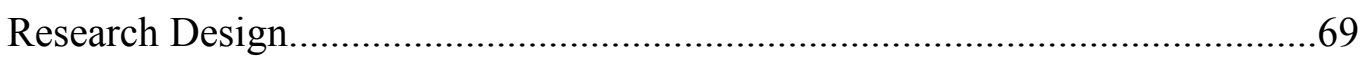

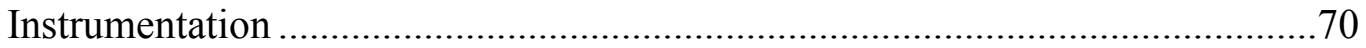

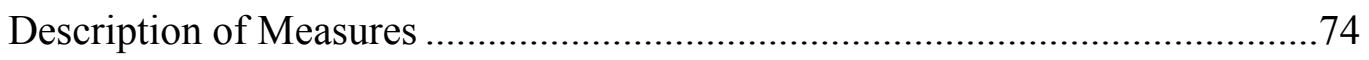

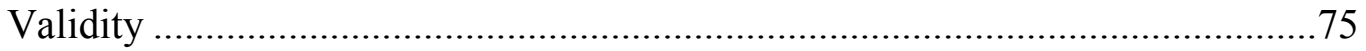

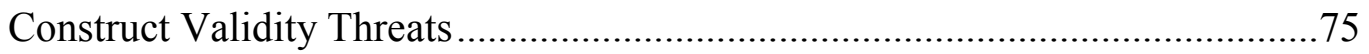

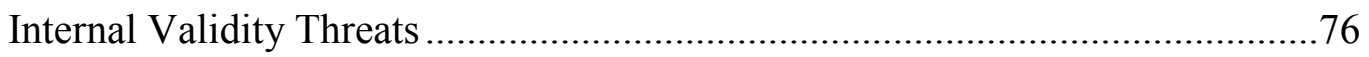

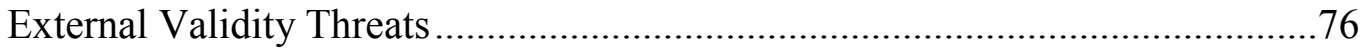

Statistical Conclusion Validity Threats ...............................................................76

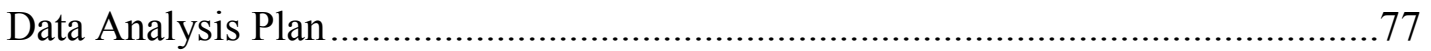

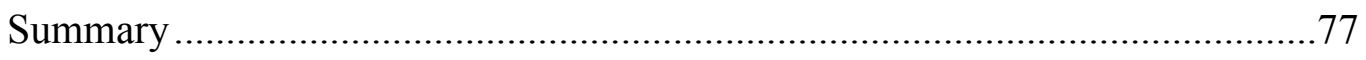

CHAPTER FOUR

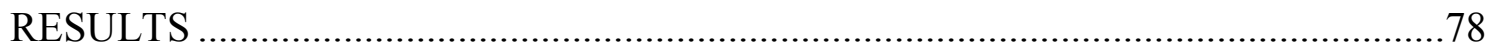

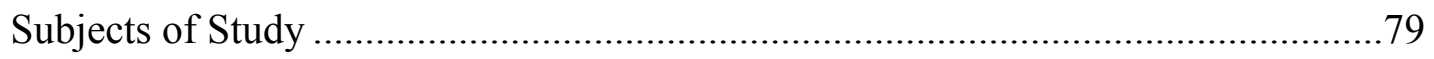

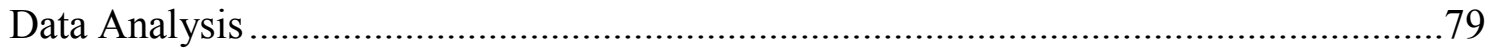

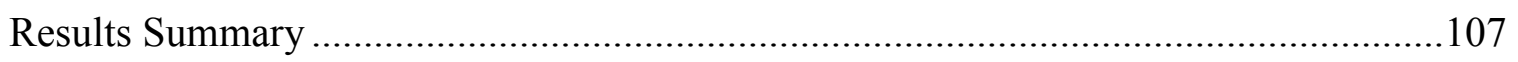

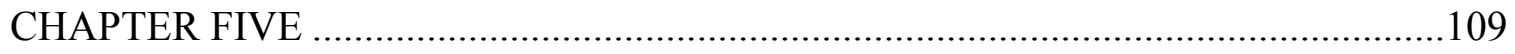

CONCLUSIONS, IMPLICATIONS AND RECOMMENDATIONS ............................109

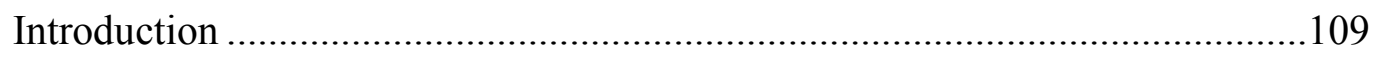

Research, Findings and Conclusions ......................................................................... 109

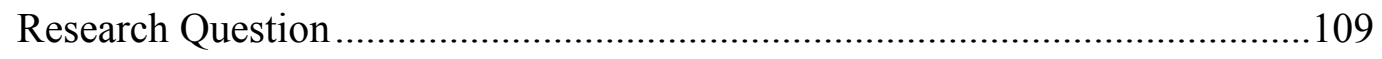

Impact of Set of Structured Articulation Activities...........................................111 
Findings Summary 122

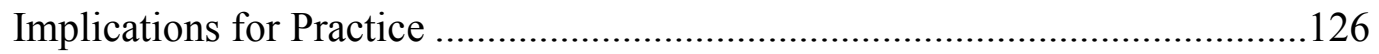

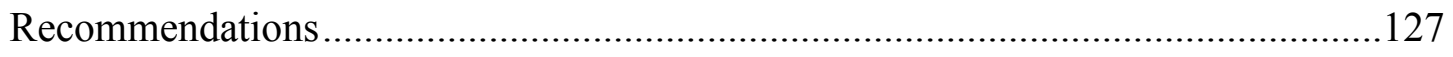

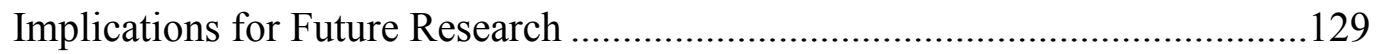

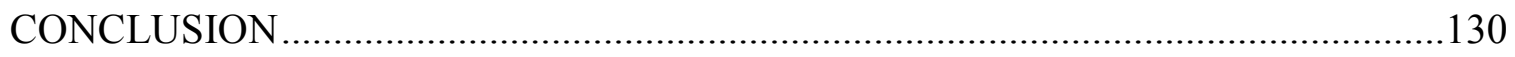

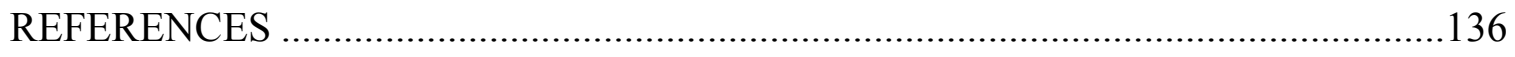

APPENDIX A: HARTER ADOLESCENT SELF-PERCEPTION PROFILE

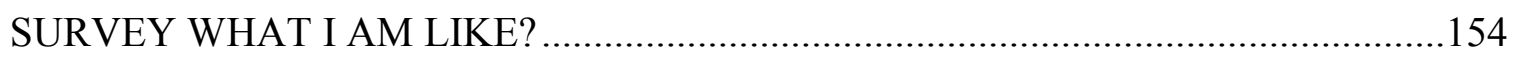

APPENDIX B: HARTER ADOLESCENT SELF-PERCEPTION PROFILE

SURVEY: HOW IMPORTANT ARE EACH OF THESE THINGS TO YOU?.............161

APPENDIX C: ANDERSON STUDENT SURVEY …………………………...........164

APPENDIX D: FOCUS GROUP INTERVIEW QUESTIONS ......................................166

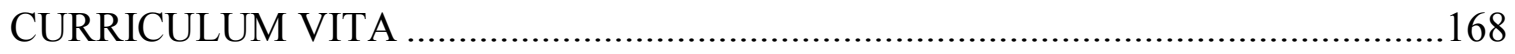




\section{LIST OF TABLES}

TABLE

PAGE

1. Structured Articulation Activities with Five Categorical Themes ........................55

2. Timeline for Implementation of Each Structured Articulation Activities.............57

3. Study Participants' Demographics for 2008-2009 Academic School Year ...........61

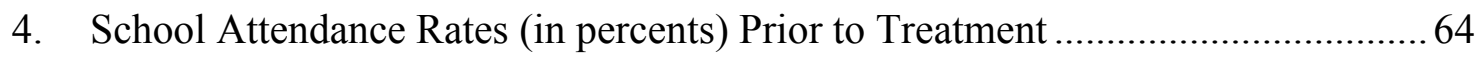

5. School Retention-by-Failure Rates (in percents) Prior to Treatment.................... 64

6. Ninth Grade School Retention-by-Failure (number of students failing)...............65

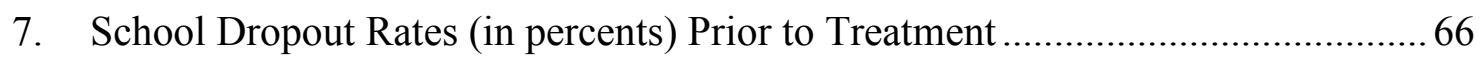

8. High Schools - Graduation Rates (in percents) Prior to Treatment ...................... 67

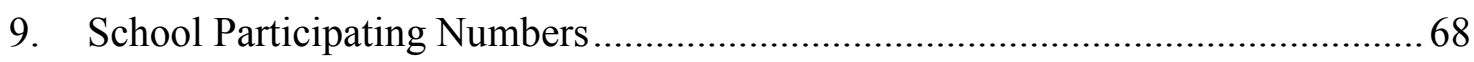

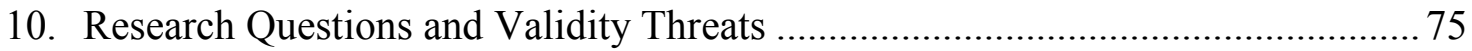

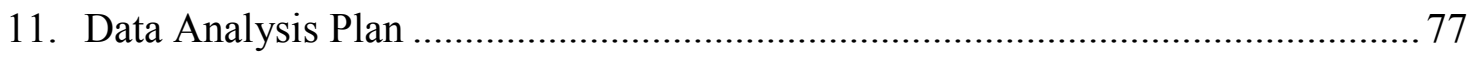

12. Cronbach Alpha Scores Harter Self-Perception Profile ...................................... 81

13. Harter Adolescent Self-Perception Profile - Part A........................................... 86

14. Harter Adolescent Self-Perception Profile - Part B ....................................... 91

15. Cronbach Alpha Scores Anderson Student Survey .......................................... 93

16. Anderson Student Academic Satisfaction Survey........................................... 94

17. Anderson Student Procedure Satisfaction Survey......................................... 95 
18. Anderson Student Social Satisfaction Survey …………………......................... 96

19. Anderson Student Interrelated Satisfaction Survey............................................... 97

20. Transition Experiences Judged After One Semester Of High School.................... 99

21. Anderson Focus Group Interview Questions ……................................................ 103

22. Anderson Focus Group Questions with Yes or No Answers (in percents) .............106 


\section{LIST OF FIGURES}

$\begin{array}{lll}\text { FIGURE } & \text { PAGE }\end{array}$

1. Overall Structure of Joint Study Participants ....................................................6

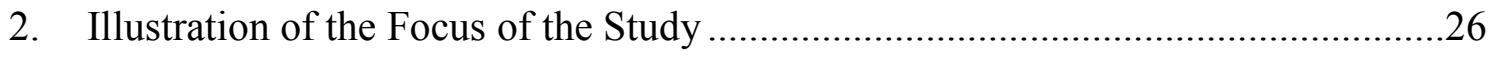

3. Grant County Transition Initiative Conceptual Framework...................................28

4. Mixed methods Research Design.............................................................. 70

5. Implementation Framework for the Grant County Transition Initiative..............74 


\section{CHAPTER ONE}

\section{INTRODUCTION}

The transition from middle school to high school is a developmental process that is a challenging period of time for the adolescents of our school age population. They are faced with an adjustment period that could affect their grades, attendance, and participation in the activities offered to them at the high school (Isakson \& Jarvis, 1999).

The new environment and academic demands that face these adolescents produce a stress level which can interrupt the path to high school graduation (Wise, 2008). This interruption is clearly evident in the present retention rate for ninth graders which has increased from $4 \%$ in the 1970 s to $12 \%$ in the 2000 s (Haney et al., 2004). The transition of these adolescents has created an experience for many students that will force them to make choices that will affect their friendships, interactions with older students, coping with more demanding and unfamiliar workloads, and the adjustment to new environmental surroundings.

As stated above, the last three decades of ninth grade enrollment had increased; however, a sizeable change was noted by the late 1970s with a steady increase of ninth grade retentions due to an increase in the number of failing grades by the students. This rate of retentions produced $12 \%$ fewer students in grade ten than in grade nine of the previous year (Haney et al., 2004). Those ninth grade students who fail two or more classes, and are retained; create a bulge in ninth grade student 
levels. This negative process then creates a combination of incoming ninth graders and a large number of students who have experienced notable failure in their first year of high school coming together to create considerably larger ninth grade class (Kennelly \& Monrad, 2007). Students that enter the ninth grade from the eighth grade with low grade point averages, high absenteeism, and discipline problems create an unprepared incoming ninth grader, which contributes to a failure cycle. Hertzog and Morgan (1999) reported in a study, which reviewed 450 middle and high schools, the ninth grade has become a holding area for students who have failed to cope with the academic and social pressures of the high school environment. The bulge that exists for the high schools has to be examined and solutions found for this dilemma.

The consequences of not addressing the retention rate in the ninth grade leads to an increase in the dropout rate of students at the high school level. Haney et al. (2004) point out that the dropout rate between the ninth and tenth grade has tripled over the last 30 years. George \& McEwin (1999) found that the highest failure rates exist in the ninth grade across the nation and that failure rate can produce high numbers of dropouts. The retention of a ninth grader can increase the dropout rate by $50 \%$.

Success at the ninth grade level is an essential ingredient towards achieving the goal of receiving a high school diploma. To accomplish this task, Fullan (1995) suggests schools must become learning centers that can develop and implement change in the structure of these centers. The capacity for innovation and reform depends on the learning center's ability to work collaboratively to improve the teaching and learning in these centers (Louis, 1994, 2006). The change needed at the eighth and ninth grade levels will have to be addressed by examining how the process of learning is occurring in 
these grade levels (Spender \& Grant, 1996). The development of systematic structures which can foster change in the existing processes and practices must be developed and reviewed by participants of the existing structures (Silins \& Mulford, 2002).

Transition studies (Blyth, Simmons, \& Bush, 1978; Isakson \& Jaris, 1999; Johnston, 1992; Lee \& Smith, 1995; Waggoner, 1994; Williamson \& Johnston, 1999) were analyzed and reviewed with the intent to understand how to implement and evaluate the use of structured articulation activities which can influence the transition of students from middle school to high school. The conceptual framework of this study centers on the development of activities designed by high reliability organizations, (Datnow \& Stringfield, 2000; Stringfield, Reynolds, \& Schaffer, 2008; Welck, Sutciffe \& Obstfeld, 2000) and effective schools (Brookover et. al., 1982; Lezotte, 2007; Sammons, 2006). High reliability organizations and effective schools are connected to the study of organizational learning (Louis, 1994; Senge, 1990). The development of structured articulation activities is aided by the structures of high reliability organization and effective schools, which address school improvement at the school and district level. The common characteristics of these organizational change mechanisms can be blended together for an improvement plan that will assist in the effective development of structured articulation activities. Schools interested in organizational learning can, at this point, clarify and blend these characteristics in order to create and implement structured articulation activities which can assist adolescents to navigate the transition from middle school to high school.

Achievement levels mandated by the No Child Left Behind Act (NCLB, 2002) require graduation rates of $90 \%$ or better to be met by all high schools in the next ten 
years. This requirement alone forces high schools to examine the causes of high retention rates at the ninth grade levels. Strategies that will help prevent high absenteeism and retention caused by repeated failures will be examined by school personnel to find ways to implement interventions.

Research which offers specific recommendations to enhance a positive and effective transition from the eighth grade to ninth grade is minimal (Akos \& Galassi, 2004; Mizelle, 1995). New information on the transitional process can provide additional strategies to an area in need of more research.

\section{Problem Statement}

Most middle and high schools do not usually implement strategies to ensure the student's successful transition from middle school to high school. Mizelle and Irwin (2000) reported that schools implement, on the average, fewer than three articulation activities to support the transition from grade eight to grade nine. Hertzog and Morgan (1999) found that schools that implement five or more articulation activities from the categorical areas of (1) Curriculum, (2) Facilities, (3) Safety and discipline, (4) Teachers, counselors, and administrators, and (5) General all increased the probability of student's successful transition from grade eight to grade nine. The general category contains any activities that do not directly fall into one of the other four categories. Therefore, with the research by Mizelle, Irwin, Hertzog, and Morgan as a foundation, this study implemented a set of structured articulation activities into an intervention titled the Grant County Transition Initiative. The Grant County Transition Initiative (GCTI) administrative team selected a structured set of twelve articulation activities that encompassed all five categorical areas from the research of Hertzog and Morgan (1999). 


\section{Purpose of the Study}

This study was the cornerstone of two linking studies prepared by Allen (2011) and Christian (2012) which used the same conceptual framework to examine the intervention of structured articulation activities during a student's transition from grade eight to grade nine. This structure is depicted in Figure 1. Allen's study was focused on the performance and behavior outcomes of students who attended Grant County High School as grade nine students and compared their results of Bullitt East high School students, who received a limited number of articulation activities. In addition, Christian's study examined the development of a learning organization at Grant County High School and Grant County Middle School as it worked together to implement the set of articulation activities into the existing transition process. The Common core linking all three studies was the recognition of the same vision for the teachers, administrators, and students whose goal was to experience a successful middle school to high school transition. The purpose of this study was to identify the impact of a set of structured articulation activities on the successful transition of students in the treatment group from grade eight to grade nine. 


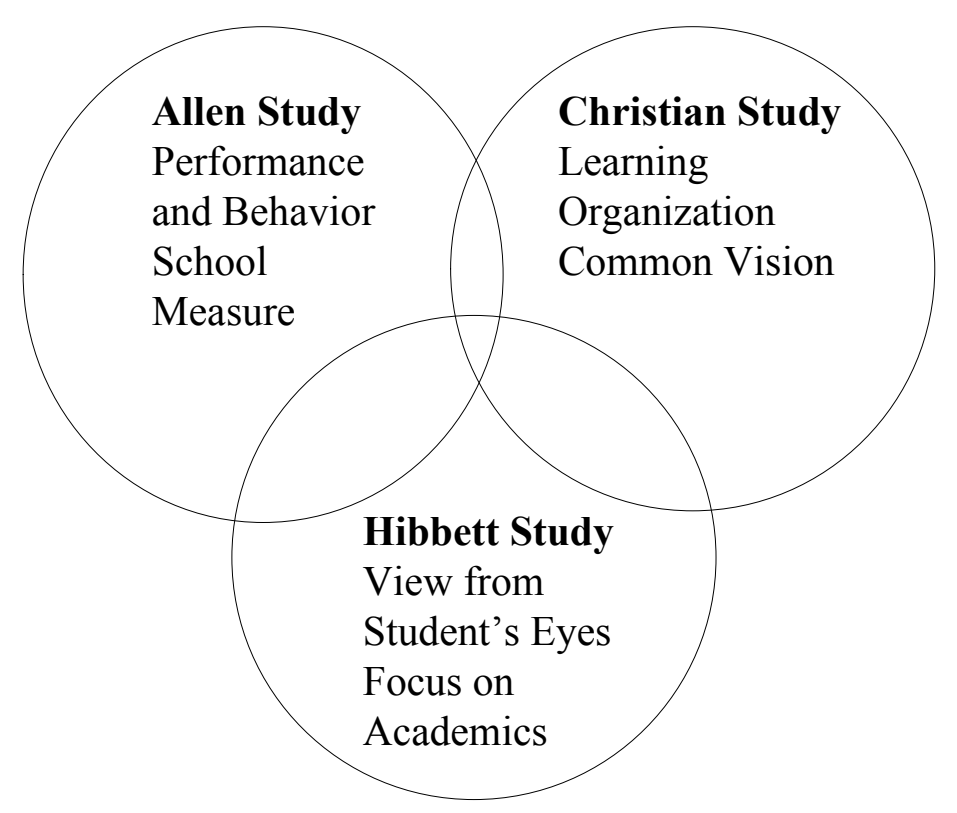

Figure 1. Overall Structure of Joint Study Participants

\section{Significance of the Study}

The failure rate at the ninth grade level creates an unfortunate pattern of disillusion for the young adolescents who are trying to start their secondary academic years on a positive path. Their social and academic success during these years can have enormous consequences in the development of their future academic success. The high percentage of ninth graders in the high school is a problem for the entire country (Kennelly \& Monrad, 2007). This dilemma creates lower levels of enrollment at the other grade levels which results in lower graduation rates and higher drop out numbers. Kennelly \& Monrad, (2007) emphasize that school leaders must focus intensely on the consequences from the failure to drop out pattern that the high school environment is producing at the ninth grade level. The failure rate exists to a degree of three to five times higher than the tenth, eleventh, and twelfth grades (George \& McEwin, 1999). Black (2004) reports ninth graders experiencing failure at this early start to the high 
school academic environment will have a 70 to $80 \%$ chance of not receiving a high school diploma with their classmates.

The impact of eighth and ninth grade transition problems could have an impact on Kentucky which has seen a 20\% higher enrollment in the ninth grade over the eighth grade in 1999. This places Kentucky with six other states that rank at the top of the list for having the largest number of ninth graders which created a noticeable bulge (Haney et al., 2004). The impact of failure at these rates has impacted the United States ranking of high school diplomas from first to thirteenth compared to global competitors (Wise, 2008). These results have placed Kentucky in a critical situation where it is important to produce a population of adults with the skills needed to compete regionally and globally.

There is little empirical evidence available which studies the failure rate at the transition point of eighth and ninth graders, where a set of structured articulation activities were introduced to improve their confidence and academic levels. The research that does exist recognized some correlation between the implementation of these activities and the improvement of student success in the ninth grade. Studies that indicated improved student progress all had specific articulation activities present in their programs (Hertzog \& Morgan, 1999; Mac Iver, 1990, Mac Iver \& Epstein, 1991). The results from these studies affirmed structured articulation activities can have a positive effect on the transition process of adolescences from middle to high school. The number and nature of activities and their effectiveness still need to be examined further.

This study expanded the present knowledge by addressing the intervention process of eighth graders transitioning to the ninth grade level. Additionally, this research 
evaluated the implementation of specific articulation activities and its impact on social and academic experiences of these students.

\section{Context and Inception of Grant County Transition Initiative}

The Grant County Transition Initiative (GCTI) was implemented during the school term of 2008-2009 at Grant County Middle and High School. A set of structured articulation activities was introduced through to the 2009-2010 school term. This study examines the impact of the GCTI had on student attitudes. Previous studies in conjunction with this study addressed student achievement and behavior (Allen, 2011) and the learning organizational structure (Christian, 2012). For this study, Grant County Middle and High School were identified as the treatment site and two Bullitt County middle schools and one high school were used as comparison sites. Both the administrations and eighth and ninth grade faculties at Grant County Middle and High school were involved in implementing the articulation activities. Performing well academically and behaviorally at the high school level was the main goal of articulation activities.

The transition research of Hertzog and Morgan (1999) and Mizelle and Irwin (2000) served as the guide for specific articulation activities which were implemented in this study. The literature review in Chapter Two outlined the various articulation activities found in the body of research which support the selection of the specific articulation activities applied in the GCTI.

The focus of this study was to (1) Create an initiative that would have positive impact on students while they transition in the ninth grade. (2) Add to the body of 
knowledge about the impact of a set of structured articulation activities on student's transition from the eighth grade to the ninth grade.

\section{Research Question}

The original project that focused on four research questions was separated into three individual studies. The four questions in the original project included:

Research Question 1: What impact does a set of structured articulation activities have on student attitudes?

Research Question 2: What impact does a set of structured articulation activities have on student academic performance?

Research Question 3: What impact does a set of structured articulation activities have on student behavior?

Research Question 4: What impact does a set of structured articulation activities have on Grant County Schools as a learning organization?

This study addresses Research Question 1: What impact does a set of structured articulation activities have on student attitudes? Key challenges confront the student who experienced difficulties of moving from grade eight to grade nine. This research question searched to find out how students will respond to the introduction of a set of structured articulation activities during the transition process. Their responses measured how the students reacted to academic, social and procedural demands of this process. In addition, Allen (2011) measured student's academic performance and behavioral conduct after the implementation of the same articulation activities. Also, Christian (2012) measured the development of the articulation activities through the lenses of the administrators and 
teachers as they operated as a learning organization. All three studies are geared towards influencing a positive outcome for students who transition to the high school.

\section{Assumptions of the Study}

The empirical research available on the transition of students from middle to high schools is limited in recognizing the individual needs of these students. Articulation activities that address these needs (Mizelle \& Irwin, 2000) can help students navigate the social, developmental, and cognitive experiences they will face in the transition process from middle school to high school. Therefore, the assumptions of this study are:

1. All the Grant County Middle School students in year 2008-2009 went to Grant County High School in year 2009-2010.

2. All the Bullitt County Middle School students in year 2008-2009 went to a specific Bullitt County high school.

3. Each of the participating high schools had a ninth-grade Freshman Academy.

4. The Freshman Academies in both counties share common traits.

5. The concept that all students in this study were included in the general education setting had the ability to demonstrate academic success.

6. The certified staff at all participating schools was highly qualified.

7. Course requirements in each high school were comparable.

8. All participating middle level schools functioned as middle schools with the teaming structure.

9. The schools in Bullitt County, which functioned as non-treatment groups, would operate under normal orientation activities. No additional articulation activities would be introduced during the time of this study. 


\section{Summary}

Kimmel and Weiner (1985) recognized three important developmental stages occur in adolescence which center on self-reliance, expanding relationships with peers, and the ability to gain intimate friendships. The ninth grade academic year represents developmental challenges for students as they strive for the emotional, cognitive, and behavioral components that will help them become autonomous (Berndt, 1989). This study examined the intervention of articulation activities in the transition process and the extent to which they affected the attitudes of adolescents during their transitional experience.

The change needed to structure positive intervention into the lives of these adolescences will require schools to understand and document both what happens in the classroom and at the school level. Organizational learning requires a shared, social construction that is common to all members of the school organization (Louis, 2006). This study examined the research on organizational learning, high reliability organizations and effective schools and how their principles can help develop and implement a program of articulation activities designed to improve the school related changes that may affect student attitudes towards the transition experiences that evolve from moving to the high school from the middle school.

Chapter Two presents research on organizational learning and how this links with the characteristics of high reliability organizations and effective schools. High reliability organizations and effective schools set the groundwork for the implementation of a structured articulation activity in an effort to improve student academic performance as they transition to a new educational environment. 


\section{Definition of Terms}

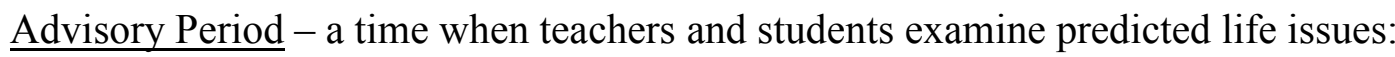
conflict resolution, diversity, goal setting, and peer relationships.

$\underline{\text { Articulation Activities }}$ - activities designed to create a smooth transition from one school level to another, thereby increasing the likelihood of success at the next level. These activities familiarize students and parents with the new school, the new teachers, and the school's policies, expectations and programs in order to create a seamless transition. In this study they are considered a set of structured articulation activities, with none of the activities considered to be of greater value than others. The activities implemented for this study have been organized into five categories: curriculum; facilities; safety and discipline; teachers, counselors, and administrators; and general.

$\underline{\text { Curriculum }}$ - these activities inform students and parents about curricular expectations, course offerings, the number of credits per year needed to stay on track for graduation ACT information, homework policies, schedules, etc.

$\underline{\text { Facilities }}$ - these activities acclimatize students to the building to which they will transition.

$\underline{\text { Safety and Discipline }}$ - these activities inform students of the school's discipline policies, dress code, behavior expectations, and student absence policies

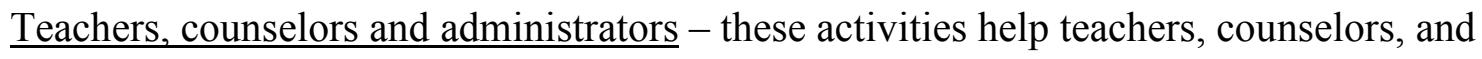
administrators build relationships with students and their parents, and provide career expectations and response to intervention opportunities.

$\underline{\text { General }}$ - these activities include any activity that doesn't fall into one of the other four categories. 
Athletic competence - the adolescent's perception of his or her athletic ability and competence at sports.

Dropout - a grade 7 through 12 student who leaves school prior to completing the school year or fails to return to school yearly until he or she has completed graduation requirements.

EXPLORE Data - a component of the ACT assessment program (a commercially marketed curriculum-based assessment program) which is designed to help eighth-grade students expand an understanding of their academic development in terms of preparation for future educational opportunities. EXPLORE assesses academic programs. $\underline{\text { GCTI }}$ - Grant County Transition Initiative.

Horizontal Planning Meeting - a meeting of teachers who teach the same content area at the same grade level. The purpose of the meeting is to analyze and monitor curriculum and student progress.

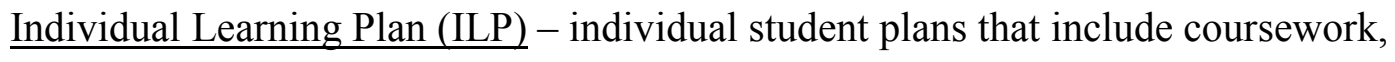
credits, learning style inventories, career goals, grades, behavior, student absence and RTI (response to intervention) plans.

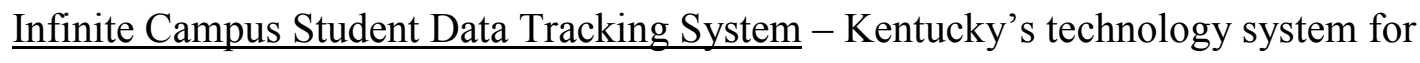
tracking student information.

Interdisciplinary Meetings - meetings in which educators who teach different content focus come together to discuss strategies to increase a particular student's progress. PLAN Data - a component of the ACT assessment that provides tenth-graders with information that will assist them in building a solid foundation for future academic and career success and provide information needed to address school district issues. 
Progress Monitoring - a system through which educators monitor student performance and set specified timelines and benchmarks.

Retention-by-Failure Rate - the percentage of students that do not meet the academic requirements of the institution to move on to the next grade level.

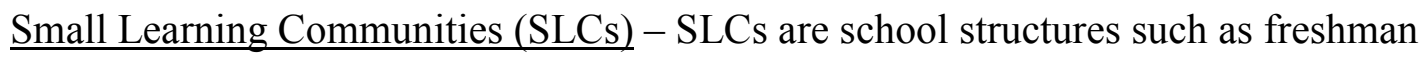
academics or multi-grade academies organized around career interests or grade level teams. Students are assigned to a particular SLC and remain with that group of peers and teachers through the school year. SLCs are also known as "schools within a school" (Bernstein, Millsap, Schimmenti, \& Page, 2008).

Set of Structured Articulation Activities - the 12 articulation activities implemented by Grant County during the 2008-2009 and continued in the 2009-2010 school year.

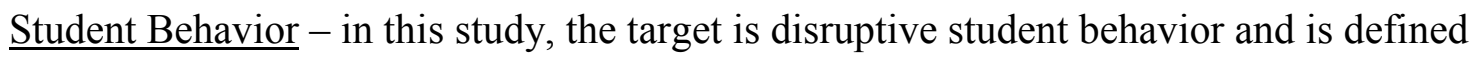
as behavior that persistently impairs or interferes with the goals and functions of the school setting. A disruptive student is one who interferes with learning process in the classroom.

Tier Consequences - levels of consequences created by the state for individual schools or districts for not meeting specific federally mandated assessment goals. Various tiers result in labeling the school/district as underperforming. Transition Committee - a committee that includes teachers and, to various degrees, counselors and administrators from a middle school and high school, whose task is to develop a transition program that consists of a set of structured articulation activities for students moving from grade eight to grade nine. 
Vertical Planning Meetings - varied grade level same content meetings or varied content (interdisciplinary) meetings. These meetings can extend to school personnel below or above the school level. 


\section{CHAPTER TWO}

\section{REVIEW OF THE LITERATURE}

This chapter contains the description of and literature to support the conceptual framework of this study, which is the result of collaborative efforts by three Doctoral candidate students, which includes the preparer of this dissertation. All three Doctoral candidates identified specific questions to answer in this joint study. As detailed in the study completed by Denise Allen (2011), and in this review of literature, this study was developed from three well established, powerful concepts: Organizational Learning (OL), High Reliability Organizations (HRO) and Effective Schools (ES). It also includes a detailed review of studies that specifically address transition of students from one grade level to another. The integration of these three concepts, organizational learning, high reliability organizations, and effective schools can help an organization increase performance and reliability. All three doctoral candidates participating in this study determined integrating these three concepts is equivalent to installing an attentive infrastructure. In this study, this infrastructure would be critical to effective and systematic implementation of the grade eight to grade nine set of structured articulation activities.

In this study, the three Doctoral candidates determined organizational learning effectively connects high reliability organizations with effective schools which provide a robust structure for school reform, lays the foundational structure for developing a transition program, and informs the research and activities for guidance of this study. 


\section{Organizational Learning}

During the last decade, organizational learning has served as a research based framework for examining school improvement (Cousins, 1998). Organizational learning, for the purpose of this study, is defined as the social processing of knowledge, or the sharing of individually held knowledge or information in ways that construct a clear, commonly held set of ideas (Louis, 1994). Central to this concept is that organizational learning involves turning facts or information into knowledge which can be shared and acted upon.

Each of the three doctoral candidates participating in this study determined each organization develops unique characteristics that influence the individual members of the organization. These characteristics are also transmitted to communities of individuals through their history and norms (Fiol \& Lyles, 1985). Senge (1990) identified the characteristics of organizations to include the following: Systems thinking, shared mental models, team-based learning, and shared vision building. Levitt and March (1988) described organizational learning as route-based, history-dependent, and target-oriented. Fiol and Lyle's definition of organizational learning appropriately summarized the particular foundational theory of this study as, "the process of improving actions through better knowledge and understanding" (p. 803).

When applying the theory of organizational learning to transition programs, schools as organizations must work collaboratively to develop a shared vision and a common set of goals for school improvement. The school organization must work systematically to create a process for sharing information within and between schools in order to turn advocacy into action. This process would provide insights on how to 
improve the efficiency of organizational learning. The school organizations can then create clear goals based on better knowledge and understanding of the school's need and ultimately the schools become smarter organizations (Coleman, 1974). Combined with vertical and horizontal communication within the organization, transition programs have the potential to successfully impact the organization, student progress, student behaviors and student attitudes. Organizational learning represents a core competency of both effective schools and high reliability organizations which is paramount to implementing organizational change.

\section{High Reliability Organizations}

Welck, Sutciffe and Obstfeld (2000) determined that the high reliability organization is a conscientious process. High reliability organizations use sophisticated forms of another concept, organizational learning (Marais, Dulac \& Levison, 2004). Organizational learning shares the following characteristics of high reliability organizations that embody the high reliability conditions of a school or school system identified by Datnow and Stringfield (2000): A set of clear goals, a shared belief across all levels, and maintenance of data bases, repeating standard operating procedures, extensive recruiting, targeted training, two-way monitoring, collegial decision making and strong communication.

Datnow and Stringfield (2000) stated that high reliability organizations such as a school require well-focused coordination among key groups within a school, district, and state. Changing the atmosphere and giving a school new direction requires that the organizational process of change occur from top to bottom during the implementation stages. Those responsible for the implementation must be involved in the development, 
yet those leaders at the top must be providing focus and setting expectations.

Stakeholders involved in the implementation process must be involved in the developmental process throughout each step of the journey. Datnow, Hubbard and Mehan (1998) propose that social structures such as schools and school systems follow a pattern of emphasis on structure, culture, and agency. In more direct terms, these structures are seen as "real people confronting real problems in classrooms, school board meetings, and reform design labs" (Detnow \& Stringfield, 2000, p.8). The process of creating the collaborative structure will foster the reform of ideas and implementation of those ideas into practical outcomes. For a positive impact on transitions from one grade level to the next, schools must work collaboratively with the feeder schools students are leaving and with the receiving schools the students are about to enter. In 1994, Dr. Sam Stringfield made a recommendation to the Memphis school system that they consider adopting a set of break-the-mold school reforms. This list of eight reforms includes "ATLAS" which is a model which established a pathway across feeder schools (Ross, 2001). All stakeholders must be involved in the development and implementation of the program for organizational change to produce high reliability organizations.

Schools that employ the characteristics of these three concepts (organizational learning, high reliability organizations, and effective schools) face an enormous amount of pressure from special interest groups that try to influence the organizational change process at both the school and district level. As was observed in the "Memphis Story" stakeholders, such as members of the school community and policymakers, expect immediate and visible results, which usually include improved test scores (Ross, 2001). Stringfield and Yonezawa (2000) critiqued the impact of district support for schools 
when implementing high reliability organization characteristics. Stringfield and Yonezawa recognized the need for unwavering district support in bringing about the changes needed for reform. The effectiveness of the implementation process relies heavily on the support and involvement from district level administrative teams. District support is a characteristic of a high reliability organization which connects at all levels of the organizational structure. For transition programs to be effective, the participants of this study determined all stakeholders must have a clear understanding of (and a commitment to) the purpose of the reform and the goals of the initiative, an understanding of the powers that impact the change, and an understanding of their power to influence change.

Stringfield and Teddlie (1991) and Teddlie and Stringfield (1993) point out that district leadership, school level administration, and building level instructors must be prepared to spend the time required to develop an effective program. Stringfield and Datnow (1998) studied numerous school districts, examining why each experienced success or failure with reform movements. Schools that experienced success in organizational change received early district support and used characteristics common to high reliability organizations to establish sustainability for reform. Schools that experienced instability of district leadership often derailed the sustainability of the reform attempt and only short term success. Researchers emphasized the need for schools to emulate the following characteristics of high reliability organizations when initiating school organizational change: The need for shared goals, a focus on measures for school improvement, the development of a systematic process for disseminating information, the development of a process of inquiry into what needs to be changed and why, the need for 
collaborative decision making, and the alignment of policy systems (Datnow \& Stringfield, 2000; Rossi \& Stringfield, 1998).

In summary, the research completed by the participants of this joint study clearly directs schools and school districts toward embracing the characteristics of high reliability organizations. These two components, high reliability organizations and an organizational learning structure are critical parts of the foundation for this study's middle school to high school transition program. LaPorte and Consoline (1991) reinforced the importance of operating under systematic plans to ensure predictable outcomes rather than relying on the trial and error method.

The concepts mentioned are strategic, systematic, and paramount to increasing the success rate of transitioning eight-graders to ninth-graders. The set of structured articulation activities used in this transition program are systematically planned, clearly defined, continuously monitored, and serve to change the organization and produce outcomes of improved student performance, student behavior and student attitudes.

\section{Effective Schools}

Schools and districts can become high reliability organizations by excelling at the carrying out of existing expertise. An effective school has been defined as one in which students advance academically further than might be presumed based on the student's likelihood of academic performance (Sammons, 2006). Therefore, it is reasonable that effective schools reflect many of the characteristics common to organizational learning and high reliability organizations. When researching effective schools, high reliability organizations and organizational learning have the following characteristics in common: A clear set of goals, systems thinking, shared mental models, collaborative efforts and a 
shared vision and strong leadership (Lezotte, 2007). These characteristics, when embodied in successful grade eight to grade nine transition programs, develop a strong structure for organizational change in schools.

Proponents of effective schools recognize the school and all its stakeholders have the power to make a difference in student achievement regardless of a student's socioeconomic status (Edmonds, 1982; Brookover et al., 1982). This study provided support to schools by providing information on how to develop school structures and programs. For example, school transition programs that positively impact the organization, student academic performance, student behaviors and student attitudes, regardless of student family backgrounds. The Brookover and Lezotte (1982) study confirmed that all students can achieve at high levels in a variety of school settings from rural to urban, elementary to high school, and among varying income levels. Edmonds' question summarizes the authority of schools in developing organizational structures that make a difference in student outcomes, 'What is the interaction between pupil performance and family background?' If there is an interaction, is it a correlation or is it a causal interaction? This is a serious question because if you conclude that family and social class can impact pupil performance, then the only way to have an impact is to intervene in the nature of the American family; especially with those families whose characteristics are of concern. If you conclude, on the other hand, that it is merely a correlation, and that social class and family background are not, in fact, causes of performance, then you do not have to intervene in the life of the family. You intervene instead in the nature of the way schools respond to the differences in families they are supposed to serve (1980, p. 5). 
Transition programs provide an avenue for schools to collaborate with students and their families in a positive manner, regardless of the family cultural or socioeconomic background.

Edmonds (1982) published the first of several updates to what became known as the Correlates of Effective Schools in the paper Programs of School Improvement: An Overview. The first correlation identified the following characteristics effective schools had in common: (1) Strong leadership of the principal, (2) A focus on instruction, (3) A safe and orderly climate, (4) High expectations for all students, and (5) The use of measures of student achievement. The characteristics of effective schools found that the research of Ainscow and Muncey (1989), Armor et al. (1976), Trisman, Waller and Wilder (1976), Doss and Holley (1982) continued to support the characteristics found in the research of Edmonds. Case studies noted in Effective Schools Review completed by Purkey and Smith (1983) indicates numerous schools followed the same characteristics of Effective Schools.

Effective schools are organizations that are entrenched in a culture of respect, communication, and collaboration among all stakeholders. An example of the connection that exists between high reliability organizations and effective schools is found in the research of Deal, Intili, Rosaler, and Stack-House (1977). This research is relative to the characteristics of high reliability organizations in suggesting the inclusion of teachers in the development of activities in order to impact change. The study by Deal et al. suggested that change would more likely be engrained within the culture of the school if teachers were empowered and involved in the process. Transition programs that involve 
all stakeholders, including teachers, in the development and implementation of a set of structured articulation activities will more likely experience success.

Effective schools research has evolved through various stages (Lezotte, 2007). Updates to the effective schools approach include the addition of the following characteristics: (1) The use of disaggregated data; (2) School effectiveness judged by results; (3) Data-driven decision making; (4) Collaboration and ownership among staff; (5) The notion that change is complex, takes time, and is a part of the process; and (6) the need to involve all stakeholders in the dialogue of change. Many of the characteristics focus on organizational change.

Lezotte recognized the importance of system-wide success. Lezotte states "Eventually it became clear that school improvement, resulting in increased student achievement, could only be sustained with strong district support” (Lezotte, 2007, p. 5). Furthermore, Lezott's research looked at relationships and interactions between and among members of the system at large.

Common characteristics appear to emerge from the literature of effective schools. Characteristics universal to organizational learning and high reliability organizations, when embedded in a middle school to high school transition program, change the organizational structure to ensure the likelihood of successful student transition. Sammons, Hillman, and Mortimore, (1995) concluded that consistent effective schools are: (1) Disciplined, safe and orderly places of learning; (2) Schools that have a culture and climate of high expectations for all students' academic achievement; (3) Led by strong instructional leaders; (4) Structured in a way that fosters a systematic process of 
monitoring student progress and program implementation; and (5) Places where teachers and leaders collaboratively make decisions based upon data

An increasing number of researchers suggest the primary focus for school improvement should be on institutional change using organization development. One group of researchers indicating this focus is Purkey and Smith (1982). Their position is that organizational change due to a transition program is likely to take root when the entire school culture is moved to action to produce changes in student academic performance, student behavior, and student attitudes. For sustained change to occur, a deeper level of commitment is needed. That deeper level of commitment requires changing behaviors and attitudes as well as the school organization. Purkey and Smith indicate commitment requires change within, among, and between people and the organization itself. Without an internal change in the culture of the school, the implementation of the characteristics of organizational learning, high reliability organizations and effective schools will happen only in the form of compliance. Structured articulation activities, such as building level tours, are surface level activities. Another concept directly related to this study is referred to as "loosely coupled systems". Scholars, such as Sarason (1990) and Cohen (1995), have described educational organizations as "loosely coupled systems". Both scholars assert a change in one area of a school's organization does not mean there will be a fundamental change in another area of the school's organization. Weick's (1976) research indicated that schools are loosely coupled organizations with regard to student achievement and classroom instruction. An example of loosely coupled systems is school based decision making. While this system may be beneficial to the individual school, the district as an 
organization does not benefit from each separate component of the district making decisions in different directions. The research and study conducted by Marzan and Waters (2009) determined those highly reliable organization and the highest performing school districts should be tightly coupled systems regarding student achievement.

Weick (1976) viewed school management and classroom instruction as "loosely coupled systems" due in part to teachers' isolations and the practice of teachers enjoying a relatively high degree of independence. In Figure 2, the model describes the progression of transition from elementary school to middle school to high school. The thin line arrow from elementary school to middle school indicates the loosely coupled system as described by Weick.

In this study, the school system is articulating schools to one another, specifically from middle school to high school. Therefore, the arrow from middle school to high school is bolder which indicates the existing loosely coupled system in this study is attempting to tighten the linkage. Another perspective is that loosely coupled systems are the "glue" that attaches the separate components of the organization together. The implementation of a set of structured articulation activities in this study is designed to tighten the linkage of the system that involves the transitioning from middle school to high school. This particular study is an example of systemic affects.

Elementary School $\longrightarrow$ Middle School $\longrightarrow$ High School $\longrightarrow$ College

Figure 2. Illustration of the Focus of the Study 


\section{Organizational Learning, High Reliability Organizations, and Effective Schools}

The intent of this study was to demonstrate that transition programs which incorporate the commonly shared characteristics of Organizational Learning, High Reliability Organizations, and Effective Schools can create organizations that produce positive outcomes. Transition programs which include a set of structured articulation activities emulating the characteristics of these three concepts increase the possibility of successful student transition from grade eight to grade nine. Research has found that when middle school students took part in a middle school to high school transition programs with several diverse articulation activities, fewer students were retained in grade nine (Mac Iver, 1990). When asked for their insight on these programs, the middle school principals indicated they would expect fewer of their students to drop out before graduation when a transition program provided supportive advisory group activities or responsive remediation programs (Mac Iver \& Epstein, 1991). When strong school leaders work collaboratively with all participants in the development, implementation, and monitoring of a transition program, they increase the probability of program success. Schools that create system structures for transition from grade eight to grade nine create organizational change that produces positive results as evidenced through student academic performance, student behaviors, and student attitudes (Hertzog \& Morgan, 1999).

\section{Conceptual Framework Foundation}

Organizational learning effectively connects the attributes of high reliability organizations and when combined with effective schools, effective programs are instituted which can develop a healthy structure for the development of a successful 
transition program. A structure formed with these ideas provides a healthy framework to interpret and evaluate studies that address transition issues for students.

Murphy’s (1992) study of organizational learning identified three critical components in creating a positive change: A focus on outcomes, attention to consistency, and coordination throughout the school community. An example of a study utilizing Murphy's components of organizational learning is Hertzog and Morgan (1999) in their study of 57 middle schools in Florida and Georgia. This study determined that transition programs which embed a set of structured articulation activities serve as the catalyst in producing organizational change that impacts academic performance, student behavior, and student attitudes.

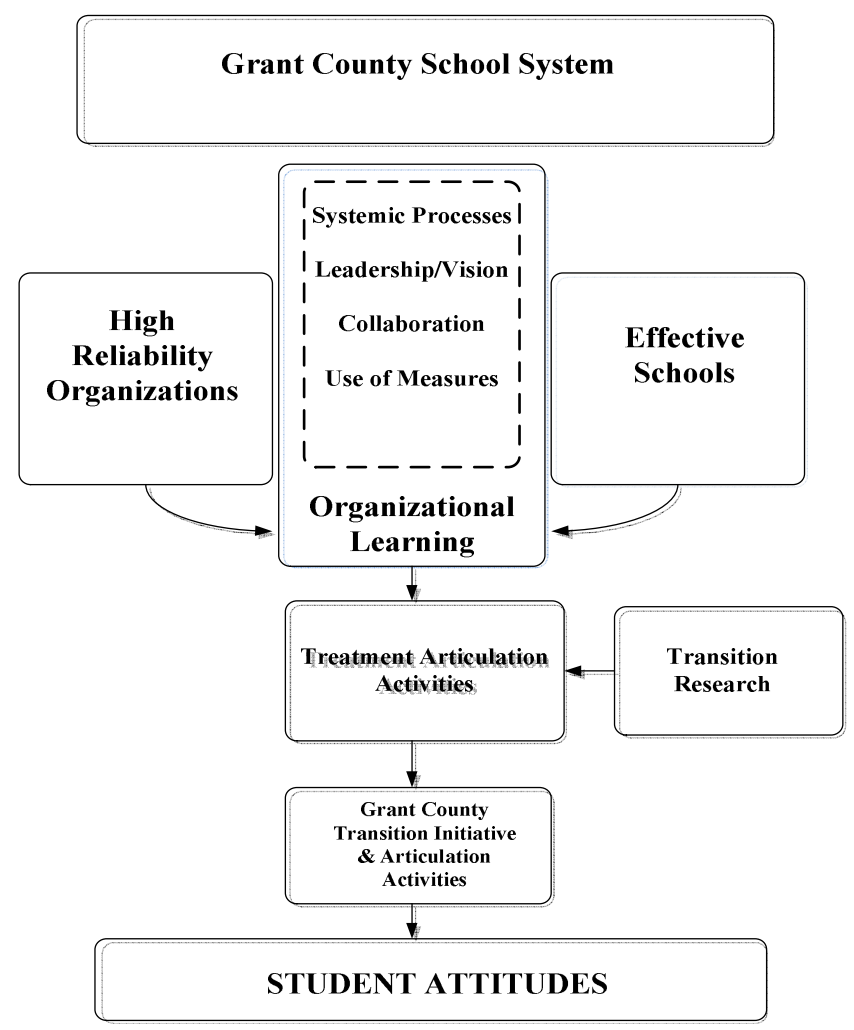

Figure 3. Grant County Transition Initiative Conceptual Framework 
The conceptual framework for this study is shown in Figure 3. Figure 3 indicates a set of structured articulation activities being implemented based on the foundation of the three concepts of high reliability organizations, effective schools, and organizational learning and based on research completed previously on students who transition from one school setting to another. The study's purpose was to show when this scenario occurs, there is the likelihood that the organization would show a positive change. Student academic performance will improve. There will be a decline in negative student behavior and student attitudes will improve. In general, the conceptual framework demonstrates when schools employ the characteristics of organizational learning, high reliability organizations, and effective schools; they can then move in the direction of developing and implementing a systemic process. This process consists of structured articulation activities. The set of structured articulation activities implemented in this study were not randomly chosen, but are contextually based on the work conducted by Connell and Wellborn (1991), Datnow, Park, and Wholstetter (2007), and Rumberger and Palardy (2005).

The Connell and Wellborn (1991) framework and Appleton, Christenson \& Furlough (2008) pointed directly to the successful transition of ninth-grade and beyond, linking teacher support to student engagement and success. This model supports the concept of teachers working together to ensure individual student success. According to Connell and Wellborn, there is a need for schools to provide a more caring, personalized learning environment that will positively influence student performance. Middle school students, with a high level of teacher support, are almost three times more likely to have high levels of engagement. Articulation activities within the structure of teams and 
freshman academics serve as the catalyst in creating more personalized environments and more positive transition experiences.

Datnow, Park, and Wholstetter's (2007) research provides another foundational pillar for this study in support of schools building capacity for data driven decisions, connecting educators across schools in the sharing of student data and the development of intervention strategies to ensure successful transition to high school. Middle school and high school teachers, who are intimately involved in the implementation of articulation activities which are based on individual student needs, can help create a smoother transition for students as they enter grade nine. Outcomes expected as a result of the implementation of a set of structured articulation activities include improvement in student academic performance, improvement in student absence and behavior, and improvement in student attitudes, which is the core of this study.

Rumberger and Palardy (2005) explored the relationship between school characteristics and student outcomes. Their study recognized that school inputs at the student level plus school experiences equals outputs in the form of test scores and dropout rates. Schools have little control over inputs, but they do have control over how they organize and manage school processes and structures. Inputs which are considered factors include gender, culture, and socio-economic status. Academics and teaming are examples of structures and the set of structured articulation activities serve as the processes over which schools have control. The conceptual framework for this transition project reflected the same findings as the Rumberger and Palardy study with regard to the characteristics that produce successful outcomes. 


\section{Transition Research}

This section describes research on three school transitions that students negotiate throughout their schooling: (1) The move or transition from elementary school to middle school, (2) The subsequent transition from middle school to high school, and (3) The move from high school to college. The goal is to smooth out these critical transitions. Student success is, in the end, a matter of productive transition. Students must successfully navigate a series of transitions through each level of their education. First, the student enters the transition: Orientation to the school's expectations; participation in the academic program; acclimating into the student body. Second, the student undergoes the involvement transition, or making progress. Finally, the student experiences the culminating transition, successful transition to the next level of education or life. With each change, students' transition experiences either add to their educational foundation or create a barrier which diminishes their chances of success. The purpose of this section is to examine the various levels of transition. In particular, this study focused on the characteristics of the environment and participating students to create a set of structured articulation activities that met the needs of students in the areas of academic, social and emotional development.

Usually, after five to six years in elementary school, students negotiate the first transition from the elementary school environment to the middle school environment. At this time, elementary students leave behind classrooms where "everybody knows their name" and where students are taught by a single teacher, who serves "in loco parentis", to enter middle schools with departmentalized, multi-teacher schedules. Ordinarily within three years, the next transition occurs as students have just become accustomed to 
the culture of middle school. Students move to larger, more impersonal high school which is grade oriented rather than student oriented (Eccles, Midgley \& Adler, 1984).

Schools which employ the characteristics of the three concepts of organizational learning, high reliability organizations and effective schools exhibit increased student academic performance and student behavior when combined with a set of structured articulation activities

\section{Elementary Transition Research}

Usually the first transition in school that a student must navigate after beginning school is the transition from elementary school to middle school. Sufficient research has been conducted on transition from elementary school to middle school to help provide an understanding of the impact such a transition has on students. Research conducted by Rockoff and Lockwood (2010), Dutrow (1997), Diemert (1992), and Wagonner (1994) provides insight into the difficulties that occur as students maneuver through one of the most significant experiences in their young lives. During this transition period, students face a range of new demands that are associated with such varied issues as school structure, classroom organization, varied teaching strategies, academic standards, and teacher expectations (Blyth, Simmons \& Bush, 1978).

The transition from elementary school to middle school can be characterized by a focus shifted more toward academics and less on the affective development of students. Major consideration should be given to meeting student's social needs. An example of this is the major issue for students of self-perception. Diemert (1992) conducted a survey of 23 fifth graders in a middle level school focusing on self-perception. The survey indicated that at least $50 \%$ of both boys and girls reported that social needs were a 
priority for them. The changes in self-perception for students making the transition from elementary to middle school is similar to that experienced by students making the transition from middle to high school. Another example of social needs is the study conducted by Waggoner (1994) which focused on 171 sixth-graders and their selfesteem. His study indicated that upper elementary students who rotated between classes have fewer concerns when transitioning into middle schools. The results indicated that these students were more confident in adjusting to the demands of the middle schools. The rotation mirrored middle school class changes and allowed students to interact with various student groups and adjust to different teachers' expectations. Another aspect that affects transition is the fact that elementary schools tend to be task oriented, while middle schools are focused on performance (Midgley, Anderman and Hicks, 1995). The situation often results in a change from small-group or individual instruction to wholeclass instruction. In middle school, the student-teacher relationships change due to the number of students assigned to each teacher. Middle school teachers may have five classes of 20 students in each, which reduces the time spent with each student and makes it harder to forge that all-important teacher-student bond. Elementary teachers may have one group of 25 students, which allows them time to personally know and assist their students.

Another aspect of the transitional period involves motivation and performance. Eccles and Midgley (1989) describe studies in which students, transitioning from the elementary setting to the middle school, experience a decline in motivation and performance. In the elementary schools, students' success depends on their efforts and guided practice with their teachers. In middle school, student success depends more on 
ability and competition. Rockoff and Lockwood (2010) conducted a study using data from the New York City schools for students in grades three through eight from 19982008. Data were gathered on individual academic achievement and measured by annual standardized test scores in English and Mathematics. Scores of students in both middle schools and K-8 settings were compared. The results, though complex, indicate that students who enter public middle schools in New York City fall behind their peers in K-8 schools. Those researchers suggested that a contributing factor may be when students enter middle school. Frequently, they are arriving from several different elementary schools.

In conclusion, as students move from elementary to middle school, they experience intellectual, moral, social, emotional, and physical changes. For a student to make a smooth transition, Schumacher (1998) recommends elementary students receive assistance before, during and after the move to avoid damage to their social, psychological, and academic well-being. To better prepare students for the move to the middle school, highly organized elementary schools should review the transition research in order to develop transition programs and include a set of structured articulation activities. Many of the same concerns students face while transitioning from elementary school to middle school are also found in the transition from middle school to high school.

\section{Middle School to High School Transition Research}

One of the initial roles of the middle level education movement was to coordinate adolescents' transition into high school (Vars, 1998). In recent years, middle schools developed transition programs to address the needs of students. However, young 
adolescents are still having trouble making the transition into high school. To ensure those issues are proactively addressed, educators must work together with parents and students to structure their programs and curriculum so young adolescents "experience a seamless transition between schools" (Williamson \& Johnston, 1999, p. 16).

The studies cited below provide empirical evidence of what matters most in determining a successful freshman year of high school. Barone, Aquirre-Deandries and Trickett (1991); George and McEwin (1999); Hertzog, Morgan, Diamond and Walker (1996) all note the challenges eighth grade students experience during the transition from the middle to the high school. As a result of these and similar studies, more "schools in the middle" are developing transition programs aimed at meeting the specific needs of the adolescent as they enter high school (Cognato, 1999). According to Gruhn and Douglas (1947); McErwin (1998), Vars (1998); and Williamson and Johnston (1999), educators need to implement a set of structured articulation activities at both the sending and receiving institutions to ensure successful entry into high school and throughout grade nine.

A longitudinal study conducted by Isakson and Jarvis (1999) and qualitative studies by Kinney (1993) and Morgan and Hertzog (2001) found many current transition programs function at the surface level by implementing a small number of activities designed to ease the transition from middle school to high school. These surface level activities usually include discussion about course offerings and building tours. Even though familiarity with courses and the facilities are important in initiating a smooth transition, they do not address issues that students themselves see as critical during this time of transition. 
A 2006 research summary by the National Middle School Association (NMSA) reported students are more concerned with affective issues, such as the need to belong, peer acceptance, and fitting in (Oakes, 2009). Academic concerns, though understood by students as important, are less important than these social issues that matter most to students during this period of growth, social development, and self-awareness. Studies showed freshmen are excited about the possibilities of becoming more involved in extracurricular activities, about meeting new friends, and about the freedom associated with this transition such as having some authority over course selection and electives (Cognato, 1999; Maute, 1991; Mizelle, 1995; Phelan, Yu \& Davidson, 1994; and Wells, 1996). This same study found students also admit to the anxieties of not fitting in, fear of harassment and bullying, concerns about getting lost, and worries about making poor grades.

Both the NMSA (2006) and research from the Center for Equity and Excellence in Education (2009) emphasize the importance of the collaborative efforts and shared responsibility from middle school and high school faculty and parents to achieve the goal of student success in grade nine. The collaborative efforts of leaders, counselors, and teachers are critical in developing and implementing a set of structured articulation activities which create a seamless and successful transition to grade nine. In this study, it was vital that all stakeholders at both affected schools be involved in the process of developing the set of structured articulation activities and the implementation of such activities.

As students transition from one school to another, parental involvement begins to fade. This loss of parental oversight is unfortunate because parental involvement is even 
more critical during the transition from grade eight to grade nine. According to Linver and Silverberg (1997); Paulson (1994); Paulson, Marchant and Rothlisberg (1998) students who have active and involved parents achieve at higher levels and, as a result, are better adjusted to the new environment (Hartos \& Power, 1997). Allensworth and Easton (2005) studied three indicators of success in grade nine: course failure, overall grade point average, and student absence. This study found that $95 \%$ of students with a B average or better, during their freshman year, later graduated from high school. In addition, course failures and the number of credits attained during the freshman year were critical to the performance of grade nine students. A student's being "on-track" is a strong predictor in forecasting graduation from high school. Students are considered "ontrack" if they received at least five out of seven credits and failed no more than one course (Allensworth \& Easton, 2005). Researchers found that "on-track" students were three-and-a-half times more likely to successfully complete high school in four years.

Student absence is a critical variable during the transition from grade eight to grade nine. The Center for Comprehensive School Reform and Improvement Fund (Oakes, 2009) determined that $90 \%$ of freshmen, who miss less than a week of school per semester, graduate. Freshman students who miss more than two weeks of school, on average, fail at least two classes. Of students who missed five to nine days of school in their freshman year, only $63 \%$ graduated. Students who missed fewer than five school days recorded a graduation rate of $87 \%$. Attendance is not only predictor of graduation, but it is also can predict course failure. Grade nine attendance rate was eight times more predictive of course failure than grade eight test scores" (Allensworth \& Easton, 2005, p. 16). Freshmen who arrive with high achievement test scores, and who miss more than 
two weeks of school, were found to be more likely to fail a course than freshmen who miss only one week of school yet have low achievement test scores (Allensworth \& Easton, 2005). Further statistics from this study have shown more than half of the Chicago freshmen failed a class, $40 \%$ or more freshmen missed more than a month of school, and the average GPA was lower than a "C". A solid transition program will include activities that focus on encouraging students to come to school. The set of structured articulations implemented in this study included strategies for encouraging students to attend school. A component of the study includes analysis of student data focused on changes in student absences after the set of structured articulation activities were implemented. The hypothesis predicted the implementation of the set of structured articulation activities will result in an improvement in individual student absence which is very critical to the success of a student in grade nine.

In summary, addressing successful transition to grade nine does not start with grade nine; it must start in the middle school. The transition into high school involves the middle school program, as well as the implementation of specific articulation practices at the time of the transitions (Gruhn \& Douglass, 1947, McErwin, 1998; Vars, 1998; Williamson \& Johnston, 1999). For a successful transition from middle school to high school, there must be purposeful focus on meeting the specific needs of the adolescent. These include academic concerns, social issues, student absence, entering ninth-grade on track, and parental involvement. This study proposed successful middle school to high school transition programs help create a seamless transition to grade nine by focusing on the needs of the adolescent. 


\section{High School to College Transition Research}

One of the last transitions to take place during a student's educational career happens during the move from high school to college. For others, this process ends as students leave high school and enter the work force. With each transition, students increase their chances of becoming lost in the process unless schools implement research based on practices that help create a sense of community (Lee \& Smith, 1995; Lee, Bryk \& Smith, 1993; Johnston, 1992; and Bryk \& Driscoll, 1988). During any transition period, students' grades, student absence, and behavior may be negatively impacted unless schools have programs in place that include a set of structured articulation activities to increase the likelihood of a successful transition.

The UCLA Center for Mental Health found school students moving on to college need a solid system of transitional activities to help students experience success during their first year of college (Journal of College Admissions, 2009, p. 18). The center suggests the following: (1) Develop an individual transition plan, (2) Ease anxieties and strengthen specific coping with self-advocacy attitudes and skills, (3) Ensure availability and access to relevant support mechanisms, (4) Ease into college demands, (5) Minimize financial concerns, (6) Monitor, problem solve, and celebrate successes, and (7) Revamp plans and supports. The use of these transitional strategies is predicated upon developing support systems at the level that a transitioning high school student will find helpful and productive. The Center's research stressed the importance of new students to find support systems that invest in their well-being. The transition from high school to college is similar to the transition from middle school to high school; it is filled with many challenges for students. 
It is important for students to be "on-track" academically when students transition from middle school to high school. Bragg and Rudd (2007) also found that students who successfully earn college credits during high school achieve significantly higher success rates in college than their peers who earn no college credits in high school. The transition process where "dual credit" opportunity existed for students proved helpful to students when they began their college experiences. Reducing the remediation process at the college level also proved to be beneficial as well. Again, the transition process from one level to another was influenced by the introduction of specific interventions that helped the high school students in transition to college. Waggoner and Blackorby (1996) found in their examination of high school seniors that almost half of the students in the population pursued a bachelor's degree. This finding supports the importance that students recognize the demands of the present day economy and the need for further education beyond high school. Another activity which will benefit students when transitioning from high school to college is career and employment preparation. Waggoner and Blackorby concluded that the employment needs of our society require educational credentials that address skill, knowledge, and work ethics. As pointed out by the Abell Foundation and their Jump Start program implemented in Baltimore City, Maryland (Abell Foundation, 2007), Technical Preparations, along with dual credit, is a strong transition activity that helps students move successfully into college. The importance of transitioning students towards the demands of post secondary academic requirements and the experience of college rigor course work has proved successful for students. The Abell study found students who took AP course work, regardless of their score on the AP exam, experienced college success. In 2009, the National Center for 
Education Statistics (http://nces.ed.gov/) reported the completion rate of college graduates from 1972 to 2007 . This information showed that students are graduating at a $67 \%$ rate from colleges in an average of six years to complete degree requirements.

Research shows that students need many of the same types of interventions when they transition from high school to college as well as when students move from middle school to high school, or move from elementary to middle school. Those interventions include the following: Help in coping with demands and expectations of the new environment, on-going assistance provided before, during and after the transition, and a focus on student academic and social needs. This study provides information that supports the belief that the transition will be more successful when schools work collaboratively with teachers and school leaders to create a systemic transition program that includes a set of structured articulation activities.

\section{Critical Models}

Oakes (2009) stated "Transition is a process, not an event". Schools and districts need to design a systematic process of transitions that begin early in grade eight and continue through grade nine. The National Association of State Boards of Education (NASBE, 2008) models support effective transition processes lasting five to six years. This long term model is supported by involving parents and school guidance counselors who work collaboratively to help students realize the connection between course offerings at the middle school and high school levels and their relevance to career goals.

NMSA (2006) found four actions critical to effective transition programs. These actions included the following: (1) Ensuring collaboration between eighth-grade and ninth-grade building personnel, (2) Providing targeted early interventions to support 
academic recovery and failing students, (3) Making available to students and families pertinent and consistent information about academic, social, and organizational similarities and differences between middle school and high school, and (4) Offering information on the curriculum, facilities, safety and discipline of the high school (p.2). Research by the Center for Equity and Excellence in Education (2009) at George Washington College made the following recommendations to ensure successful transition from grade eight to grade nine: (1) Ensure that curriculum standards are aligned to prepare eighth-grade students for the challenge of high school work, (2) Communicate the importance of literacy, mathematics, science, and social studies through policy and funding initiatives, (3) Prepare teachers for teaching challenging content in middle grades, (4) Provide structure to support middle school students with the extra help they need for success in high school, (5) Ensure that middle school leaders are prepared to implement a program that prepares all students for the transition to college preparatory courses in high school, and (6) Ensure that middle-grade students and parents receive guidance and advice to plan for high school, postsecondary learning, and careers (p. 51$55)$.

Herzog and Morgan (1999) conducted a study of 57 high schools in Georgia and Florida. The results indicated that high schools which offered extensive transition programs had significant reductions in failure and dropout rates. The researchers concluded that schools which included activities such as counseling, schools visits and special summer programs produce students with higher academic performance. Schiller (1999) noted that when students enter high school "on-track" with their middle school peers, they tend to earn better grades. 
Many studies have been conducted on the effect on student success of double transitions versus the single transition. Double transitions are defined as a move from elementary to middle and then another move from middle school to high school. Single transitions are experienced by students who make only one transition from grade eight to high school.

Alspaugh (1998) found when students participated in the double transition, greater achievement loss and higher dropout rate occurred than if they had only taken part in one transition. In response to this research, schools incorporated transition programs in an attempt to provide students with extra help with academics and provide other types of support. This support came in forms of tutoring, counseling, advocacy, and included an effort to increase parental involvement. Manning and Baruth (1995) provided evidence that such programs produced positive results in student performance and attitudes. An example of a school attempting to make such changes was the Culbreth Middle School communities-In-Schools High School Transition Initiative. Chapman and Sawyer (2001) supported the needs for schools to provide collaborative efforts among middle school and high school faculty to address the needs of at-risk students. All participants deemed the program to be successful.

Sunrise Middle School, which is located in inner city Philadelphia, created a comprehensive program for middle school students as they transitioned into high school. The Community for Learning Program (CFL) provided the following key components to middle school students at Sunrise Middle: (1) Support and training for the middle school teachers, (2) Learning systems to assist students in developing a sense of responsibility for their own learning and behavior, and (3) Emphasis on community and family 
involvement. The results from this program indicated students who participated were more successful as they transitioned into high school than students who did not have the opportunity to participate in the program (Oates, Flores \& Weishew, 1998).

In an effort to keep incoming ninth-grade students from getting 'lost' in the high school setting, Needham B. Broughton High School in Raleigh, North Carolina, created a comprehensive transition program called Project First Step. The program included strategies to help students stay on track and was designed with the student driver as the theme. Along with other activities, this program included "Homework Repair Shop" and a lunchtime program which allowed students to spend their lunchtime completing missing assignments for credit. Project First Step was determined to be successful as it provided an avenue for students who have been sheltered in middle school to find success in the high school setting (Hertzog \& Morgan, 1999).

Allensworth and Easton (2005), working at the Consortium on Chicago School Research at the University of Chicago, determined that not only was course failure common in Chicago high schools, but also approximately half of ninth-graders were failing at least one course during their first semester of high school. The consortium worked to develop a statistical predictor of student progress toward high school graduation. The consortium, in collaboration with the Chicago Public Schools, worked to develop and incorporate an "on-track" indicatory to measure high school student performance. Reports showed improvement in freshman "on-track" rates in Chicago Public Schools during the period of 1993-1994 and 1999-2000 school years (Allensworth \& Easton, 2005) due to the change in the school climate and structure. 


\section{Summary}

In summary, students struggle with the physical changes, social pressure and increased academic expectations that come with every transition, whether it occurs from elementary to middle school, middle school to high school or high school to college. During this time of transition, students frequently begin the downward spiral in academic performance, student absence and poor behavior in schools and colleges where there is an absence of a systematic process for addressing the transition. During times of transition, schools that work collaboratively in developing systematic processes for implementing a set of structured articulation activities increase the chances of student transition success, minimizing drop-outs, retention-by-failure, and poor academic and behavior performance.

In this study, the GCTI focused on the implementation of a set of structured articulation activities introduced to the eighth-grade class of 2008-2009 at Grant County Middle School and involved the ninth-grade class at Grant County High School that same year. To strengthen the study, two middle schools in Bullitt County, Eastside Middle and Mount Washington Middle were used as comparisons. The two middle schools in Bullitt County did not receive articulation activities.

\section{Implementation}

The discussion of fidelity of implementation in educational studies of transition and structured articulation activities should include the Hertzog and Morgan (1999) study of 56 high schools in the states of Georgia and Florida. The work by Hertzog and Morgan was referenced more than any other study connected to transitions. In the past, most of the literature consisted of individual school's efforts to smooth the transition 
without the details of program effectiveness. The Hertzog and Morgan study was different in that the researchers developed a survey which included 97 middle schools and 56 high schools. The purpose of the study was to evaluate the transition practices in place at that time. The analysis provided interesting connections between the various types of programs and the extent of implementation in the participating institutions. The researchers found a connection between the number of transition articulation activities and successful transition from grade eight to grade nine.

The National Education Longitudinal Study of 1988 (NELS: 88) and Ingels et al. (1998) was the first stage of a major longitudinal study which was designed to provide trend data gathered at critical transitions in a student's life. The data were gathered as students moved from elementary school to middle school to high school and on to college or career. At the time of the study's implementation, it was the first to contain such comprehensive objectives in the educational arena. The study contained the following specific characteristics: (1) Four different sources of information; (2) Planned integration of student, parent, school and teacher studies; (3) Initial concentration on eighth-grade cohort with planned two-year interval follow-ups; (4) Components that allow for geographic and demographic subgroup analysis; and (5) links designed to connect to previous longitudinal studies and current studies (Ingels et al., 1998). The central theme of this study was that education in America is a lifelong process intertwined in a complex social context. The key topics in the NELS: 88 included: (1) Math and science programs, (2) Effective schools, (3) Academic growth, (4) Dropouts, (5) Disadvantaged students, (6) Language minority, (7) Transition to high school, and (8) Peer groups. This longitudinal study consisted of a large, nationally representative sample of eight-grade 
students $(\mathrm{N}=24,599)$ from 1,052 schools, with 22, 651 parents, 1, 035 administrators, and 5,193 teachers completing job related questionnaires. The longitudinal study has been cited in numerous articles since its implementation.

\section{Fidelity and Implementation of Organizational Change}

The process of change in the educational community can lead to "overload and extreme fragmentation" according to Fullan $(2000$, p. 1$)$ if the fidelity of the implementation encounters problems. Fullan described reform efforts as not fully developed and never developed into "strong institutionalization". In other words, the change process is introduced, but early success fails to create the implementation of the change into long term sustainability. Newmann and Wehlage (1995) found that successful change required the following elements: (1) The development of professional learning communities by teachers and administrators; (2) A clear focus on student work, and (3) The change of instructional strategies that produce results. They indicate that these changes need to be continuous and long term so that the change or reform becomes sustainable and effective. Recognizing the problems and developing action plans that will address problems is a strong characteristic of positive change. Fullan (2000) explained that simply restructuring provided little or no improvement in the "quality of teaching and learning" (p. 3). He indicated that "reculturing involves going from a situation of limited attention to assessment and pedagogy to a situation in which teachers and others routinely focus on these matters and make associated improvements" (p.3). This process, along with structural change, can produce "internal school development" which enhances positive change. Therefore, the transitional changes which can influence 
student behavior and academics will require a combination of culture and structural change.

Huberman (1973) reported that "things or information are easier to cope with than change in practice, attitudes or values" (p. 10). For example, it is easier for teachers to understand and accept the introduction of the white boards as added equipment in a classroom than the implementation of common course planning. This aspect of change in reference to the transitional process of moving eighth-grade students to the ninth-grade successfully is more than a physical movement of students to another level of academics. It represents a change in the implementation of new strategies that will enhance success for students. These strategies are directed toward district and building level administrators and teachers during the implementation process to assist with practices, attitudes and values.

The change process is difficult to develop, complicated to implement, and even harder to sustain. Greenwood, Mann, and McLaughlin (1975) found in their in-depth examination of education change process that projects generated based on opportunism were characterized by a lack of interest and commitment on the part of local participants, from district administrators to classroom teachers (p. 20). This culture created an atmosphere of indifference toward the change and results of the change had little or no impact on the desired outcomes from the process. In contrast, Iver, Abele, Kemper, and Stringfield (2003) in their four year study of the Baltimore Curriculum Project found that district and building level support can produce positive outcomes. They reported "In schools where teachers have become heavily invested in the program and scores are rising, we believe it is particularly important to continue implementing the reform, as 
change would be potentially disruptive" (p. 7). This aspect of acceptance is an important aspect of the change process that Datnow and Stringfield (2000) identified as a clear need for any change to occur with reliable results.

Miles (1998) examined the change process in education and in that process developed a list of the change "odyssey". He described many strategies implemented over the years directed specifically at school change: (1) Train individuals in group skills; (2) Clarify concepts of innovation; (3) Diffusion and adoption, and (4) Train change agents. These variables of the change process describe the necessary skills teachers and educators need to change how students will perform academically. The transition of students from grade eight to grade nine is a good example of that process, in which Lee (2001) suggests that outcomes be evaluated on the basis of two tiers: One being the "effectiveness, popularity and fidelity" of the change, and; the other being "adaptiveness and survival or longevity" of the outcomes of the process. The process of watching students achieve better results as a result of the transitional, physical, and mental movement from one grade level to another provides teachers and educators clear vision of the implementation processes. Results will help guide the school district in the right direction to meet their achievement goals.

\section{Summary of Implementation of Organization Change}

Vail (2010) indicated that change "takes courage and it's not for the faint of heart" (p.3). She explained that fidelity of implementation of change requires the total buy-in by all individuals involved in the change. In her examination of the Adams County School District 50 in Colorado, Vail found the change process fully implemented. Fidelity of implementation was evident in her review of the district's Re-Inventing 
Schools Coalition which created skill levels for students to progress through grade levels. The program produced a $95 \%$ transition success rate of students going to college or to the military in schools. Before the changes were made, Adams County School District 50 success rate was only $47.5 \%$. A key element for success was the commitment from $80 \%$ of all the teachers working together in this format.

Horner et al. (2005) researched on the implementation process of a "practice" introduced and concluded in order to make significant change, the goals "must be described with sufficient precision so that individuals other than the developers can replicate it with fidelity" (p. 176). To be successful with education reform efforts, the aspect of creating change must have longevity. Horner and other researchers emphasized the importance of documenting the change so the implementation of the practice was done with fidelity. The outcome should be proved with solid documentation supporting the implementation.

McLaughlin (1990) found through his study of educational change that the following variables needed to occur consistently in effectively delivered educational change: (1) Concrete, teacher-specific and extended training, (2) Classroom assistance from local staff, (3) Teacher observation of similar projects in other classroom, schools, or districts, (4) Regular meetings that focused on practical issues, (5) Teacher participation in project decisions, (6) Local development of project materials, and (7) Principals' participation in training (p. 12). According to Laughlin, the emphasis on "local expertise, capacity, and sophistication" will enhance the motivation and implementation of the change process. The building of a transitional action plan for 
moving students from grade eight to grade nine requires the fidelity of implementation to be strong and effective.

\section{Summary of Implementation}

With monitoring comes the responsibility of ensuring that fidelity of implementation is followed, as prescribed, in order to add validity to the program or process. As with the implementation of this study's grade eight to grade nine transition programs embedded with a set of structured articulation activities, school leaders must:

(1) Work collaboratively with all stakeholders to create the vision of the study, (2) Collaboratively develop the systemic processes to be followed in the program, and (3) Monitor the fidelity of implementation for program effectiveness. Far too many programs are initiated and dropped due to lack of successful results when the lack of program success was due in great part to the lack of fidelity of implementation. This study on the implementation of a set of structured articulation activities in the Grant County Transition Initiative provided a systematic process of monitoring to ensure the fidelity of implementation to support the program's validity and reliability.

\section{Final Comments}

The supporting literature of this study provides a foundational structure for developing a grade eight to grade nine transition programs which incorporates the characteristics common to organizational learning, high reliability organizations and effective schools. Louis $(1994,2006)$ contended that a school's ability to implement innovation and reform depend on the school's ability to process, understand, and apply knowledge as a group towards teaching and learning. Therefore, schools need to 
establish "systematic structures, processes and practices that facilitate continuous learning of all its members" (Silins \& Mulford, 2002, p. 444).

The introduction of the Grant County Transition Initiative included a systematic process for organizational change through a set of structured articulation activities that may impact outcomes in the transition from middle school to the high school. The GCTI used the knowledge of the literature to create the vision for employing change by working collaboratively with school leaders and district stakeholders in the development and implementation of the initiative. For long term sustainability, changes in school structure and the organization must occur as well as changing people and processes. A set of structured articulation activities occurs at the surface level to some degree in most schools across the country during the transition from grade eight to grade nine. To ensure a positive outcome of student academic performance, student behaviors and student attitudes during that transition, schools must intentionally, systematically and collaboratively develop a process for implementation. A structure for monitoring the progress and fidelity of implementation of a set of structured articulation activities must be included.

The product of this study, the Grant County Transition Initiative, examined the results of a systemic process for implementing a set of structured articulation activities in the transition from grade eight to grade nine that serve to develop organizational change which produces the outcomes of improved student academic performance, student behavior, and student attitudes. 


\section{CHAPTER THREE}

\section{METHODOLOGY}

This chapter describes the research question, the population and samples, development of GCTI, instruments, implementation of the treatment, analytic methods and limitations inherent in the study.

\section{Research Design}

\section{Research Questions and Purpose}

The research reviewed to this point indicates that middle and high schools have implemented interventions to help adolescents navigate the transition experience. The purpose of this study was to examine the implementation of a set of structured articulation activities injected into the transition process of eight graders transitioning to the ninth grade. The larger study on which this study was based included four research questions. Allen (2011) addressed two of these questions: What impact does a set of structured articulation activities have on student academic performance? What impact

does a set of structured articulation activities have on student behavior? Christian (2012) addressed one question: What impact does a set of structured articulation activities have on Grant County Schools as a learning organization? The final question was addressed in this study: What impact does a set of structured articulation activities have on student attitude? 


\section{Implementation of Grant County Transition Initiative (GCTI)}

\section{The Development of GCTI}

Grant County Middle School's eighth grade faculty and principal, along with Grant County High School's ninth grade faculty and assistant principal recognized in early 2008 that the failure rate of ninth grade students (students failing two or more core classes per semester) was creating a $36 \%$ retention rate in the ninth grade. The district's superintendent and the assistant principal of the Freshman Academy organized a committee to address this specific problem with the eighth and ninth grade faculties. The committee evaluated the present literature on articulation activities and collaboratively selected the activities to use in this study. Research completed by Hertzog and Morgan (1999) stated when five or more articulation activities are introduced in to the transition intervention process, the impact on the transition is more successful. The Committee selected articulation activities based on strong research which emphasized convenience and feasibility. Also considered, from available literature, were activities that were considered successful in their intervention process. From this foundation, the committee selected twelve structured articulation activities for this program. These activities focused on the categorical areas of curriculum, facilities, safety and discipline, teachers, counselors, administrators, and general (as referenced in Chapter Two).

\section{Structured Articulation Activities}

The research of Hertzog and Morgan (1999) found that transition interventions which implemented five or more articulation activities within the areas of curriculum, facilities, safety and discipline, teachers, counselors and administrators increased the likelihood of a successful transition from the eighth grade to the ninth grade. The GCTI 
committee selected a set of 12-structured articulation activities based on the research of Hertzog and Morgan (1999) and Mac Iver and Epstein (1991). These articulation activities are listed by category in Table 1 :

Table 1

Structured Articulation Activities With Five Categorical Themes

Curriculum

Facilities

Safety \& Discipline
1. A meeting proceeding the freshman year was held with grade eight parents so that parents could become familiar with the high school scheduling process and to develop a preliminary student schedule for their child's upcoming freshman year.

2. Teachers were engaged in team building sessions with grade eight and grade nine students to discuss college readiness and review prior EXPLORE data and PLAN data to prepare students for these assessments. These meetings also addressed the impact of a set of structured articulation activities on student progress.

3. Grade eight teachers and grade nine teachers met to discuss each student's progress. The frequency of the meetings varied depending on the needs of each child, but most teachers met once a month to review student progress. A data summary was developed for each student. Included in this tracking system were: Absences, behavior, GRADE POINT AVERAGE (GPA), final grades in language arts and mathematics, and number of student F's earned.

4. Grade eight students toured the high school in the spring semester.

5. Two freshman orientation meetings were held with grade eight parents. The first meeting was held preceding the freshman year to discuss the freshman academy, high school behavior expectations, discipline and safety. These meetings were separate meetings from the scheduling meeting.

6. Freshman Academy teachers (grade nine) and grade eight teachers participated in vertical alignment meetings to discuss curriculum, alignment, behavior and philosophical aspects to prepare students for the transition. 
Teachers, Counselors \& Administrators
7. Grade eight teachers and freshman academy teachers swap places for a day.

8. Freshman teachers, counselors and administrators attended the following: Grade eight dances, grade eight trips, and the grade eight picnic and grade eight graduations. This strategy was intended to build positive relationships with students.

9. Identified teachers in core academic area subjects participated in individual meetings with students identified as "at risk" to build rapport and relationships prior to the start of their freshman year in high school.

10. High school special education teachers attended eight grade Annual Review Committee (ARC) transition meetings after January $1^{\text {st }}$. All students that have an IEP and are in the eighth grade were required to have a transition meeting in the spring of their eighth grade school year prior to entering high school.

General

11. During a two day summer transition program for incoming freshmen, Junior Reserve Officer Training Candidates (JRROTC) orchestrated leadership activities to promote teamwork and organization. Cadets from the high school came to the middle school to lead these sessions.

12. Staff members conducted Counselor/Parent meeting transition sessions. This meeting involved eighth and ninth grade counselors and eighth grade parents.

The implementation plan, agreed upon by the GCTI Transition Committee members, required that each month at least one element plan of the articulation activities would be introduced and implemented. Committee members specified which articulation activity to implement during a particular month, and each member had the responsibility of overseeing the implementation and follow-through for a specific activity. Some activities were one-time activities, while others were continuous. The following 12 activities, detailed in Table 2, were implemented during a time frame that coincided with the purpose of the activity. 
Table 2

Timeline for Implementation of Each Structured Articulation Activities

Activity $1 \& 2$

Curriculum

Activity 3

Teachers,

Counselors, \&

Administrators
Activity

Purpose

Activity

Purpose

Activity 4

General

Activity 5

Curriculum
January-March: Freshman orientation meeting grade eight students at the middle school.

The first meeting for grade eight students included parents and school counselors. The purpose of the meeting was to provide an overview of the school, the schedule, course offerings, extra-curricular activities, and academic help available to students. Curriculum and behavioral syllabi were provided. The second orientation meeting occurred in March and focused on the scheduling process.

January - March: Teacher swap with grade eight and grade nine teachers.

Middle school and high school content area teachers traded teaching responsibilities for one day. Teachers traded places in mathematics, science, social studies and language arts. The purpose was to familiarize grade eight students with their high school teachers and to build student-teacher relationships in advance of students entering high school. These swaps also provided valuable information for the participants of the grade eight and nine vertical alignment meetings with regard to academic and behavioral needs of the incoming freshman.

Activity January-May: Ninth grade teachers participated in grade eight activities.

Purpose Grade nine teachers began participating in grade eight activities, such as dances, picnics, sporting events, awards night, graduation and other extra-curricular activities. The expected result of this activity was to develop teacher/student relationships that would carry forward into grade nine.

Activity January-May: Vertical alignment meetings. 
Purpose Grade eight and grade nine teachers met monthly in content area meetings to focus on students' academic and behavioral issues, such as student absence, behavior, GRADE POINT AVERAGE (GPA), language arts and mathematics grades, and failure rate.

Activity 6

Curriculum

Activity 7

Activity 8

Safety and

Discipline

Activity 9
Activity

Purpose

Activity

Purpose

Activity

Purpose

Grade eight students and parents met with the high school counselors. The purpose of this one time meeting was to discuss possible pitfalls of the transition to grade nine (student absence, behavior, homework, etc.).

Activity May: Grade eight tour of the high school. 
Activity 10

Facilities

Activity 11

Facilities

Activity 12

Teachers,

Counselors \&

Administrators
Purpose Grade eight students were provided a tour of the high school. The purpose of this activity was to acclimatize students to the new environment and to familiarize students with classroom locations.

Activity June: Grant County Transition committee met to analyze data. (Curriculum).

Purpose Develop and implement student data information forms to use to analyze academic and social needs of the students.

Activity July: Summer Transition Program (General).

Purpose During the summer between grade eight and grade nine, all students were invited to participate in a twoday summer session that took place two weeks prior to the start of the freshman year. The purpose of this two-day session was to provide students with organizational, teambuilding, and leadership skills. All activities were led by high school upper class members and student Reserve officer Training Candidates (ROTC).

Activity July: At-risk student meetings.

Purpose Two weeks prior to the start of the freshman year, Administrators and parents of students who had been identified as at-risk students were invited to attend a private session with school counselors and the academic principal to develop a student data form to help monitor student absences, behavior, and grades. At-risk students were identified as students missing at least 20 or more school days and/or failing one more courses in grade eight. 


\section{Monitoring GCTI Implementation}

Monthly transition team meetings were scheduled to monitor articulation activities and student achievement progress. Meetings were data driven with committee members reviewing data with regard to the following: Student absences, behavior, grade point average (GPA), language arts and mathematics grades, failure rates, and EXPLORE and PLAN data. Individual student monitoring data were gathered along with data for the entire grade eight. Data were collected for the eight dependent variable areas.

\section{Sample}

Two similar school districts in Central Kentucky (Bullitt County and Grant County) were chosen for this study. They constitute a convenience sample because they were chosen based on the researcher's access to the requisite district data and ability to influence the implementation of a freshman transition plan. Both districts are located in rural areas with very little ethnic student diversity. The districts were in proximity to urban areas; yet, they have retained a conservative, close knit, sense of community. Bullitt County is the seventh largest school district in the state of Kentucky, consisting of 24 schools, with six middle schools and three high schools. Grant County, a smaller district, has only seven schools, with only one middle school and one high school. At the inception of this project, both school districts had smaller learning communities in place with teaming at the middle school level and freshman academies at the high school level. Neither school district had structured freshman transition plans in place. No systematic process for implementing articulation activities was in place in either district. The two participating high schools, Bullitt East High School and Grant County High School, serve 
students in grades 9-12. Table 3 displays school-level demographic variables for the schools included in the study.

Table 3

Study Participants’ Demographics for 2008-2009 Academic School Years

\begin{tabular}{lccccc}
\hline & BEHS & GCHS & EMS & MWMS & GCMS \\
\hline $\begin{array}{lccc} \\
\text { Population }\end{array}$ & 1153 & 1090 & 531 & 509 & 848 \\
Number of Caucasian Students & 1126 & 1058 & 511 & 505 & 818 \\
Number of African-American Students & 3 & 8 & 6 & 1 & 6 \\
$\begin{array}{l}\text { Number of Hispanic Students } \\
\text { Number of American Indian Students }\end{array}$ & 2 & 3 & 0 & 0 & 0 \\
$\begin{array}{l}\text { Number of Asian Students } \\
\text { Number of Other Students }\end{array}$ & 1 & 2 & 2 & 0 & 2 \\
$\begin{array}{l}\text { Number of Limited English Language } \\
\text { Students }\end{array}$ & 10 & 7 & 0 & 0 & 0 \\
$\begin{array}{l}\text { Number of Free or Reduced Lunch } \\
\text { Students }\end{array}$ & 0 & 0 & 0 & 0 & 11 \\
$\begin{array}{l}\text { Number of Identified Students with } \\
\text { Disabilities }\end{array}$ & 114 & 107 & 55 & 55 & 102 \\
\hline
\end{tabular}

Note: BEHS - Bullitt East High School

GCHS - Grant County High School

EMS - Eastside Middle School (Bullitt County)

MWMS - Mount Washington Middle School (Bullitt County)

GCMS - Grant County Middle School 
Bullitt East high School in Bullitt County is a small town/rural community school, serving 1,153 students in Mount Washington, Kentucky. It is the second largest high school in the county and has rich traditions and a strong connection to the community. The students at the school perform well both academically and athletically. Bullitt East High has outstanding parental and community support and traditionally scores the highest in state testing among the three district high schools.

Grant County High School is in Dry Ridge, Kentucky. The school is centrally located in the county and, as the only high school, serves as a hub for community activities. Grant County High School is traditionally known for quality academic, fine arts, and vocational programs.

Eastside Middle School is one of two schools feeding into Bullitt East High School. It was built during the 2005-2006 academic school year and students moved into the building in January 2006. Due to the school's status as a new institution, their scores for the 2005 are simply the district scores. Therefore, Tables 4, 5 and 7 include a dash for the year 2005-2006, a consequence of the school's being new and not having designated state assessment scores that year. The school is housed in a state-of-the-art facility. Eastside Middle School's academic focus is on technology. Eastside is a top performing middle school in the State of Kentucky.

The other feeder school for Bullitt East High is Mount Washington Middle School in Mount Washington, Kentucky, located in the eastern portion of Bullitt County. This middle school is one of the oldest schools in Bullitt County, having been a vital part of the Mount Washington community for over 50 years. The school offers a comprehensive range of courses for all students at all ability levels, as well as a full range of 
extracurricular activities. Eastside Middle and Mount Washington Middle are both nationally recognized schools to watch.

Grant County Middle School is the only middle school in Grant County. The mission of the school is to involve students, parents, school staff, and the community in establishing a learning environment that promotes the educational, social, and emotional needs of all students. The school's main academic focus is on school-wide reading.

Tables 4 through 8 describe each participating school's data with respect to student absences, retention-by-failure, dropout, and graduation rates prior to the start of the study. The data were presented to establish characteristics of the schools and describe similarities among the schools.

The tables below represent each of the school's non-cognitive performance indicators from 2004 to 2009. The data were valuable when examining relationships among the confounding and dependent variables. Table 3 defines each school's population as it relates to the study's confounding variables: disability, ethnicity, gender, and socioeconomic status. The numbers indicate that all the schools combined had fewer than 25 total students of minority ethnicity group representation. All of the schools had in the range of $15 \%$ to $57 \%$ of the students receiving free/reduced lunch and one out of every 10 students having an identified disability. The data indicated the student bodies of all participating schools were composed of primarily middle class Caucasian students. The smallest percent of Caucasian students were enrolled at Eastside Middle School with $511 / 531$ or $96.2 \%$ to Mount Washington Middle School with 505/509 students or $99.2 \%$ Caucasian students. 
Table 4

School Attendance Rates (in percents) Prior to Treatment

\begin{tabular}{lccccc}
\hline School & 2004 & 2005 & 2006 & 2007 & 2008 \\
\hline Bullitt East High School & 93.3 & 94.0 & 94.0 & 93.0 & 93.0 \\
Grant County High School & 92.2 & 92.0 & 92.7 & 92.0 & 92.8 \\
Eastside Middle School & --- & --- & 96.2 & 96.0 & 96.1 \\
Mount Washington Middle School & 95.2 & 95.0 & 95.0 & 95.0 & 95.4 \\
Grant County Middle School & 94.8 & 94.9 & 95.2 & 95.0 & 94.9 \\
\hline
\end{tabular}

Table 4 provides data on the five schools respective attendance rates over time.

Student absences were identified as a dependent variable and the focus of research for Question 2. Both high schools had a lower rate than the middle schools. There was very little fluctuation over time with the percents ranging from $92-96 \%$.

Table 5

School Retention-by-Failure Rates (in percents) prior to Treatment

\begin{tabular}{lccccc}
\hline School & 2004 & 2005 & 2006 & 2007 & 2008 \\
\hline Bullitt East High School & 3.70 & 1.90 & 3.40 & 2.80 & 4.60 \\
Grant County High School & 7.70 & 8.30 & 12.80 & 13.40 & 1.00 \\
Eastside Middle School & 3.8 & --- & 0.20 & 1.10 & 0.40 \\
Mount Washington Middle School & 1.90 & 1.30 & 2.90 & 3.80 & 6.20 \\
Grant County Middle School & 0.80 & 0.10 & 0.30 & 1.10 & 0.00 \\
\hline
\end{tabular}

Table 5 reflects the retention-by-failure rates over time for all five schools in this study. Several pieces of data were significant. Grant County High School reduced its 
retention-by-failure rate by approximately $12 \%$ in a single year at a time when retentionby-failure and dropout rates are increasing; GCHS accomplished an astonishing task in reducing the retention-by-failure by this amount. In 2008 , the $12 \%$ decrease in retentionby-failure mathematically breaks down to approximately 135 students not failing at Grant County High School that year. On the other hand, Mount Washington Middle School doubled its retention-by-failure rate in one year from 3 to $6 \%$.

Table 6

Ninth Grade School Retention-by-Failure (number of students failing)

\begin{tabular}{lccc}
\hline Number of Students retained in $9^{\text {th }}$ Grade & 2007 & 2008 & 2009 \\
\hline Bullitt East High School & $27(9.5 \%)$ & $13(4.3 \%)$ & $18(6.1 \%)^{\mathrm{a}}$ \\
Grant County High School & $12(6.3 \%)$ & $10(5.0 \%)$ & $7(3.4 \%)^{\mathrm{a}}$ \\
\hline
\end{tabular}

Note: ${ }^{\text {a }}$ Treatment year was 2009

Table 6 displays the number of students retained in ninth-grade for each of the participating high schools. In the past three consecutive years in Grant County High School (GCHS), the number of students retained in ninth-grade decreased whereas that was not the case for Bullitt East High School. The 2008-2009 school years were the year of actual implementation of the treatment of the set of structured articulation activities.

The number of students retained at the ninth-grade for each of the high schools represented the students in the trend data group, year 2008-2009. For the year 20082009, Bullitt East High School (BEHS) retained 13 students in grade nine reflecting a decrease of 14 students from the previous year. GCHS retained 10 ninth graders, which was also a decrease from the previous year, of only two students. The year after the treatment, BEHS actually an increase of five students retained in the ninth grade. BEHS 
students in the ninth grade that year were part of the comparison group or non-treatment group. GCHS, which had ninth graders that year participating in the treatment, decreased the number of ninth graders retained by three, for the second consecutive year. The data demonstrated the values fluctuated and continued monitoring is necessary to identify a trend.

Table 7

School Dropout Rates (in percents) Prior to Treatment

\begin{tabular}{lccccc}
\hline School & 2004 & 2005 & 2006 & 2007 & 2008 \\
\hline Bullitt East High School & 0.5 & 0.8 & 0.2 & 1.0 & 1.3 \\
Grant County High School & 6.3 & 2.7 & 4.3 & 5.7 & 3.5 \\
Eastside Middle School & 1.9 & --- & 0.0 & 0.0 & 0.0 \\
Mount Washington Middle School & 0.0 & 0.2 & 0.0 & 0.0 & 0.3 \\
Grant County Middle School & 0.2 & 0.2 & 0.0 & 0.0 & 0.0 \\
\hline
\end{tabular}

Table 7 describes changes in dropout rates over time for each school. The middle schools had insignificant numbers of dropouts which is normal for elementary and middle schools. The three middle schools' dropout rates ranged from 0.0 to $1.9 \%$ with one school recording a rate of 1.9. School counselors make sure students that withdraw are re-enrolled in another middle school and document that information. Otherwise, a student is declared as dropping out. For the 2008-2009 school year, which was a pretreatment group already in the high school, the Grant County High School recorded nearly three times the rate of student dropouts as Bullitt East High School. For 20082009, Bullitt East High School had a 1.3\% student dropout rate and Grant County Middle School had a $3.5 \%$ drop out rate. The data shows over the five-year period, Bullitt East 
High School rate of dropouts increased and, during the same time period, Grant County High School reduced its number of student dropout's by $50 \%$.

Table 8

High Schools - Graduation Rates (in percents) Prior to Treatment

\begin{tabular}{lccccc}
\hline School & 2004 & 2005 & 2006 & 2007 & 2008 \\
\hline Bullitt East High School & 96.9 & 97.8 & 97.6 & 93.6 & 94.0 \\
Grant County High School & 75.6 & 79.4 & 76.9 & 79.3 & 82.2 \\
\hline
\end{tabular}

Table 8 presents the graduation rates for each high school. Five years of data used in this study were from the school report cards. During this time, Bullitt East High School recorded a 3\% decrease in graduation rates whereas Grant County High School recorded an $8 \%$ increase in graduation rates. What stands out Table 8 is the change for both schools from 2006 to 2007. During this time frame, the two schools made approximately the same change numerically; one was an increase and the other a decrease in graduation rates. During this time span, BEHS decreased in graduation rate by $4.0 \%$ and GCHS increased in graduation rate by $3.6 \%$.

Table 9 reflects the number of students participating in the study in the comparison, a non-treatment and treatment group. 
Table 9

School Participating Numbers

School Number of Students

Bullitt East High School

Grant County High School

Eastside and Mount Washington Middle

(Combined)

Grant County Middle School

234

\section{Dependent Variables}

The dependent variables of this study are student attitudes that have been influenced or impacted by a set of articulation activities introduced to their transition process from grade eight to grade nine. Dependent variables were identified through questionnaires that target the specific student attitudes towards many experiences that the transition process produced, and the development of their student profile data.

\section{Independent Variables}

The set of articulation activities introduced to the transition process of moving from grade eight to grade nine are the independent variables of this study. This information is detailed in Table 2.

\section{Confounding Variables}

The confounding variables are variables over which schools have no control. Confounding variables characteristically frame the context of the school. The confounding variables in this study include: gender, race socioeconomic status (free/reduced lunch) and disability status. These variables are detailed further in Table 3. 


\section{Research Design}

The study used a quasi mixed-methods research design that included both quantitative and qualitative analysis. The type of mixed methods research design includes several research design approaches for various parts of the study. This study used post treatment one time study with a treatment group and one comparison group to establish if there were trends in the strands which could be used to compute means and standard deviation. The Non-treatment comparison group design consisted of Harter Survey parts, Appendix A (A) with 45 questions, and Appendix B (B) with 16 questions. Comparisons were made between the two groups of middle school students in their (A) self perception profile and (B) sense of competence. The purpose of this portion of the research is to establish differences and/or similarities between these two groups which may assist in the interpretation of articulation treatment effects on one of the group. The Quasi-experimental research design with comparison and treatment groups uses a postmeasure only. The Anderson survey of grade nine experiences has 15 Likert questions. The Focus group questions, which is the qualitative measure, had multiple choice and open responses. The analysis technique was to do open coding within a prior established construct of: Academic, social and procedural categories. These categories were based on major themes intended to be addressed by the treatment set of articulation activities.

Creswell (2005) through his analysis of both quantitative and qualitative data found that better conclusions and analysis of collected data can help the understanding of the research problem by using both types data evaluation. The following model is a description of the variable and the conceptual design of this study: 


\section{Strand 1}

Non-Treatment Comparison Group

\section{$\underline{\text { Strand } 2}$}

$\mathrm{T} \quad \mathrm{xO}_{1}$

NT' $\quad-\mathrm{O}_{1}$

$\mathrm{x}=$ Treatment happens

$\mathrm{O}_{1}=$ Observation (measurement) of each group (surveys) + focus group

Figure 4. Mixed Methods Research Design

The formula consists of Strand 1 which is Bullitt County and Grant County schools completing the Harter Survey. Strand 2 consists of a treatment and non-treatment observation (measurement) of each group surveys plus the Anderson Student Survey focus group.

The post-test data was collected from Bullitt and Grant grade nine students during the 2008-2009 school year. The post-test data documented student attitudes related to the structured articulation activities as reported by the students at the end of the first semester of grade nine.

\section{Instrumentation}

This study used two surveys to gather information on the sample population: The Susan Harter Self-Perception Profile for Adolescents, and the Susan L. Anderson Student and Focus Group Survey. Creswell (2005) points out surveys can produce information that describes behaviors, characteristics, attitudes, and opinions of the sample group. The purpose of the Harter and Anderson surveys was to collect data on the non-treatment 
group (Bullitt County middle and high school students) and the treatment group (Grant County middle and high school students) for analysis of their self-perception and attitudes about their experiences of transitioning from eighth to ninth grade.

The surveys collected data from ninth grade students during the last nine weeks of the school term. This allowed students to reflect on their experiences in participating in the articulation activities during their eighth and ninth grade school years. The Harter Self-Perception Profile for Adolescents and the Susan Anderson Student Survey and Focus Group Survey collected the students' attitudes covering many topics on their perceptions of themselves, peers, and procedural, social and academic concerns about their experience with over the last two years of transitioning to the high school.

The Harter Adolescent Self-Perception Profile was administered to a random group of students in the 2009-2010 freshman class from two high schools in Bullitt County and one in Grant County. This profile was developed by Susan Harter in 1988 and has been used extensively by Harter, Jay Hertzog and Lena Morgan (Lozeau, 1998). One of the strengths of this instrument is the manner in which the questions are written. The profile uses the four point Likert Scale and participants choose between two answers for each question. After selecting the answer that most resembles them, students choose whether the answer is "sort of" or "really like" them. The survey has built in validity checks. The following nine domains were included:

1. Athletic competence

2. Behavior conduct

3. Close Friendships

4. Global self-worth 
5. Job competence

6. Physical appearance

7. Romantic appeal

8. Scholastic competence

9. Social acceptance

The Harter Adolescent Self-Perception Profile (Appendix D) was devised to tap domain-specific judgments of competence or adequacy in nine separate domains consisting of 45 questions. Each subscale provides a separate score which allows one to develop a profile of a student's perception of their competence across all nine domains. The structure of the questions required the student to first decide which teenager is most like them (left or right column on the page) and then to decide whether this is only sort of true or really true for him or her. The questions are scored on a scale of 1 to 4 , where a score of 1 reflects a low perceived competence or adequacy and a score of 4 indicated a high-perceived competence or adequacy. A total of 696 students participated in the Harter Self Perception Profile; 30 students attended Bullitt County Schools and 39 students attended Grant County Schools.

Hertzog and Morgan (1994) used this survey to assess grade eight to grade nine transition. The instrument has been used successfully in a study similar to the present study (Lozeau, 1998).

Validity is substantiated for this instrument by the following: The applicability to studying grade eight to grade nine transitions in the Hertzog and Morgan study, field testing of the instrument by Harter in 1998, and by using the Cronbach Alpha to 
determine internal reliability. For this study, the instrument will be retested, using student samples, for reliability.

\section{$\underline{\text { Scholastic Competence }}$}

Scholastic competence measures the adolescent's perception of their ability to perform academically in the classroom. It also measures the adolescent's perception of how smart or intelligent they might perceive they are in the academic environment of the classroom. The examination of a student's self-worth in the area of academics is an important aspect of measuring the response of adolescents when asking them to compare themselves to the other young ninth grade students. Harter (1981) found that younger elementary students are significantly more motivated intrinsically and, as they progress through middle school to high school, they become more extrinsic in their motivational development. Harter continues to be more specific with this identification of grade motivation by finding that reading, math, science, and social studies grades are influenced by this development to extrinsic motivation.

The final qualitative component of this study will be the Susan Anderson Student Survey and Focus Group Survey. These surveys were administered to the same 30 students that participated in the survey portion of the study. The student surveys allowed for clarification of the responses and will provide triangulation in obtaining qualitative information as to best practices in a transition program from students' perspectives.

Figure 5 below visually explains the implementation of the set of structured articulation activities. By following the diagram visually from left to right, the details pertaining to the comparison or non-treatment group can be interpreted. 


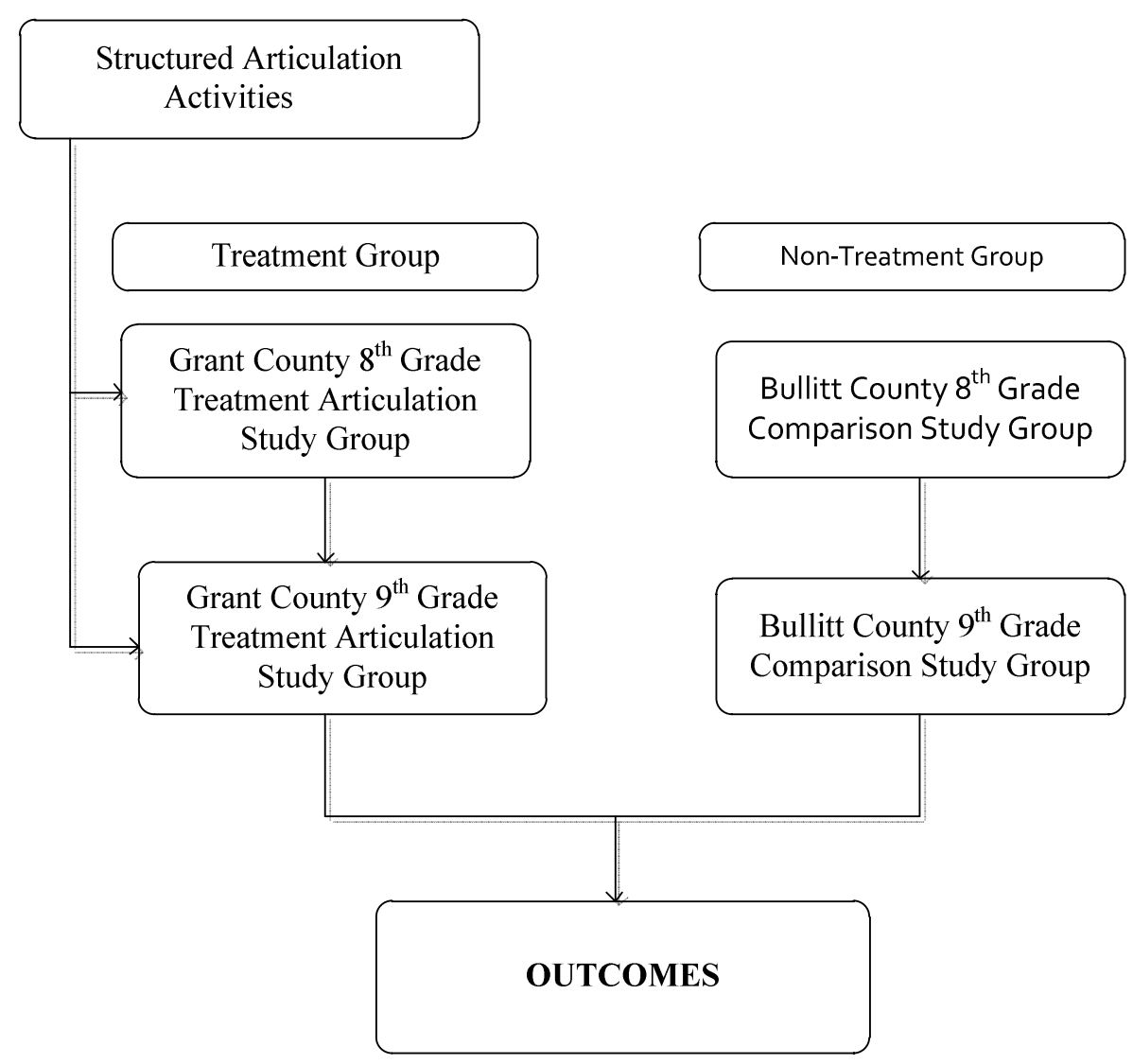

Figure 5.Implementation Framework for the Grant County Transition Initiative

\section{Description of Measures}

The questions used in the surveys were Likert-type that could produce a measure of degree on how students perceive the experiences that influence their transition process. Likert-type scales can measure through the use of a technique that uses participants rating form a high emphasis to a low emphasis. Anderson (2008) developed her surveys to measure the students opinions from a strongly agree to a strongly disagree format. Her focus group survey centered on producing clarification about procedural, academic, and social areas of information provided by the students. These questions allowed the students to review the question in a more open ended manner so they could explain how their experience with the transition process influenced them or did not influence them. The questions were also more direct about certain issues in the transition process. 
The Harter Adolescent Profile uses Likert-type questions for the survey used in this study. The Harter survey builds self profile that reflects the concerns of adolescents.

\section{Validity}

Cook and Campbell (1979) define validity as the "best available approximation to the truth or falsity of a given inference, proposition or conclusion" (p.37). In this study, the four types of validity (construct, internal, external, and statistical conclusion) were addressed and how they will be minimized was discussed based on the validity types from Shadish, Cook, and Campbell (2002). Table 10 presents a summary of the research questions and the specific categories of threat to validity for each question.

Table 10

Research Questions and Validity Threats

\begin{tabular}{lllccc}
\hline $\begin{array}{l}\text { Research } \\
\text { Question }\end{array}$ & Research Question & $\begin{array}{l}\text { Construct } \\
\text { Validity }\end{array}$ & $\begin{array}{l}\text { Internal } \\
\text { Validity }\end{array}$ & $\begin{array}{c}\text { External } \\
\text { Validity }\end{array}$ & $\begin{array}{c}\text { Statistical } \\
\text { Conclusion } \\
\text { Validity }\end{array}$ \\
\hline RQ1 & $\begin{array}{l}\text { What impact does a } \\
\text { set of structured } \\
\text { articulation activities } \\
\text { have on student } \\
\text { attitudes? }\end{array}$ & $\mathrm{X}$ & $\mathrm{X}$ & $\mathrm{X}$ & $\mathrm{X}$ \\
& & & & & \\
& & & & \\
\hline
\end{tabular}

\section{Construct Validity Threats}

Some treatment diffusion was expected to occur during the study because public schools are dynamic systems and students continually move in and out of school. Also, existing patterns indicated that some students missed excessive school days. The comparison school may attempt to implement some of the treatment articulations once the administration learned about them from teachers and administrators from the 
treatment district. However, they intentionally did not implement due to the impact it may have had on the study which reduced this particular threat.

\section{Internal Validity Threats}

In this study results may be attributed to the school climate to which the students transition. The two school districts were similar, yet the school climates were different, resulting in some deviations in performance. Another factor beyond the researcher's control was the combined academic abilities of the participants in one class compared to those of another class.

\section{External Validity Threats}

In this particular study, specific limitations which caused difficulty in making these generalizations existed. The limitations included: The use of only two schools in Kentucky; the schools' rural settings; and the lack of diversity. However, these results may generalize to other schools that match the characteristics of these schools.

\section{Statistical Conclusion Validity Threats}

Statistical validity refers to the quality of the data and the analysis used on that data. There were several concerns in this area. First, both school districts in 2007 used the Software Technology Information (STI) computer program for collecting data in the areas of: absences, behavior, GPA, and grades. In 2008, the State of Kentucky converted to the Infinite Campus system for data collection. The STI program's format for collecting data were to round to the nearest tenth of a whole number, and the format was to keep student absence information separate from behavior. The Infinite Campus Program, on the other hand, reports student absence data to the nearest thousandth of a whole number, and the records for student absence letters are kept in the file with 
behavior events. Therefore, the data collector had several issues to resolve. When collecting the behavior events, the data collector had to accurately determine the number of events, eliminating student absence reports. Therefore transferring data accurately was essential.

\section{Data Analysis Plan}

Table 11 outlines the overall data analysis plan implemented in this study, including the analysis tool applied to each research question.

Table 11

Data Analysis Plan

Research

Question Research Question Data Instrument Analysis Method

$\begin{array}{lll}\text { RQ1 What impact does a } & \text { Data retrieved } & \text { Construct Analysis structured } \\ \text { set of Articulation } & \text { from Student } & \text { Quasi Mixed Methods } \\ \text { Activities have on } & \text { surveys } & \text { research } \\ \text { student attitudes? } & & \text { Post treatment one } \\ & & \text { time study with two } \\ & & \text { comparison groups }\end{array}$

Summary

Chapter Three identifies data collection methods and details the process used to complete the analysis in this study. This study was a post treatment one time study with one treatment group and one comparison group to measure and determine if there were trends to compute means and standard deviation. The objective was to determine if the structured articulation activities had a significant effect on student attitudes.

Chapter Four will detail the result of the Harter Adolescent Self-Perception Profile for Adolescents and the Anderson Student Survey. 


\section{CHAPTER FOUR}

\section{RESULTS}

This study focused on the impact of a set of research-based articulation activities on students transitioning from middle school to high school. This study used post treatment study with one treatment group and one comparison group to establish if there were existing trends and to compute means and standard deviation so that post-treatment impacts could be compared. The study involved two comparison groups: Bullitt County (BEHS), Kentucky which consists of two middle schools, Eastside Middle, Mount Washington Middle and one high school Bullitt East High School; and Grant County (GCHS), Kentucky which consisted of one middle school Grant County Middle School and one high school Grant County High School. This study is centered on a sampling of these students in both groups on their attitudes involving their self perception and their experiences with the transition process after a set of structured articulation activities had been introduced during their grade eight and grade nine school terms.

A quasi mixed methods research, post treatment one time study with two comparison groups and Construct Analysis was used to report both quantitative and qualitative results which focused on the comparative mean scores from the treatment group GCHS and the non-treatment group BEHS. This research focused on comparing results based on the Harter Self-Perception Profile For Adolescents and the Susan Anderson Student survey. 


\section{Subjects of Study}

The overall project treatment group consisted of 234 eight graders in 2008-2009 at Grant County Middle School. The non-treatment (control) group in the study had 262 eighth grade students in 2008-2009 at Eastside Middle and Mount Washington Middle schools. The students from Grant County live in an expanded area of very small community groupings. The elementary schools that feed Grant County Middle Schools are located in rural locations in the county. The students from this feeder pattern have very little or no interactions with other students in the county. The first organized interactions between these students come when they arrive at Grant County Middle School. In contrast, the Bullitt county students from Mount Washington Middle and Eastside Middle School come from very similar, close-knit communities. The communities within Bullitt County are similar in demographics and population size. There are many common areas within these communities which foster interactions between students prior to their start of their middle school years.

This study took a random sampling of the overall project population during their last semester of the grade nine at Grant County High School (treatment group) and Bullitt East High School (non-treatment group). These numbers consist of 39 students from the treatment group and 30 students from the non-treatment group.

\section{Data Analysis}

Research Question: What impact does a set of structured articulation activities have on student attitudes?

To answer this question, two surveys were conducted to establish four strands of data pertaining to the impact a set of structured articulation activities had on students 
transitioning from grade eight to grade nine at Bullitt East High School (BEHS) and Grant County High School (GCHS). The first survey, Appendix A, was the Harter SelfPerception Profile for Adolescents (Harter, 1988) which was divided into two parts. Part A compared the self-perception similarities and differences of BEHS versus GCHS grade nine students. Part B compared the similarities and differences of the competence profile of BEHS versus GCHS grade nine students.

The Anderson Student Survey (Anderson, 2008) was also divided into two parts. Part 1 (Anderson Likert questions) measured GCHS grade nine student's reactions to grade nine articulation activities. Grant County High School students received the articulation activities during the second semester of grade eight and the beginning of the first semester of grade nine. Bullitt East High School did not receive a targeted set of articulation activities but instead received traditional orientation activities required in their school district. Part 2 (Anderson open-response focus group) of the Anderson Student Survey, Appendix D, recorded qualitative focus group responses from students to identify the impact of transition activities for the treatment group, GCHS students and the comparison group from BEHS. The surveys were issued one time at the end of the first semester of the student's grade nine year at BEHS and GCHS. The results were separated into three core constructs built from the student survey responses.

Quantitative and qualitative analysis was prepared based on the Harter SelfPerception Profile for Adolescents survey and the Anderson Student Survey. Harter Self-Perception Profile For Adolescents - Part A

The first calculations made were to determine internal reliability for all of the nine domains. Cronbach Alpha was chosen as the tool for examining internal 
reliability. Cronbach Alpha is considered the most effective test for reliability. The higher the value the more reliable the test is considered. A value of .70 or above is considered to be acceptable (Hinton, 2004; Nunnally, 1978). Table 12 indicates the Cronbach Alpha score for each of the domains for the overall school data exceeded .70 indicating that the data used for Part A was internally reliable.

Table 12

Cronbach Alpha Scores Harter Self-Perception Profile

\begin{tabular}{lcccccc}
\hline Domain & Question & Question & Question & Question & Question & Alpha \\
\hline Scholastic & 1 & 10 & 19 & 28 & 37 & .83 \\
Social & 2 & 11 & 20 & 29 & 38 & .70 \\
Athletic & 3 & 12 & 21 & 30 & 39 & .86 \\
Physical & 4 & 13 & 22 & 31 & 40 & .79 \\
Jobs & 5 & 14 & 23 & 32 & 41 & .71 \\
Romantic & 6 & 15 & 24 & 33 & 42 & .74 \\
Behavioral & 7 & 16 & 25 & 34 & 43 & .86 \\
Friendships & 8 & 17 & 26 & 35 & 44 & .74 \\
Self-Worth & 9 & 18 & 27 & 36 & 45 & .83 \\
\hline
\end{tabular}


Tables 13 and 14 display results of the Harter Self-Perception For Adolescents Part A and B. A t-test was created for the nine categories comparing BEHS versus GCHS in Part A. A t-test was also created for the eight categories in Part B comparing BEHS versus GCHS. The first column in each table describes the domain of the Harter Self-Perception Adolescent Profile. The second column indicates the mean and standard deviation (sd) scores for BEHS and GCHS. The third column represents the p value comparison of BEHS and GCHS. Column four represents the comparison of the Cohen $d$ for each domain (Hinton, 2004).

$\underline{\text { Scholastic Self-Profile Part A }}$

The BEHS and GCHS students found the academic areas important to their selfperception. The findings were not significant in comparison but the mean scores were grouped at the high level of self-identity as reported in Table 13. The Scholastic SelfProfile centered on how an adolescent perceives his/her performance on class work and how smart or intelligent they feel about themselves. The set of articulation activities were formulated to give students of solid support system in the area of academics. The GCHS students showed interest in the development of their academic self-identity. $\underline{\text { Social Self-Profile Part A }}$

The BEHS and GCHS students' results were significantly different on this domain as reported in Table 13. The Social Self-Profile centered on the degree in which the adolescent perceptions of acceptance with peers, popularity with others, and he/she perceived their ability to be liked by others. The BEHS students showed that the social aspects were very important to their development while the GCHS students showed that the social aspects of the self-identity were not reported as highly. The set of structured 
articulation activities were intentionally geared towards bringing the students together in all orientation activities which would include an emphasis on the social aspects of the transition. The influence of the students being in more close-knit communities versus very rural settings emphasized the importance of the social aspects of the articulation activities.

\section{$\underline{\text { Athletic Self-Profile Part A }}$}

The BEHS and GCHS students' mean scores were not significant in their findings as reported in Table 13 but the importance of the similarities show a set of structured articulation activities introduced to the GCHS students did not emphasize the importance of establishing a self-identity in the area of athletics. The Athletic Self-Perception Profile centered on how he/she might perceive their athletic ability and whether they think their skills in this area are good. The set of articulation activities encouraged the involvement in all extracurricular activities despite how the student might interpret their ability levels in these activities.

\section{Physical Appearance Self-Profile Part A}

The BEHS and GCHS students were not significantly different on this domain as reported in Table 13. The Physical Appearance Self-Profile centered on how happy an adolescent is with the way he/she may look, likes their body, and how they feel about their body image. With this in mind, the results can be connected to the results of the social aspects of the results. The trending data of the BEHS students show the social transition to the high school was important as to how one feels about themselves in that arena. In contrast, for GCHS students, the set of articulation activities centered on 
building the adolescent an overall positive image in their ability to manage problems in their academic self identity growth.

$\underline{\text { Job Competence Self-Profile Part A }}$

The BEHS and GCHS students' results did not produce any significant difference but both groups showed a similar interest level in their self-identity with the job perceptions as reported in Table 13. The Job Competence Self-Profile centers on the adolescent perception in their job skills and their abilities and how they used their skills to find a part-time job or to do well at a job they already have. The key area in this measurement is that both groups of students trended towards understanding the importance of their self-identity and how it relates to their job abilities. The set of structured articulation activities did emphasize the importance of staying on track to graduate which, in turn, would assist a student with plans for further education or training for skills that would secure a future job in the areas they were interested in exploring or securing.

\section{$\underline{\text { Romantic Appeal Self-Profile Part A }}$}

The BEHS and GCHS students' response data showed a trend towards the grouping of Social and Physical Appearance are in line with the similarities of the Romantic Appeal Self-Profile as reported in Table 13. This profile asked the adolescent to what extent they feel attractive to those they are interested in knowing, are dating the people they would like to date, and that they feel they are fun and interesting on a date. The BEHS students trended towards establishing important relationships with their peers in social interactions. GCHS students, again, trended toward the need of becoming more social which would enhance or improve their abilities in the area of romantic appeal. The 
set of structured articulation activities did not center on the specific skill building areas of social development. Instead the emphasis was academic confidence building that would help them with some aspects of social development.

\section{Behavioral Conduct Self-Perception Profile Part A}

The BEHS and GCHS student responses did produce significant statistical results in the area of Self-Perception of Behavioral Conduct as reported in Table 13. This area of the self-perception profile identifies what the adolescent perceives the degree to which one likes how he or she behave, does the right thing, acts the way one is supposed to, and avoids getting into trouble. The significance of the results had a direct connection to the set of structured articulation activities' main goal of developing a confident, selfadjusting student who recognizes the importance solving their problems effectively. The direct connection of getting good grades and being responsible for their actions in the classroom enhances their abilities to stay on track to graduate.

\section{$\underline{\text { Close Friendship Self-Perception Profile Part A }}$}

The BEHS and GCHS student results did not produce significant differences in this domain of Close Friendship Self-Perception Profile as reported in Table 13. Yet there was a strong trend by both groups towards recognition of the importance to develop friendships. This area of Close Friendship Self-Perception Profile is examined by the adolescent's ability to make close friends they can share personal thoughts and secrets. The set of structured articulation activities emphasized using the support systems available to help students stay on track during the transition period, especially with academic needs. The BEHS showed strength in the social areas as whereas the GCHS students continue to trend toward the academic areas as strength. 


\section{Global Self-Worth Perception Profile Part A}

The BEHS and GCHS student results did not show a significant statistical finding in the Global Self-Worth Perception but again, the trending data did show a connection to the Behavioral Conduct area as reported in Table 13. The Global Self-Worth Perception emphasized the extent to which the adolescent views himself or herself as a person; are they happy with how they are leading their life, and are they generally happy with the person they perceive they have become. This aspect of the profile is perhaps the most important for the part of the set of structured articulation activities as students' transition to high school. The importance feeling good about your progress academically can perhaps take the stress away from the other areas of concern for development of the student's identity during the transition process.

Table 13

Harter Adolescent Self-Perception Profile - Part A

\begin{tabular}{|c|c|c|c|c|c|}
\hline \multirow[b]{2}{*}{ Subscale } & & $\begin{array}{l}\text { BEHS } \\
(n=30)\end{array}$ & $\begin{array}{l}\text { GCHS } \\
(n=39)\end{array}$ & \multirow[b]{2}{*}{ p-Value } & \multirow[b]{2}{*}{ Cohen's d } \\
\hline & & $\begin{array}{c}\text { Mean } \\
(\mathrm{sd})\end{array}$ & $\begin{array}{c}\text { Mean } \\
(\mathrm{sd})\end{array}$ & & \\
\hline \multirow[t]{2}{*}{ Scholastic } & & 3.03 & 3.18 & 0.47 & - \\
\hline & sd & 0.87 & 0.84 & & \\
\hline \multirow[t]{2}{*}{ Social } & & 3.51 & 3.15 & 0.03 & -0.56 \\
\hline & $\mathrm{sd}$ & 0.54 & 0.73 & & \\
\hline \multirow[t]{2}{*}{ Athletic } & & 2.89 & 2.76 & 0.53 & - \\
\hline & sd & 0.82 & 0.85 & & \\
\hline \multirow[t]{2}{*}{ Physical } & & 2.86 & 2.79 & 0.72 & - \\
\hline & $\mathrm{sd}$ & 0.73 & 0.86 & & \\
\hline \multirow[t]{2}{*}{ Jobs } & & 3.18 & 3.19 & 0.95 & - \\
\hline & $\mathrm{sd}$ & 0.70 & 0.87 & & \\
\hline Romantic & & 3.00 & 2.86 & 0.49 & - \\
\hline
\end{tabular}




\begin{tabular}{|c|c|c|c|c|}
\hline $\mathrm{sd}$ & 0.76 & 0.95 & & \\
\hline Behavioral & 2.96 & 3.37 & 0.06 & - \\
\hline sd & 0.92 & 0.83 & & \\
\hline Friendships & 3.23 & 3.50 & 0.18 & - \\
\hline sd & 0.84 & 0.85 & & \\
\hline Self-Worth & 3.29 & 3.46 & 0.35 & \\
\hline $\mathrm{sd}$ & 0.75 & 0.73 & & \\
\hline
\end{tabular}

Note: Boxed cells will be discussed further in Chapter Five

\section{$\underline{\text { Harter Self-Perception Profile For Adolescents Part B }}$}

Part B of the Harter survey, Appendix B, measured the adolescent's competence versus their interpretation of their self-worth. The importance of Part B is that determining through the adolescent's responses to their own perceptions of their competency/adequacy judgments, the self-profile domains lead to a better understanding of the positive and negative aspect of their life. The goal was to measure how adequate the adolescent feels in the areas he or she judged to be important to them. These results helped to understand if an adolescent's self-worth is high or low.

For the Competence Profile Part B, Table 14, each domain construct consisted of only two items, so a Cronbach Alpha was not used to examine the internal reliability of only two items each. The threshold value of .70 could not be attained with only two items available for computation. Also, there were eight domains in Part B to measure the mean, standard deviation, p-Value, and Cohen d.

$\underline{\text { Scholastic Sense of Competence Part B }}$

The BEHS and GCHS student results in the area of Scholastic Sense of Competence showed a trend of high competence towards the importance of the academic 
aspects in relation to their self-worth, which is reported in Table 14. The trend is not statistically significant but the high mean scores indicated both groups of students felt academics were important and help students understand their self-worth. The set of structured articulations activities emphasized the importance of establishing a confident student GCHS who can resolve the academic problems that arise from transitioning to grade nine at the high school.

\section{$\underline{\text { Social Sense of Competence Part B }}$}

The BEHS and GCHS results for the Social Sense of Competence showed a trend in Part A where the BEHS students found the social aspects of their self-identity more easily than the GCHS students. As indicated in Table 14, the competence profile showed, once again, that the GCHS students need more social encouragement which could help build a more confident adolescent. The set of structured articulation activities were geared to build that level of competency in this area by introducing many tools that could help the student problem solve at high levels.

\section{$\underline{\text { Athletic Sense of Competency Part B }}$}

The BEHS and GCHS students' results produced trending data toward similar understandings of their sense of competency in the area of athletics which is reported in Table 14. The emphasis on whether you should be athletically talented or whether that talent is beneficial to you did seem to draw some attention in determining competency. Both groups gave that area a high score. The set of structured articulation activities did specifically address involvement in extracurricular activities as a way to stay involved with what was going on in a school. This in turn would help students keep their grades strong through athletic eligibility requirements. 


\section{Physical Appearance Sense of Competency Part B}

The BEHS and GCHS students' results produced similarities in how they perceived the value of Physical Appearance Sense of Competency as reported in Table 14. Both groups of students found physical appearance a positive aspect in interpreting a sense of competency. The set of structured articulation activities did not address physical appearance directly in the information given to the students GCHS. The importance of being on time and dressing appropriately for school was mentioned numerous times.

\section{$\underline{\text { Job Sense of Competency Part B }}$}

The BEHS and GCHS students produced similar results Job Sense of Competency in Table 14. Although not statistically significant, the results do have similarities between the groups of students. Both groups' results indicate a high mean score which indicates performing well on a paying job was extremely important to their self-identity. The set of structured articulation activities did address the importance of personal work effort in connection to being successful in the classroom. This same attitude was also emphasized because it could lead to positive outcomes outside of the classrooms.

\section{Romantic Appeal Sense of Competency Part B}

The BEHS students trended towards a more social connection with other students, while GCHS students showed less social connection which is reported in Table 14. The Romantic Appeal Sense of Competency emphasized making a connection with people you really like and those feelings, in turn, play an important role in how competent students feel around their peers. The set of structured articulation activities did emphasize to the students that respecting the culture of relationships in the classroom made earning good grades much simpler and effective. 


\section{$\underline{\text { Behavioral Conduct Sense of Competency Part B }}$}

The BEH and GCHS students show a trend of differences in the reporting in the

results of the Behavioral Conduct Sense of Competency which is listed in Table 14. The GCHS students indicated they recognize that behavior conduct in school is essential to getting good grades. The set of structured articulation activities emphasized the importance of performing at high behavioral levels will produce excellent grades. This aspect was always a topic of the formula for graduating on time and is an important skill outside of the classroom.

\section{Close Friendship Sense of Competency Part B}

The BCHS and GCHS student results present close similarities in the Friendship Sense of Competency as reported in Table 14. These similarities are represented by the importance each group gave to being able to have a close friend that they can trust. The set of structured articulation activities did emphasize the importance of treating everyone in the classroom with respect to the rules that manage the classroom.

\section{Summary of the Harter Self-Perception Adolescent Profile Results}

The two areas that stand out statistically significant in Tables 13 and 14 are the Social and Behavioral findings of both Part A and Part B. This is significant because the self-perception and sense of competency were similar in their results. It also sets up a perception of how both groups of students approach their social and behavioral experiences in the school environment. The information from the Harter Self-Perception Adolescent Profile gave a strong background of how these students perceive their selfidentity in the school environment and, with the exception of Social and Behavioral domains mentioned above, the two groups of students were statistically similar on all of 
the other domains on both parts of the Harter survey. The next surveys administered will more specifically address students' experiences while transitioning to grade nine.

Table 14

Harter Adolescent Self-Perception Profile - Part B

\begin{tabular}{|c|c|c|c|c|}
\hline \multirow[b]{2}{*}{ Subscale } & $\begin{array}{l}\text { BEHS } \\
(\mathrm{n}=30)\end{array}$ & $\begin{array}{l}\text { GCHS } \\
(\mathrm{n}=39)\end{array}$ & & \multirow[b]{2}{*}{ Cohen's c } \\
\hline & $\begin{array}{c}\text { Mean } \\
\text { (sd) }\end{array}$ & $\begin{array}{c}\text { Mean } \\
\text { (sd) }\end{array}$ & P-Value & \\
\hline Scholastic & 3.64 & 3.76 & 0.35 & - \\
\hline sd & 0.51 & 0.49 & & \\
\hline Social & 2.86 & 2.59 & 0.14 & - \\
\hline sd & 0.73 & 0.76 & & \\
\hline Athletic & 3.02 & 2.94 & 0.67 & - \\
\hline sd & 0.78 & 0.86 & & \\
\hline Physical & 2.99 & 2.97 & 0.93 & - \\
\hline sd & 0.77 & 0.70 & & \\
\hline Jobs & 3.57 & 3.64 & 0.60 & - \\
\hline sd & 0.56 & 0.63 & & \\
\hline Romantic & 3.28 & 3.18 & 0.57 & - \\
\hline sd & 0.70 & 0.75 & & \\
\hline Behavioral & 3.35 & 3.75 & 0.03 & 0.57 \\
\hline sd & 0.85 & 0.55 & & \\
\hline Friendships & 3.66 & 3.84 & 0.26 & - \\
\hline sd & 0.78 & 0.41 & & \\
\hline
\end{tabular}

Note: Boxed cells will be address further in Chapter Five. 
The third instrument used in this study was the survey developed by Susan Anderson in her dissertation of 2008 titled The Anderson Student Survey, which is identified as Appendix C (Anderson, 2008). A total of 69 students participated in the Anderson Student Survey; 30 students were from Bullitt County and 39 students attended Grant County Schools. Data were collected, analyzed, and interpreted to determine students' perspectives on practices implemented in the ninth grade. The instrument scale was 1 to 5 with the larger number indicating higher student satisfaction in the three main core constructs. The data were segregated by school, and each table includes means, standard deviations for each question. Questions 3, 4, 8, 12 and 13 were reported with pValue and Cohen d statistical results and focused on the academic aspects of transition. Overall student responses from this survey are displayed in Table 24 for Bullitt County and Grant County Students. Questions 7 and 14 make up the Procedural Satisfaction aspect of transition, and the Bullitt County and Grant County student results are displayed in Table 25. Table 26 consist of Questions 2, 9 and 15, and displays the results of the Social Satisfaction aspect of transition for Bullitt County and Grant County students. Lastly, Questions 1, 5, 6, 10 and 11 focus on Interrelated Questions aspect of transition and the results for Grant County and Bullitt County students is detailed in Table 27. 
Table 15

Cronbach Alpha Scores Anderson Student Survey

Cronbach

Alpha

Domain Question Question Question Question Question Score

Academic

Satisfaction

$\begin{array}{ll}3 & 4\end{array}$

8

12

13

.38

Procedural

Satisfaction

7

14

Social

Satisfaction

2

9

15

.35

Interrelated

Questions

1

5

6

10

11

.18

\section{$\underline{\text { Anderson Student Academic Satisfaction Survey Part } 1}$}

Student responses to the survey questions that focused on academic satisfaction in grade nine indicated both groups of students rated academic satisfaction similarly as reported in Table 16. Their overall academic scores were similar in their totals. The questions centered on how students perceived their experience in their schedule, workload, grading policy, teacher interactions with them to motivate students to do well, and the support systems available to them. BEHS and GCHS students found the academic experience similar in small effects. The set of structured articulation activities introduced to the GCHS students were heavily geared towards developing academic satisfaction during the transition process. In comparison, the treatment and non-treatment group revealed no statistically significant findings. The data for GCHS did show the articulation activities had some effect on the process of establishing satisfaction in the area of academics. 
Table 16

Anderson Student Academic Satisfaction Survey

\begin{tabular}{|c|c|c|c|c|c|}
\hline \multirow{2}{*}{\multicolumn{2}{|c|}{ Subscale }} & $\begin{array}{l}\text { BEHS } \\
(n=30)\end{array}$ & $\begin{array}{l}\text { GCHS } \\
(n=39)\end{array}$ & \multirow[b]{2}{*}{ p-Value } & \multirow[b]{2}{*}{ Cohen's c } \\
\hline & & $\begin{array}{l}\text { Mean } \\
(\mathrm{sd})\end{array}$ & $\begin{array}{c}\text { Mean } \\
(\mathrm{sd})\end{array}$ & & \\
\hline \multirow[t]{2}{*}{3} & $\begin{array}{l}\text { Was the school schedule } \\
\text { confusing in ninth grade? }\end{array}$ & 3.77 & 3.53 & 0.40 & - \\
\hline & & 1.01 & 1.23 & & \\
\hline
\end{tabular}

4 Did you feel the academic workload in high school was different from middle school?

$2.43 \quad 2.22 \quad 0.46$

sd $\quad 1.22 \quad 1.10$

8 Was the grading policy explained at the beginning of each semester?

$\begin{array}{lll}4.27 & 3.86 & 0.11\end{array}$

sd $\quad 0.69 \quad 1.22$

12 Did you feel that your ninth grade teachers motivated you to succeed?

$\begin{array}{lll}3.93 & 4.03 \quad 0.66\end{array}$

sd $\quad 0.94 \quad 0.81$

13 Were you satisfied with the academic support you received in ninth grade?

$\begin{array}{lll}4.10 & 3.83 & 0.21\end{array}$

$\begin{array}{lll}\text { sd } & 0.76 \quad 0.91\end{array}$

Academic overall

$\begin{array}{lll}3.70 & 3.49 & 0.39\end{array}$

$\begin{array}{lll}\text { sd } & 0.92 \quad 1.05\end{array}$ 


\section{$\underline{\text { Anderson Student Procedural Satisfaction Survey Part } 1}$}

Student responses to the survey items showed similar responses for both groups from BEHS and GCHS. The students from both groups agreed that school procedures were clearly explained as reported in Table 17. Akos (2004) found that an important concern for ninth graders transitioning into high school is the unknown expectations of the procedures they will encounter. The set of structured articulation activities addressed this concern and the trend in the total scores indicated GCHS students (the treatment group) were very positive about their first experiences in grade nine.

Table 17

Anderson Student Procedure Satisfaction Survey

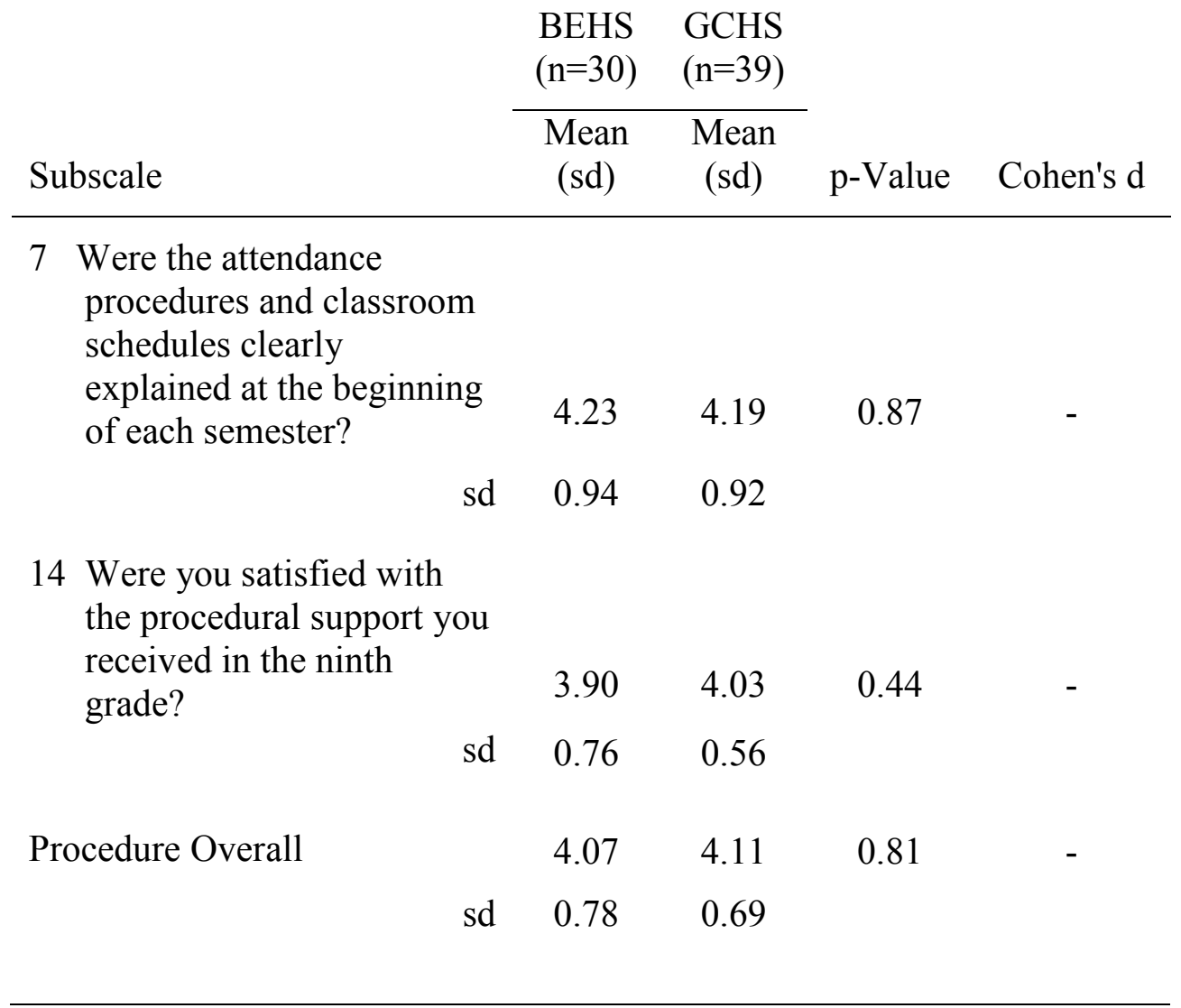




\section{$\underline{\text { Anderson Student Social Satisfaction Survey Part } 1}$}

BEHS and GCHS student responses to the Social Satisfaction survey trended similarly as reported in Table 18. Both groups showed they were looking forward to making new friends and felt there was social support in their new grade nine surroundings. Ascher (2006) found that grade nine students look forward to the chance to meet and make new friends in the high school. The set of structured articulation activities introduced to the treatment group (GCHS) emphasized orientations that occurred with their peers. The intent was to help the students understand the support systems that are available to them.

Table 18

Anderson Student Social Satisfaction Survey

\begin{tabular}{|c|c|c|c|c|}
\hline \multirow[b]{2}{*}{ Subscale } & $\begin{array}{l}\text { BEHS } \\
(\mathrm{n}=30)\end{array}$ & $\begin{array}{l}\text { GCHS } \\
(n=39)\end{array}$ & \multirow[b]{2}{*}{ p-Value } & \multirow[b]{2}{*}{ Cohen's d } \\
\hline & $\begin{array}{c}\text { Mean } \\
(\mathrm{sd})\end{array}$ & $\begin{array}{c}\text { Mean } \\
(\mathrm{sd})\end{array}$ & & \\
\hline $\begin{array}{l}2 \text { Were you looking forward to } \\
\text { making new friends? }\end{array}$ & 4.17 & 4.03 & 0.53 & - \\
\hline sd & 0.79 & 0.97 & & \\
\hline $\begin{array}{l}9 \text { Was classroom discipline } \\
\text { fair, consistent, and } \\
\text { conducive to learning? }\end{array}$ & 3.67 & 3.75 & 0.75 & - \\
\hline sd & 1.32 & 0.87 & & \\
\hline $\begin{array}{l}15 \text { Were you satisfied with the } \\
\text { social support you received } \\
\text { in the ninth grade? }\end{array}$ & 4.20 & 4.28 & 0.72 & - \\
\hline \multirow[b]{2}{*}{ Social Overall } & 0.76 & 0.97 & & \\
\hline & 4.01 & 4.02 & 0.97 & - \\
\hline sd & 0.94 & 0.87 & & \\
\hline
\end{tabular}




\section{$\underline{\text { Anderson Student Interrelated Satisfaction Survey Part } 1}$}

BEHS and GCHS Student responses to items in the survey that were interrelated (academic, procedural, and social) were similar as reported in Table 19. Both sets of students showed they were well supported by the social environment of the school and this helped them to recognize the importance of staying in school. The students from both groups indicated they did not feel they were lost at the high school. The treatment and non-treatment groups emphasized that dropping out was not an option and that the support from their parents/guardians, faculty and staff was very important to them. The comparison between the two groups showed more similarities in this area than differences. The overall findings showed a large effect on the comparison of each group.

Table 19

Anderson Student Interrelated Satisfaction Survey

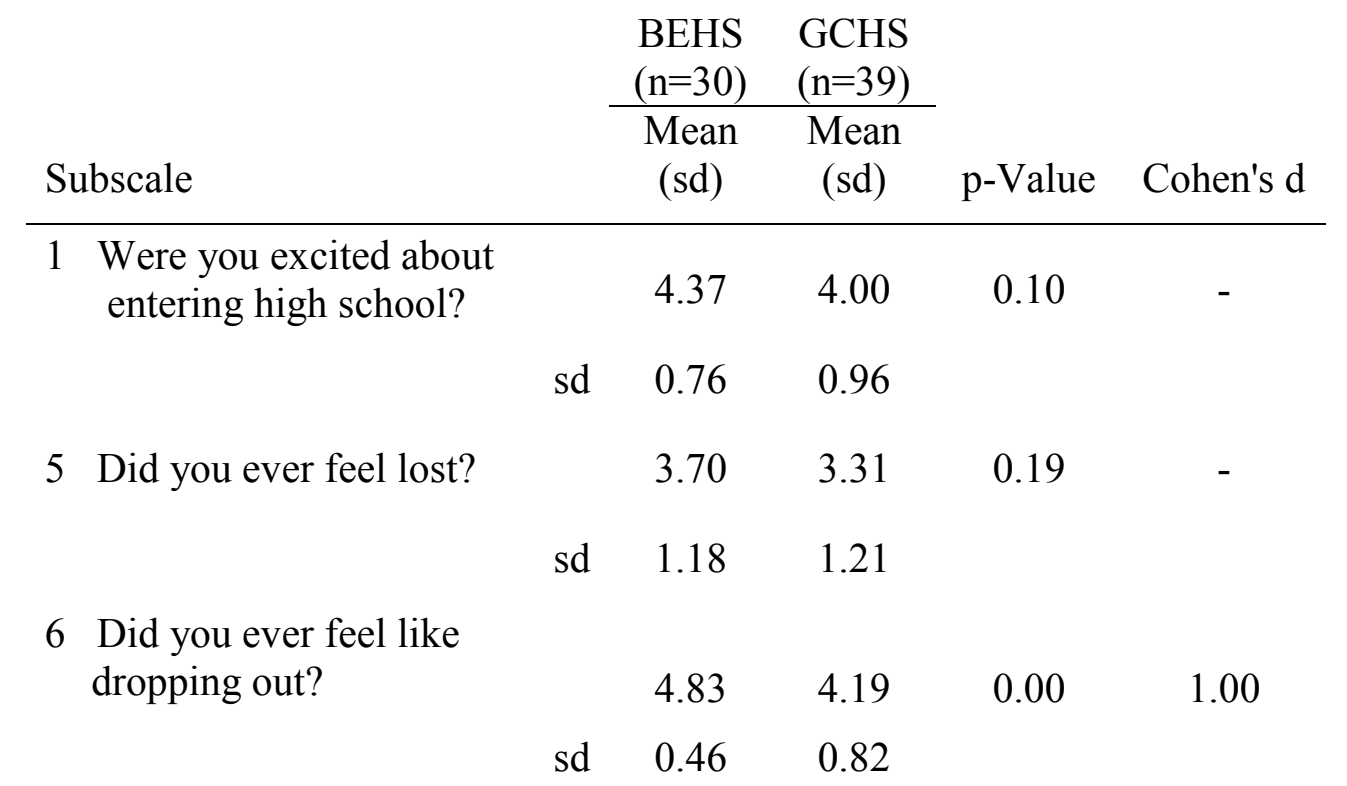

10 Did you feel that you received support from school faculty and staff?

$\begin{array}{rrrr} & 3.97 & 4.03 & 0.76 \\ \text { sd } & 0.93 & 0.70 & \end{array}$


11 Did you feel that you received support from your parents/guardians?

$\begin{array}{llllc} & 4.33 & 4.39 & 0.75 & - \\ \text { sd } & 0.66 & 0.73 & & \\ & 4.24 & 3.98 & 0.00 & 0.42 \\ \text { sd } & 0.26 & 0.24 & & \end{array}$

\section{Anderson Focus Group Question Part 2}

Anderson Focus Interview Questions, identified as Appendix D, starts with two questions in the focus group format where students could choose one or more of the response options offered. These two questions asked students to judge elements of both sides of the transition, what they missed about middle school and what they were looking forward to in high school. Responses selected were categorized into the same three categories as the open-ended responses (see Table 20). Based in large part on the emphasis included in the set of structured articulation activities, the selected responses were categorized as: 1c, 1d, = academic (connections to teachers or co-curricular activities are integrally meshed with academic performance); $1 \mathrm{a}=$ social; $1 \mathrm{~b}=$ procedural. For Question 2, the categorizations were decided in a similar manner: 2b, 2d, $2 \mathrm{e}=$ academic $; 2 \mathrm{a}=$ social; $2 \mathrm{c}=$ procedural. Among all the responses from the group of students, the percent that fell into each of the three categories are reported in Table 20.

The next five questions in the Anderson Focus Group Questions are open response categories. They include the question, the satisfaction category, the responses in percentages, and the representative quotes of the BEHS and GCHS students. The comparison of the treatment group responses (GCHS) and the non-treatment group (BEHS) is focused on the representative quotes and the representation of the 
percentages. The emphasis was directed toward the three core areas of academics, social, procedural and the interrelated items which included all three areas.

Anderson Student Focus Group Questions Part 2 (Transition Experiences Judged After One Semester of High School)

Table 20

Transition Experiences Judged After One Semester of High School

No

Question School Academic Social Procedural Response

1 What were some of the things you missed about middle school, (if any)?

\begin{tabular}{l|l} 
Bullitt & $39.1 \%$ \\
Grant & $69.4 \%$ \\
& \\
\hline
\end{tabular}

$8.8 \% \quad 30.4 \% \quad 21.7 \%$

$27.8 \% \quad 33.3 \% \quad 8.6 \%$

2 What were you looking forward to in high school?

\begin{tabular}{l|r}
\cline { 2 - 2 } Bullitt & $17.5 \%$ \\
Grant & $47.2 \%$ \\
\end{tabular}

$13.0 \%$

$30.4 \%$

$21.7 \%$

$0 \% \quad 52.8 \%$

$0 \%$

Bullitt $n=30$, Grant $n=39$

Note: Percentages add up to more than $100 \%$ because students could choose more than one response. Boxed cells will be covered further in Chapter Five.

The distribution across these categories overall showed GCHS students were focused more on the academic aspects of the transition when compared to BEHS students. In particular, GCHS students expressed that they missed the middle school academics but, simultaneously, were looking forward to high school level of academic challenges. The higher percentage of GCHS students who expressed they were looking forward to procedural aspects of high school suggests that they may have felt more 
comfortable with new high school procedures because of the structured set of articulation activities.

\section{Anderson Focus Group Questions Part 2}

The GCHS students, who received a set of structured articulation activities, centered their open responses towards the academic and procedural areas on Question 3 as reported in Table 21. Comments focused on the major differences in the demands of the academic requirements of the high school. Comments such as 'Difficult projects and homework', 'Final exams need more time to prepare for because they are longer' and 'Count for more and more pressure to get good grades'. GCHS student's 51.7\% response in Table 21 was reflective of the importance that set of structured articulation activities placed on the academic development of the students. In contrast, the BEHS students rated the procedural area as the most important difference to them during their transition to the high school. They commented that the schedule, class length, class size and longer classes influenced their perceptions of the transition process.

Question 4 asked: What was the easiest transition to the high school? GCHS student's responses measured the highest with $50 \%$ found procedural the easiest aspect of the transition to high school. Students comments in this area centered on 'Knowing what is expected of me in a class helped me keep my grades up' and 'It is important to know how teachers grade'. The set of structured articulation activities focused on the importance of teacher familiarization as a significant aspect of getting and keeping good grades. BEHS students choose the academic area has the easiest transition to high school as reported in Table 21 . Their comments unexpectedly centered on the procedural area 
instead of the academic area with responses as 'Less strict', 'More responsibilities on knowing where I should be', and 'It is important to know the schedule of the day'.

Question 5 asked the students to identify what was the most challenging aspect of their transition to the high school which was reported in Table 21. In the survey, 58.7\% of GCHS students centered their comments on the academic areas such as 'Teachers expect more out of you', 'Teaching myself sometimes', 'Strict rules about grades' and 'Responsible for doing work on your own'. The set of structured articulation activities emphasized the importance of self-responsibility when dealing with the academic demands of the transition process to high school. The BEHS students similarly rated Academics with a 53\% response and commented: 'Difficult work', 'The work was harder in math and science', and 'Getting to know what teachers wanted from me'.

Question 6 asked the students what transition activity was the most helpful to the transition process. Table 21 reported $69 \%$ GCHS students based their responses on the procedural area. They commented 'School tours', 'Teacher swap day', and 'High school tours' were helpful in their transition process. The set of structured articulation activities promoted and implemented numerous meetings and orientation was geared towards preparing students for the transition process to the high school. BEHS students scored academic and procedural with an equal response of $43.5 \%$. They commented on the social areas that emphasized Freshman orientation such as 'Staying with friends' and 'Freshman Academy meeting was helpful'.

Question 7 asked the students the direct question: How important is graduating from high school? Both groups of students centered their responses on the Academic and Procedural areas as reported in Table 21. GCHS students rated procedural with a 56\% 
responses that 'It is super important because I am going to college', 'It is very important because my Mom and Dad did not graduate from high school' and 'Want to get ready for the real world'. The set of structured articulation activities clearly encouraged students to finish high school in all their activities. For the same direct question: How important is graduating from high school; BEHS students' responses centered on Academics with comments such as 'I want to succeed', 'Very important part of growing up', and 'It allows me to move on to other goals.' 
Table 21

Anderson Focus Group Interview Questions

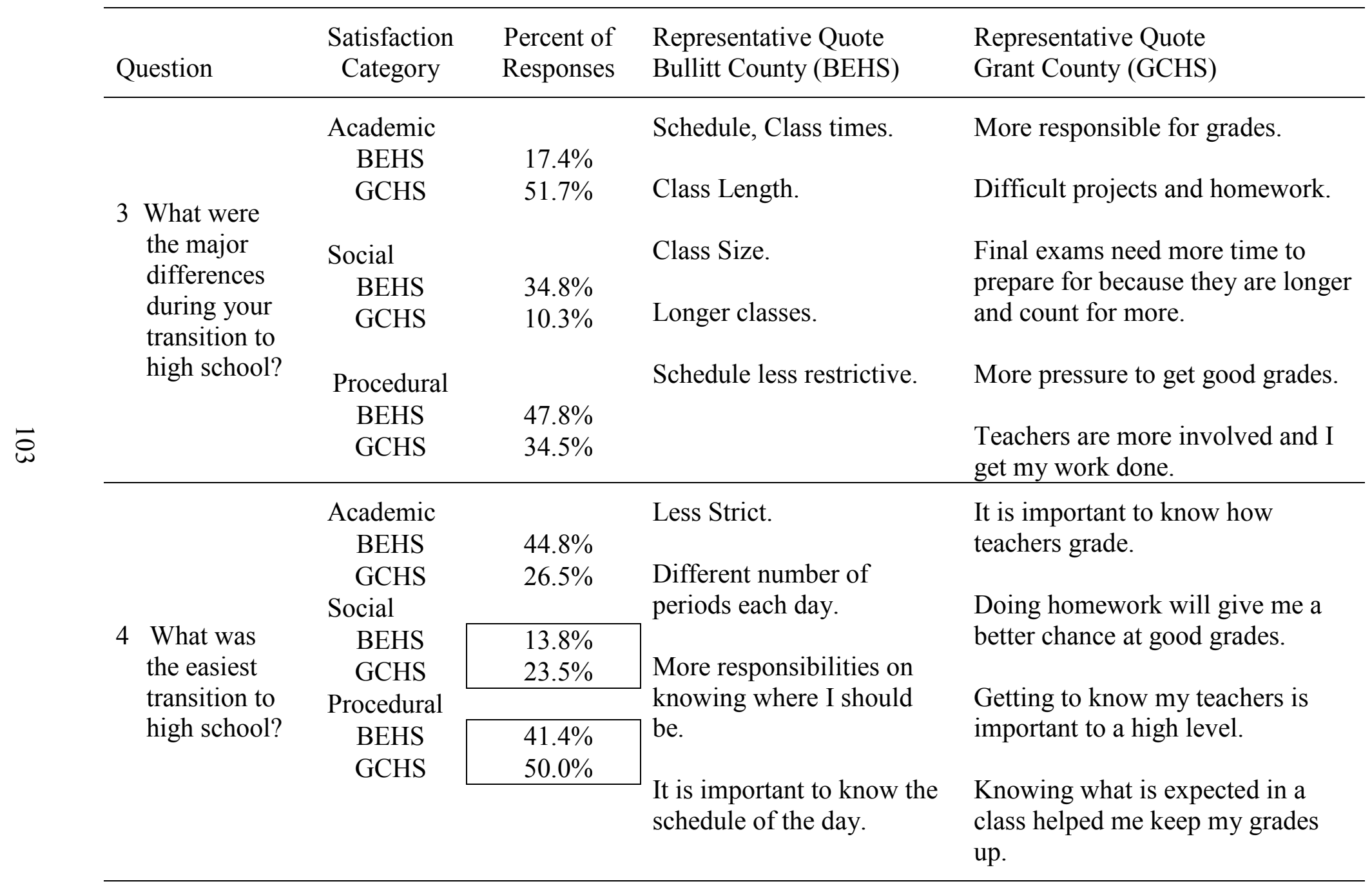




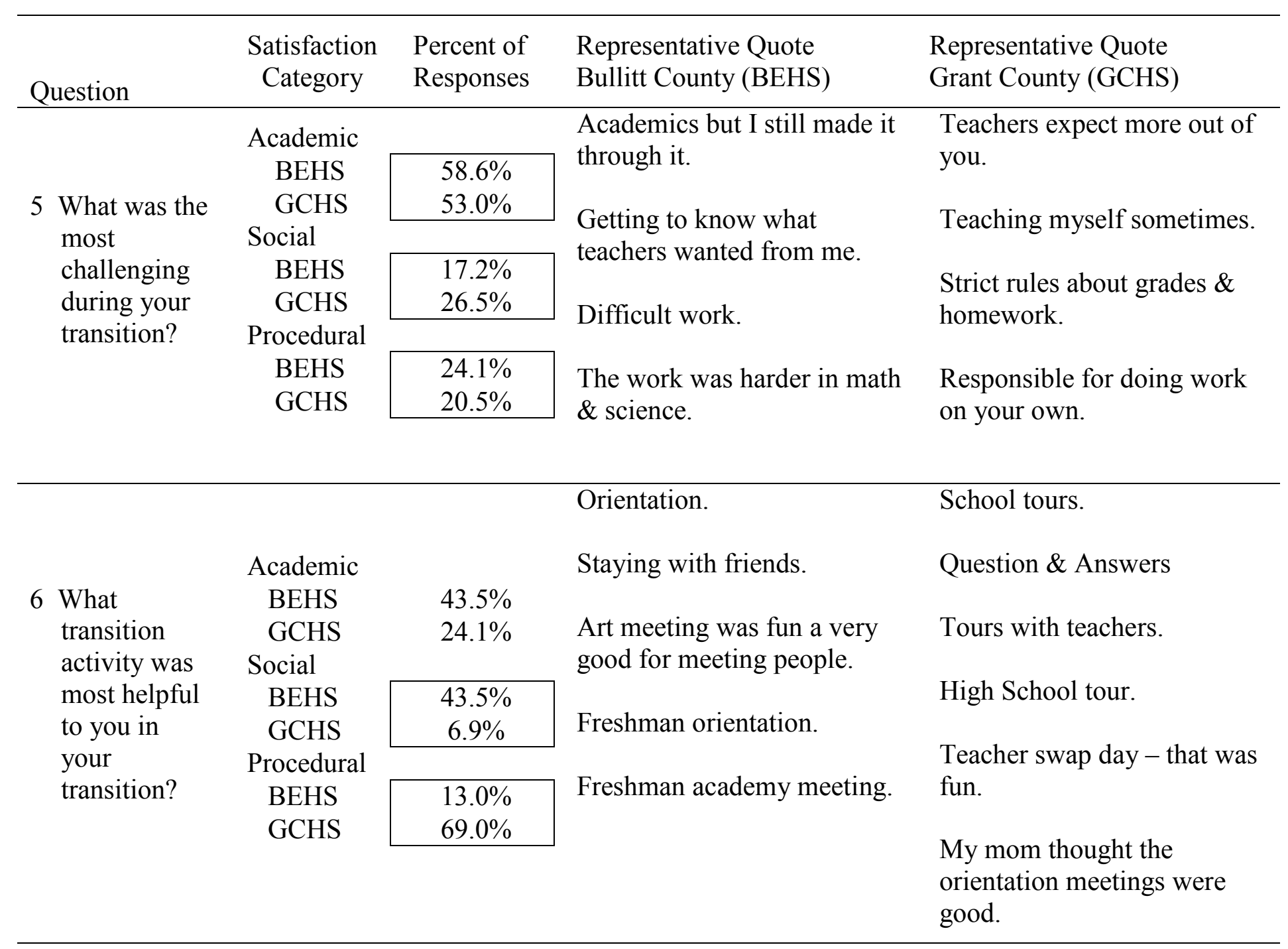




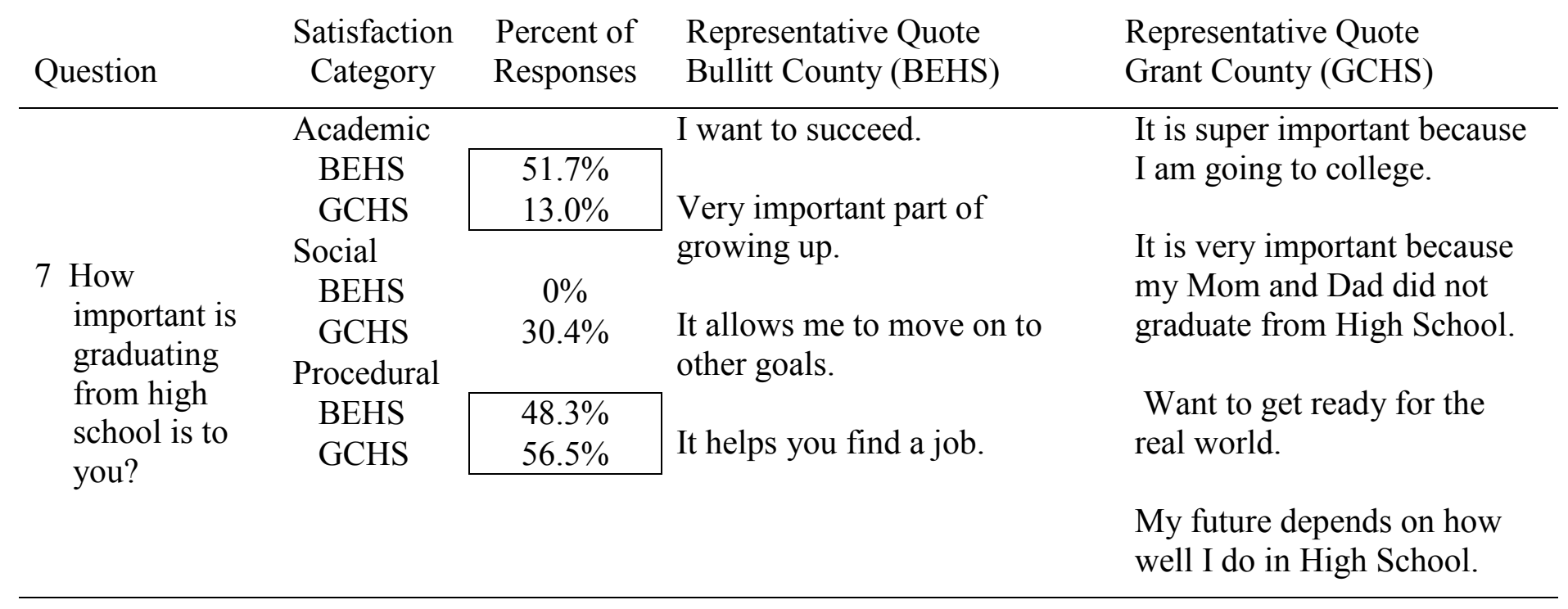

Bullitt $n=30$, Grant n=39 
Table 22

Anderson Focus Group Question with Yes or No Answers (in percents)

\begin{tabular}{llll}
\hline Question & School & Yes & No \\
\hline $\begin{array}{l}\text { 8 Have you ever thought about leaving } \\
\text { school? }\end{array}$ & Bullitt & $2.9 \%$ & $97.1 \%$ \\
& Grant & $0 \%$ & $100 \%$ \\
$\begin{array}{l}\text { Overall, did you feel you had a } \\
\text { successful ninth grade school year? }\end{array}$ & Bullitt & $44.8 \%$ & $55.2 \%$ \\
& Grant & $100 \%$ & $0 \%$ \\
\hline
\end{tabular}

Bullitt $n=30$; Grant $n=39$

The Anderson Focus Group Questions with yes and no answers, reported in Table 22, show in Question 8 that students from both schools emphasize the importance of staying in school. The GCHS students who received the set of structured articulation activities were given numerous experiences that showed why staying in school was crucial to achieve the goal of having a more successful career. The non-treatment group, BEHS students, experienced similar activities which also had an influence on how they responded to this question.

For Question 9, 44.8\% of BEHS students responded "Yes", they had a successful ninth grade year whereas 55.2\% responded "No" when asked if they had a successful year. These results indicate a split of the sample group into two distinct categories. The students who responded with a negative response centered their concerns on the stress of adjusting to the high school demands and this resulted in not taking their academics seriously. The students who responded "Yes" also recognized the stress of getting good grades in their comments and felt their efforts to be successful were fulfilled. The GCHS 
students responded with very positive comments about their grade nine year. Student's positive remarks indicated they had good support from their teachers and keeping up with homework usually results in good grades. Results for GCHS students indicate no one entertained the thought of dropping out of school. The emphasis of the set of structured articulation activities was to build self-confident student who had the skills and grades to support the vision of graduating from high school. In contrast, the BEHS students showed they were confused even though they overwhelmingly indicated they would not consider dropping out of school. These results showed significant differences between the treatment and non-treatment group. The GCHS students pointed out very clearly in a response that they "Were not quitters" and that motivated them to stay the course to successfully finish high school.

\section{Results Summary}

This study investigated the effectiveness of a specific program that was directed to increase the success ratio of students transitioning from grade eight to grade nine.

The statistical analysis of the data for the research question, which was associated with student attitudes, revealed that the implementation of a set of structured articulation activities had a positive change in student impressions of their self image and their experiences with the transition process from grade eight to grade nine. A significant change in attitudes was found when compared to a group of students not receiving the structured articulation activities.

Our results from the data were sufficient to recommend continued organized effort to influence student attitudes with the set of structured articulation activities. Results support implementation at the crucial influence point of grade eight to grade nine 
transition. The twelve articulation activities used by the Grant County School system to influence the specific needs of the students in the school system did positively impact the results for GCHS students. Although this study provided some answers about using this set of articulation activities to improve student performance and orientation at grade nine, more research is required to understand how these activities work and what populations are impacted most. For example, researchers should increase the number of variables for student demographics, and measure their specific attitudes towards the demands of the transition from middle school to high Also, to provide a more robust solution for schools, more years of study is required to provide longitudinal data. Nevertheless, our results provided ample evidence that consistent use of structured articulation activities can have a positive impact on student orientation and performance. 


\section{CHAPTER FIVE}

\section{CONCLUSIONS, IMPLICATIONS AND RECOMMENDATIONS}

\section{Introduction}

The rationale for undertaking this research study was to determine if the introduction of a set of structured articulation activities could impact the transition of students from grade eight to grade nine. Analysis of the data presented in Chapter Four showed that students' attitudes could be influenced in specific core constructs of academic, social, and procedural areas of the transition process. This chapter provides a synopsis of the implications a set of articulation activities can have on the attitudes of students striving to be successful in grade nine.

\section{Research, Findings and Conclusions}

\section{Research Question}

Two studies directly connected to this study, prepared by Allen (2011) and Christian (2012) recognized the same interpretation of the literature and, with this study, agreed on the same construct format used for development of the articulation activities. Activities would center on: (1) curriculum; (2) discipline and safety; (3) facilities; (4) general student needs; and (5) teachers, counselors, and administrators. The focus of this study was to determine whether implementing a set of structured articulation activities, based on these categorical areas, would have an impact on students as they transition from grade eight to grade nine. The research question framed for this study: What impact 
does a set of structured articulation activities have on student attitudes? Chapter Four presented the findings based on this research question.

The dependent variable identified in this study was student attitudes. The independent variables were the structured articulation activities implemented at grade eight and continue through the first semester of the grade nine school term. The treatment group (Grant County) demonstrated significant improvement on several attitude constructs when compared with the comparison non treatment group Bullitt County. The Harter profile measured the importance of the "self" in the adolescent's own image and how they viewed other students. The introduction of a set of structured articulation activities in a systematic and highly reliable format revealed practical results.

As indicated in Table 3, students were presented with a time-implemented set of articulation activities that were intended to influence student attitudes in a positive deliberate format. A committee that constituted the GCTI, which was referenced in Chapter Three, developed and implemented a set of structured articulation activities. The results of this implementation was measured by two other researchers, Allen (2011) who found the a set of structured articulation activities can affect the grades and behavior of the students in the transition process and, by Christian (2012), who concluded that the GCTI had developed into a learning organization that could produce a systematic process to develop and implement a set of structured articulation activities. While working in parallel with these two studies, this study measured how these articulation activities would affect student attitudes in the post environment of the first semester at grade nine. 
The organization of this chapter is outlined around the study's research question and includes a description of the results of each data source analysis presented in Chapter Four.

\section{Impact of Set of Structured Articulation Activities}

Findings are summarized in four categories: Harter Self-Perception

Similarities/Differences, Harter Sense of Competency Similarities/Differences, Anderson Likert Questions Similarities/Differences, and Anderson Focus Group

Similarities/Differences. These findings will be followed by a summary statement addressing the research question and implications for practice which includes this study.

\section{$\underline{\text { Harter Self Perception Similarities/Differences }}$}

Table 13 presents to this research a portrait of how students perceived their selfidentity in specific categories. Two strands, social and behavioral conduct, showed statistical significant findings that present profiles of the two student groups being compared. The Allen (2011) study showed academic improvement as well as a decline in behavioral incidents among GCHS students. Allen reported statistical significance in the areas of grade point averages, final mathematic grades for a given year, student behavior and results on standardized tests. The other profiles provided trending data that show a representation of how the students perceived the events around them with the set of structured articulation activities being implemented into their daily routines.

The social strand findings, listed in Table 13, show that BEHS students demonstrated a better understanding of the importance of the social aspect of the environment. Their social environment is considered rural but they come from close-knit communities with larger populations than those in Grant County. GCHS students have 
less densely populated centers of community support and activities. Although they come together to one middle school they are housed in small groups of 50 to 60 students. In comparison BEHS students come from two middle schools comprised of teams with 120 students in each team. These numbers suggest that BEHS students are more aware of the social interaction issues at a higher knowledge level than their peers at GCHS. This difference was recognized by the GCTI, which scheduled two additional trips to the high school for orientation to compensate for the noted deficiency. GCHS students were also encouraged to visit the high school, on their own during the summer, when the Freshman Academy principal was there, to assist them with the tour and introductions to the Freshman Academy faculty. GCTI felt it was important for students to have more knowledge of the high school environment while GCHS students adjust to the social demands of the high school.

The behavioral conduct strand, as reported in Table 13, showed that GCHS students were significantly more aware of the importance of cooperating with their teachers and administrators. Allen (2011) in her study showed discipline actions for GCHS students were significantly less that the BEHS student. The set of articulation activities held in numerous venues emphasized the importance of adjusting to the classroom demands of acceptable behavior. The meeting with students who were struggling with behavior in the middle school had special orientation meetings in the summer to help the students establish new problem solving skills that would help them cope with the demands of the grade nine classroom environment.

The similarities portrayed in Table 13 showed that students from BEHS and GCHS trended towards recognizing that scholastic or academic awareness was essential 
to their self-identity. The set of structured articulation activities centered heavily on making students aware of the importance of staying on track to produce good grades and getting all their grade nine credits. The results of Jobs Self-Perception in Table 13 supported this trend as students from both groups recognized the importance of having strong work ethic skills and how their success in the classroom was associated with this form of skill success. The set of structured articulation activities presented robust efforts to this area during orientation, which presented a connection between having good grades and the ability to find part-time work in the surrounding communities.

Another similarity identified in Table 13 was Friendships and Self-Worth profiles. The data indicated both groups of students understood it was important to develop good relationships with their peers because it had a direct correlation to their self-identity and

their success in the classroom. The set of articulation activities supported both strands by providing examples, in the orientations and teacher swap activities, how strong support from their community and peers can help to develop good habits and also enhance relationships and good grades.

\section{$\underline{\text { Harter Adolescent Self-Perception Profile Similarities/Differences }}$}

The findings found in Table 14 show that BEHS and GCHS students did have the same statistical trends in Social and Behavioral Conduct as reported in Table 13. This trend confirmed the importance of GCHS needing more development in the social interactions area. This need was addressed in the set articulation activities which sponsored activities like the dances which brought teachers from both the high school Freshman Academy and the middle school teachers together to work with the students in a positive social environment. This activity helped build support lines of communication 
between the incoming grade eight students with new high school teachers. Students found this to be one of the most valuable ways of getting to know their teachers as reported by Christian (2012) who interviewed teachers who attended these dances. This activity set the tone for GCHS to feel at ease about approaching their new teachers in grade nine. Remember that the sense of competency measured in these strands showed what students perceived were abilities they had improved over the past 12 months.

The Behavioral Conduct findings found in Table 14 support the differences that the BEHS and GCHS portrayed in the previous findings noted in Table 13. Although not classified as significant, the trending data showed that students from GCHS felt more confident navigating their way through problem solving and produce less behavioral incidents as reported by Allen (2011). Christian (2012) reported teachers and administrators developed strategies to help students cope with the stress of getting good grades and to keep behavioral incidents to a minimum. The set of structured articulation activities were geared to help students develop a sense of competence and making them realize that good grades can reduce the stress of coping with the demands of teachers and their peers in the classroom. For example one topic in the teacher swap was showing students how to "survive" in their grade nine classroom environments. The grade nine teachers presented plans for staying current on homework and test requirements, and how not to get behind which would be important to get good grades over the academic term.

The students showed similarities in the competency strands of Physical Appearance, Job, Romantic Appeal, and Close Friendship as reported in Table 14. These common trends support that building a strong competency levels can produce the abilities needed to cope with the stress of the grade eight to grade nine transition. The Close 
Friendship and Romantic Appeal showed how the students of both groups found that they were comfortable with their appearance and their ability to make friends they could trust. This trend is very important to recognize for this research. Creating support systems that could help students assist students resolve classroom demands proved to be beneficial in improving and sustaining their grades as revealed by the Allen (2011). That study showed grades did improve when the articulation activities were implemented and trend can help other strands improve in other aspects. Good grades and progress towards graduating from high school produces a positive self-identity for students who are then confident in creating positive relationships with other people in the school.

\section{$\underline{\text { Anderson Student Academic Satisfaction Similarities/Differences }}$}

The academic satisfaction strand showed similarities between BEHS and GCHS students are depicted in Table 16. This showed that the emphasis of the set of articulation activities was centered on achieving academic satisfaction during their transition process. The trending of the results gave a picture of students at GCHS completing their first semester with satisfaction with their schedule and grading policy. They also show that GCHS students found that their teachers were supportive and that academic support was always available to them. The set of structured articulation activities presented to the students gave them the abilities to use their support systems effectively. Familiarization with their teachers prior to the starting of their grade nine year proved to be very beneficial in producing a sense of satisfaction in this strand.

The differences in the strand only surfaced at low levels which are listed in Table 16. Both groups responded in similar trends towards satisfaction. It could suggest the results for the GCHS students may have been more dissatisfied without the articulation 
activities. Prior to the introduction of the set of structured articulation activities, GCHS students only received one high school tour and one scheduling meeting at the middle school. They were left to adapt to the transition process on their own. Pretest data from Allen (2011) shows that the students were dropping out at high rates and this was directly tied to poor academic performance in the grade nine year. However, the results of this study of attitudes demonstrated that the treatment group measured statistically similar to the comparison group of students in an academically high-performing district, which suggests that not only did the structured articulation activities positively impact with a lower drop out rate, but that student attitudes may have also been changed which would be a precursor to that improved behavior as documented in the Allen (2011) research.

\section{$\underline{\text { Anderson Student Procedural Satisfaction Similarities/Differences }}$}

The procedural impact on students from BEHS and GCHS were similar in the total scores reported in Table 17. Both groups trended towards small difference in their feelings of satisfaction to understand the attendance procedures. This was supported in the Allen (2011) research which presented data to support the set of articulation activities had no statistically significant effect on attendance for the students. The set of structured articulation activities did emphasize the practice of good attendance but evidence surfaced that their attendance improved because of the articulation activities. The key is that the students understood what was expected of them in reference to the requirements of good attendance. Knowing these facts resonate with being satisfied as indicated in Question 14 located in Table 17. Predictability in the support systems that were available to the students proved to be beneficial to reduce the stress level of transitioning to high school. 


\section{$\underline{\text { Anderson Student Social Satisfaction Similarities/Differences }}$}

The social satisfaction strand showed similarities for the BEHS and GCHS students as presented in Table 18. Both groups rated the social overall score high in satisfaction. The questions were directed at making new friends and social support received in the ninth grade. The set of structured articulation activities did address the importance of meeting new people at the high school and how important it was to stay positive in those relationships. For example, much emphasis was placed on working with others to maintain good grades. This result would support the findings that showed making new friends were important to the GCHS students. Creating and maintaining the support systems in grade nine was crucial and emphasized by the Freshman Academy principal in all orientation meetings with the grade eight students, and then again when they arrived as grade nine students. This emphasis was a hallmark of the set of structured articulation activities. The trending data did not show any significant differences between the two groups. This might be the result of how the questions were formatted in the Anderson survey. The questions in the Anderson study specifically ask the students to respond in a negative or positive manner for their responses. Therefore, the results are geared towards describing the students' experience with a certain social activity. The set of articulation activities were formulated to provide specific positive experience.

\section{$\underline{\text { Anderson Student Interrelated Satisfaction Similarities/Differences }}$}

The interrelated satisfaction strands for the BEHS and GCHS students showed similarities in Table 19. The students of both groups gave high ratings to being satisfied overall with their experiences in grade nine at the high school. The question centered on being excited about entering the high school, whether you felt lost, did you consider 
dropping out once you started and did the support systems available prove to be helpful. The set of structured articulation activities did address all these concerns and supports the high rating that the GCHS students gave each question. They were encouraged to be excited about the new settings at the high school and the opportunities this would provide to them. The emphasis of seeking out support for help in solving problems was presented to students with examples of problems grade nine students might have and how to solve them. This proved very valuable according to Christian (2012) who presented collaborated agendas from grade eight and grade nine teachers working together on curriculum and articulation activity planning. This is a direct reflection of the satisfaction students reported from their transition experiences.

\section{Anderson Focus Group Questions Similarities/Differences}

In Table 20, Question 1, percentages indicated that the GCHS students who experienced the set of structured articulation activities found that they missed the academic experiences they had in the middle school. The articulation activities were geared towards how the grade nine academic life would look after one semester. Students were asked to make the comparisons between what they had known and what was happening now to them. The set of structured articulation activities helped students prepare for the demands of the new structure of high school academics. Although GCHS students indicated they missed the predictable ways of the middle school, they were still prepared for the demands of grade nine academic programs. This was affirmed by Anderson (2008) that students must be prepared for the rigor of the academic requirements of grade nine. 
In Table 20, Question 2, percentages indicated that the GCHS students found both their expectations for high school academics their main concern in comparison with the BEHS students. This is consistent with the students performing well on their academic requirements as reported by Allen (2011). The focus on staying up to date and all homework was a major topic of the grade nine teaches during the teacher swap day activities. Akos (2004) emphasized that people who are in charge of transition activities need to pay close attention to researched problems of grade nine students since they provide instructions on how to solve those problems for both adults and students.

In Table 21, Question 3 percentages indicate that the GCHS students found academics provided the major difference in their transition to high school. This suggests the demands of high school academics proved to be the main concern of the GCHS students. The BEHS students found the procedural changes had more influence on them because of the added responsibilities. The GCHS students found their grade eight teachers collaborating with the grade nine provided academic consistency for them in the classroom. Mac Iver (1990) found that collaboration between teachers from both middle and high school proved very helpful to building the confidence skills in students as they transitioned to the high school. Christian (2012) found teachers more prepared for the students in grade nine because they were more familiar with their grade eight academic and social needs.

In Table 21, Question 4, the percentages indicated that the GCHS students found both social and procedural types of transition easier than the comparison group BEHS. This suggest that GCHS students may have been able to focus more intently on academic transition, thereby enabling them to earn higher grades in grade nine than the BEHS 
students. This trend is supported by the research of Allen (2011) which detailed stronger academic outcomes. Oakes (2009) concluded that transitions are a process not an event, and a systemic process introduced in grade eight and continued through grade nine, will give the students a highly reliable support system.

In Table 21, Question 5, the percentages indicated that the GCHS students found the academic type the most challenging during their transition. In comparison, the BEHS students found academics also challenging but not at as high of percentage. The consistent approach of establishing academic goals for the GCHS students proved to be very helpful keeping the GCHS focused on the academic challenges of grade nine. Alspaugh (1998) found when students are provided with extra help with academics, and other types of support, less achievement is lost which results in lower dropout rates.

In Table 21, Question 6, the percentages indicated that the GCHS students found procedural types of transition more helpful in their transition process than the comparison group BEHS students. This suggests that the increased number of structured articulation activities had an impact on the attitudes of the GCHS grade nine students. The introduction of 12 articulation activities over a 12 month span proved to be influential in the students' transition process. In contrast, the BEHS received only four articulation activities. Herzog and Morgan (1999) found that high schools that offer five or more articulation activities for their grade nine students see a reduction in failures and dropouts.

In Table 21, Question 7, the percentages indicated that the GCHS students found procedural types of transition more important towards graduating than the BEHS students (which chose academic). This contrast may be explained by student comments made 
about staying track to graduate. BEHS students identified the importance of succeeding, which suggest that academics are the direct line to that success. While the GCHS students perceived that having plans to attend college, getting ready for the real world, and accomplishing a task my parents were not able to complete were all driving forces to want to graduate. Kennelly \& Monrad (2007) found that students needed to develop goals and celebrate those accomplishments of those goals so that their journeys are impactful and effective.

In Table 22, Question 8, the percentages indicated that the GCHS students found that $100 \%$ of the students would not consider leaving school. In comparison, BEHS student responses indicate $97.1 \%$ in favor of never leaving school. This obviously is good information for both schools. The structured articulation activities were centered on making students understand that there were not options open to them except for finishing school. Perhaps a hard stance, but the decision was made by GCTI that this goal had to be established for each student if the interventions were to be effective. Harter (1988) emphasizes that the growth of an adolescent's self-identity is directly related their view of competency in areas of their life. The importance of creating successful experiences for students at early stages of transitional periods in their life is of the utmost importance.

In Table 22, Question 9, the percentages indicated that the GCHS students found that their ninth grade year (in this case one semester) successful. The BEHS students in comparison only rated their first semester as $44.8 \%$ successful. This contrast supports the main objective of the set of structured articulation activities which was to give GCHS students a positive and successful experience in their transition from grade eight to grade nine. The development of a highly reliable set of structured articulation activities was 
implemented for the students to experience success in their first semester. Datnow and Stringfield (2000) found that high reliability organizations, such as schools, could create well-focused and organized coordination between schools. Grant County Middle and High School created that organization by implementing GCTI.

\section{Findings Summary}

The use of multi sources of data provided ample evidence that answered the study's research question. Undoubtedly, the formation and work of the GCTI and the ensuing implementation of structured articulation activities enabled GCHS and GCMS to come together and impact the transition process for the GCHS students. As a result of this effort, the students developed effective personal skills to transition to the high school with confidence and competence in academic, social, and procedural skills. Through these skills students, in the Grant County School System, have created a grade nine class that is on an $85 \%$ graduation rate path to success. This level of achievement is an exceptional level of improvement since the class before them was on a $65 \%$ graduation rate path

The impact of the set of structured articulation activities during the transition of grade eight to grade nine:

1. Teachers and administrators collaborated to develop a program that would assist students to transition from grade eight to grade nine with positive results and created 12 articulation activities.

2. Students developed academic skills that helped them maintain effective grades during the transition period. 
3. Students developed social skills that enhanced their self-identity in the new culture of grade nine.

4. Students developed an effective level of confidence in building a support system that will help them adjust to the procedural demands of the transition process to grade nine.

Akos (2004) observed the student's perception of the transition process is sometimes ignored by those who should be paying very close attention to their progress to receive a diploma. Students, parents, and teachers need a platform to advocate for a transition process that can eliminate the high rate of unsuccessful grade nine students.

This study examined and utilized the research of Hertzog, Morgan, Mizelle, and Irwin by introducing to the grade eight students an increased number of structured articulation activities. GCTI developed and implemented 12 articulation activities at the middle school and the high school level. Hertzog and Morgan did not specify what activities were implemented in the transition process. The results of this study did substantiate that structured articulation activities had a positive impact on student attitudes in some areas of the academic, social, and procedural transition process. The study also substantiated when examining the development of the student self-image during the transition process, a set of structured articulation activities did have a significant impact on certain areas of self-perception. Herzog and Morgan (1999) developed one of the most complete studies of active research on the middle school transition to the high school. Students transitioning from grade eight to grade nine, who experience lower achievement and have less positive attitudes, are at risk for failure of dropping out and not completing their high school education. This study found that 
students were positively influenced by the introduction of structured articulation activities with respect to their developing self-image. This research is important because improving the self-perception of students may increase their willingness to persevere in their schooling (Harter, 1996).

The data from the Grant County administration, presented by Allen (2011), examined the number of students retained in a three-year period and revealed student success with a steady reduction of the failure rate at grade nine. This study examined the student attitudes during this reduction process and the results were compared with nontreatment groups from Bullitt County, which received fewer articulation activities. Student attitudes were measured after the students completed their first semester of the ninth grade using the adolescent profile tool and a student survey specifically directed at the how the student experienced the transition process. Although students were not asked directly about the success or failure of a certain articulation activity to impact their transition, the study did attempt to measure how the transition process affected them. The structured articulation activities were developed to create a culture of success for the students and determine if they felt success or failure. This was important to better understand the process and the impact of the structured articulation activities.

Creating a support system for grade eight students transitioning to the high school was the purpose of the GCTI. The structured articulation activities in this study did have a positive effect on the adolescent's self confidence in certain categorical areas. In the curriculum, the grade eight-orientation meeting was centered on developing a grade nineclass schedule for the grade eight students. This meeting helped students and parents create a level of confidence with their choices of classes that are mostly required at the 
ninth grade level. This type of meeting was done with small groups and gave both parents and students the opportunity to use their support systems at the middle school and be introduced to high school personnel who would soon become their new support systems. Scholastic Competence was viewed as very important to the adolescents from Grant County and Bullitt County. The Grant County students did recognize that performance in the classroom is very important to succeed at the high school level. Getting a good start is essential and the structured articulation activity described previously centered on preparation for a successful experience.

Social Acceptance development showed significant findings in Chapter Four and several of the structured articulation activities had an effect on those areas. The activities did emphasize the collaboration of the individual, their parents and the school personnel but some collaboration also took place with their peer group, which was included in all their experiences. As explained previously, the adolescent is developing his or her strengths of identity with their peers. For example, when the students were presented with grade eight tour of the high school environment, they toured with their friends and classmates. Their introduction to the safety and discipline areas of the articulation activities was also experienced with their friends and classmates. Finally, the experience of having grade nine teachers come to their classes and talk to them about what to expect at grade nine in the high school in specific subject areas was done in a classroom setting. Getting to know their new instructors and experiencing the presentation of class requirements with their peers was an attempt to help the students begin to build confidence and relationships of support and trust. Observing how their peers reacted to these experiences helps the adolescent develop their own self-identity they are trying to 
formulate. The emphasis of all the activities was to create a trusting and predictable environment that would encourage success. The GCTI articulation activities presented in this study showed specific significance with the Grant County students in the area of Social Acceptance.

\section{Implications for Practice}

Creating the trademark characteristics of High Reliability Organizations can give these structured articulation activities the basis for a trusting environment that adolescents need to experience. Transition programs need to include the following aspects of organization:

1. Provide extensive training for all stakeholders in advance of implementing the structured articulation activities. Include in this training an overview of the adolescent population that will be served by the implementation of this transition process. The importance of recognizing each group's academic and social needs is essential to the success of the intervention. The reinforcement of the clear goals for stakeholders will enhance the effectiveness of their interactions with students.

2. Develop a consistent and reliable data bank of student opinions while they progress through the transition activities. Measure their responses as the events happen so that corrections can be made to the next event if there are signs students are not receiving experiences they need to negotiate the transition.

3. Organize activities that produce awareness to the goals of success, academic and social skills, and the importance of developing problem solving techniques to cope with the transition process. 
4. Encourage and require teachers to develop classroom activities that reinforce the skills and information that is provided for the students during their orientation meetings.

5. The development of an Anderson-type survey formulated into an assessment tool which can be used by different schools for their respective purposes.

\section{Recommendations}

No one particular set of the structured activities had the most impact during the transition process. Students did find that many of the structured articulation activities did help them work with their peers, teachers, and communicate with parents on issues that occurred in the ninth grade. The perception of how the transition process effected their adolescent development was clear after they were asked to respond to the Harter survey. This aspect of the study shows the importance of allowing students to discover their selfidentity. The understandings of how their needs were addressed academically, socially, and procedurally reinforce the importance of developing strong transition programs that assist students during a stressful time change and development.

Local school administrations know that failure at the early stage of the high school experience can be devastating to student and graduation rates. In the era of accountability, it important to embrace a transition program which can produce success. Deciding what articulation activities should be used to create this pattern of success must be a local decision. Yet putting together a high reliability organization that can produce successful results must be done in a very structured, well researched, and thought out manner. Implementation must be reinforced at all levels and constant input by all stakeholders must be encouraged at all times. 
The study of these structured articulation activities introduced in Grant County middle and high school had one very attractive aspect that should be considered when reviewing the results. This program was developed at no additional cost to the district. Meetings and orientation activities did not require additional expenditures from the schools or district budget. There was no need for additional staff to implement the program because the activities are inserted into already established transition activities. Creating a cost efficient program that can produce positive results cannot be overlooked. Introducing practices that have a research base and implemented by a practitioner can impact the successful outcomes and be a valuable tool for the educator of today.

Intervention at the grade nine levels is essential to prevent a student's loss of motivation which can result in failing many classes early in their high school career and eventually leads to dropping out of school (Anderson, 2008). Educators responsible for the transition process must identify the needs of these students and then organize an intervention which will focus on academic, procedural, and social needs of the grade eight students as they transition to the grade nine demands of the high school. These actions are essential to the future success of this group of students.

A highly reliable, organized effort with input by all stake holders can produce the successful transition that students, parents, and the school community attempt to build and secure for their school population. Future intervention efforts with structured articulation activities should include the following activities.

1. Although the articulation activities were drawn from high reliability organization and effective school research, this project required a flexible and dedicated team to be effective. We followed the ideas presented in the learning organization 
research as noted in our conceptual framework. Building a team along this model, with common goals, was critical to our success.

2. Survey participants before and after intervention efforts to establish pre and post data.

3. Arrange a larger survey sample of students and schools.

4. Identify which specific structured articulation activity had the most impact and which activity had no impact.

Moreover, answering the following questions may provide valuable information that schools could use to understand and refine their interventions for maximum impact.

1. How many structured articulation activities are needed to be effective?

2. Which structured activities are the best fit for your schools?

Akos' research, referenced in Chapter Two of this dissertation, indicated Philadelphia's Sunrise Middle school recognized the importance of a comprehensive program which emphasized full cooperation at all levels of the students' transition into high school. Organizations who enlist help from the community and family will establish a strong support system to the students as well as support the teachers all of which will help students develop confidence in their academic abilities and behavioral coping skills.

\section{Implications for Future Research}

The findings in this study propose a set of new ideas on how to influence students during their formative adolescent years during the transition from grade eight to grade nine. Continued study is recommended that would measure the success rate of students who received the structured articulation activities and their ability to stay on a pathway to graduation would help examine the long term effects of structured articulation 
activities. Evaluating what activities proved to be the most effective for longitudinal results would also be very beneficial.

The planning of articulation implementation requires an examination of what activity has the most effect on student attitudes towards the transition process. Future investigation is necessary on what activities prove to be most effective helping students express their feeling about the manifestations of stress that the transition process can create. The problems of low self-esteem, poor motivation, and inadequate peer acceptance, often can lead to disruptive and maladaptive behavior. Additional research is necessary to examine how students are coping with the changes of the transition process. This can help adults responsible for the transition select effective articulation activities.

The future of students in transition lies with those who lead them through the process. Research should continue to help these leaders understand the school context, organization and related factors that have varying degrees of effect on the transition from grade eight to grade nine. Evaluation on the type of training it takes to develop the skills needed for transition is necessary and could produce teachers that understand the developmental process of the adolescent with more effectiveness.

\section{CONCLUSION}

The transition to high school is a challenging experience for young adolescents who face this experience with undeveloped self- identity. The school communities in this country place students in the dilemma of facing and coping with the challenges of transition with limited coordinated effort and support. The terms "they need to grow up" and "we are not going to baby them" unfortunately persist from the high school faculties. This approach unfortunately has created a "Freshman Bulge" at most high schools in the 
United States. This dilemma has created freshman classes that are adjusting poorly to the demands of academic, procedural, and social experiences found in the transition process.

The importance of implementing structured articulation activities that can impact the well-being of grade nine students as they transition into the high school was researched in this study. From those results a set of structured articulation activities were constructed and developed to impact the academic and behavioral performance of grade nine students. The conceptual framework introduced in this study is based on the understanding that structured articulation activities can have an effect on student attitudes towards the transition process. Employing a set of structured articulation activities using the characteristics found in high reliability organizations and effective schools can impact students and how they perceive and experience the transition process in an organizational learning structure.

This transition requires the connection among organizational support, student involvement, and the experiences of success. It also must include the involvement of all stakeholders, parents, teachers, counselors, and administrators in the process of each stage of the transition program. One aspect of this study was to increase the involvement the grade eight and grade nine teachers and administrators from the high school and middle school in planning and implementing the program. The continuous collaboration of school personnel from the high school and the middle school supports the research of Datnow, Park, and Wohlestetter (2007). The effectiveness of the structured articulation activities depended on the training and input from the schools as the students proceeded through each aspect of the transition. The systematic processes used by the GCTI were geared towards creating a culture of success for the students. This culture impacted the 
students' attitudes while functioning as grade nine students. Their overall academic and behavioral patterns increased into a strong culture of successful performance.

After recognizing that grade eight students were not transitioning to high school with success rates that warrant or produce graduation rates of $90 \%$ or more, Grant County school administrators decided to build a robust program based on many factors. Prior to the implementation of new strategies to address the debilitating effects of course failures, surveys of grade nine students were compiled, collected and reviewed by teachers and administration personnel. The data from these surveys showed that students struggled with the confusion of expectations of their grade nine teachers, experienced difficulty with the procedural requirements of their new settings at the high school and the academic demands which, in some cases, seemed much different to them when compared to their grade eight year. These results produced numbers the high school could not accept: $65 \%$ graduation rate, $25 \%$ of the grade nine classes failed one subject which put them behind the projection of a four year to graduation schedule, and a fluctuating dropout rate that could move anywhere between 3 to $5 \%$ consistently each year. These factors, and others, required an aggressive new strategy to improve the success rate of grade nine students. Administrators recognized intervention at grade eight was essential to the program development.

The Grant County Transition Initiative (GCTI) was developed by a research team, then reviewed and approved by a committee composed of the faculty and administration of the middle and high schools. From this organized effort, 12 structured articulation activities were developed and implementation of these activities started in the beginning of the second semester of the 2008-2009 for the grade eight student academic school 
term. The development of this program had only one boundary: funding. The staff of both schools understood that this effort would be funded with only existing funds available to the schools. The effort by both schools was successful and required no new funds; the school's plans included strategies, attention to detail, and organizational structures that became a normal part of their school day.

To be effective, organizations that implement transition programs must include the following requirements:

1. Teacher support and student engagement,

2. The ability for teachers and administration to use data driven decision making in implementing clear goals, and

3. School personnel need to create a culture of success by establishing activities that students can experience.

In her studies, Harter (1981) recognized an important aspect about student attitudes. The degree of approval or disapproval we attach to the adolescent's attempts to be successful feeds directly into their sense of competence. This means that the feeling of perceived competence results from success or a history of success in an achievement context. When students leave the middle school and begin their journey into the high school, the critical aspect of experiencing success is essential. Schools that create transition programs that can affect the feeling of competence for their students will see achievement levels become consistent and effective.

In summary, this study investigated the perceptions of grade nine students at the end of the first semester in the high school. Looking through their eyes we can see that the twelve structured articulation activities introduced to students in their second 
semester of grade eight through to the first semester of their grade nine year had an impact on their academic, social and procedural transition experiences. These articulation activities were developed through the conceptual framework designed (Figure 3) for this intervention which was also replicated in the Allen (2011) and Christian (2012) studies. The results show, from all three studies, that structured articulation activities can influence the academic performance, behavioral conduct, and the development of a learning organization which can implement these structured articulation activities into an effective, organized effort to improve the transition process for the young adolescents facing this challenging event. This study specifically identified areas of strong improvement in the following areas of the transition process:

1. The learning organization created by the GCTI did not require any additional funds needed for the implementation of this intervention.

2. GCHS students, who received the structured articulation activities, rated their satisfaction of their transition to high school with a $100 \%$ rating. In contrast, the BEHS students (the non-treatment group) rated their high school transition satisfaction with a rating of only $45 \%$. Improving the transition process was the goal of this study.

3. GCHS was able to match the academic results of BEHS which historically performs at high levels on state testing during this documented study as indicated in the Allen (2011) study. The transition survey results indicate Grant County students deemed academics as highly important which sets the stage for a successful academic year. This factor showed a habitual pattern of change in the GCHS structure and created a community of learners. 
Underlying this successful middle to high school transition program is a key concept of bringing middle and high school administrators, counselors, and teachers together to learn about how academic, social, and procedural aspects of the transition can be changed to help the grade nine student become successful. This result is well documented by the increase of graduation rates from $65 \%$ to an increased rate of $85 \%$. 


\section{REFERENCES}

Abell Foundation (2007). A "jump start" on college: how early college access programs can help high school students in Baltimore City. Baltimore: Abell Foundation.

Ainscow, M., \& Muncey, J. (1989). Meeting Individual Needs. London: David Fulton.

Akos, P., \& Galassi, J. (2004). Gender and race as variable in psychological adjustment to middle and high school. The Journal of Educational Research, 98 (2).

Allen, D. (2011). Lost In Translation: A Grade Nine Transition Program using Articulation Activities. Dissertation. University of Louisville, Louisville, Kentucky

Allen, J. P. \& Land, D. (1999). “Attachment in Adolescence.” Handbook of Attachment: Theory, research and clinical applications. 311-335.

Allensworth, E. M., \& Easton, J. Q. (2005, June). The on-track indicator as a predictor of high school graduation. Consortium on Chicago School Research at the University of Chicago.

Alspaugh, J. W. (1998, September/October). Achievement loss associated with the transition to middle school and high school. The Journal of Educational Research, 92(1), 20-26.

Anderson, S. (2008). Ninth Grade Transition: Best Practices For A Successful Transition to High School. Dissertation. Capella University. Minneapolis, Minnesota. 
Appleton, J. A., Christenson, S. L., \& Furlong, M. J. (2008, April). Student engagement with school: Critical conceptual and methodological issues of the construct. Psychology in the Schools, 45(5), 369-386.Armor, D., Conroy-Osgura, P., Cox, M., McDonnell, L., Pouly, E., Zellman, G. (1976). Analysis of the school preferred reading programs in selected Los Angeles minority schools (Rep. No. R-207-LAUSD). Santa Monica, CA: RAND.

Ascher, C. \& Maguire, C. (2007). Beating the Odds: How Thirteen NYC Schools Being Low-Preforming Nineth-Graders to Timely Graduation and College Enrollment.

Barnes, N. (2000). Teachers training teachers. Education Week, 19, 38-42.

Barone, C., Aquirre-Deandries, A. I., \& Trickett, E. J. (1991). Means-ends problemsolving skills, life stress, and social support as mediators of adjustment in the normative transition to high school. American Journal of Community Psychology, 19(2), 207-225.

Berndt, T. J. (1982). The features and effects of friendship in early adolescence. Child Development, 53, 1447-1460.

Bernstein, L., Millsap, M. A., Schimmenti, J., \& Page, L. (2008). Implementation study of smaller learning communities' final report-appendices. U. S. Department of Education, Office of Planning, Evaluation and Policy Development and Program Studies Services.

Black, S. (February, 2004). The pivotal year. American School Board.

Blyth, D. A., Simmons, R.G. \& Bush, D. (1978). The transition into early adolescence: longitudinal comparison of youth in two educational contexts. Sociology of Education, 51, 149-162. 
Brace, N., Kemp, R., \& Snelgar, R. (2003). SPSS for psychologists: a guide to data analysis using SPSS for Windows. New York: Polgrace MacMillan, 239.

Bragg, D. \& Rudd, C. (2007). Career pathways, academic performance, and transition to college and careers: the impact of two select career and technical education (CTE) transition programs on student outcomes. Office of Community College Research and Leadership, University of Illinois at Urbana-Champaign.

Brookover, W. B., Beamer, L., Eftim, H., Hathaway, D., Lezotte, L., Miller, S., Passalacqua, J., \& Tornatsky, L. (1982). Creating Effective Schools. Holmes Beach, FL: Learning Publications, Inc.

Brookover, W. B., \& Lezotte, L. (1982). Creating effective schools. Holmes Beach, FL: Learning Publications, Inc.

Bryk, A. S. \& Driscoll, M. E. (1988). The school as community: Theoretical foundations, contextual influences, and consequences for students and teachers. Madison, WI: National Center on Effective Secondary Schools, University of Wisconsin.

Carroll, S. J., \& Scherer, E. (2008). The impact of educational quality on the community, a literature review. Rand Corporation: Santa Monica.

Center for Equity and Excellence in Education (2009). Strengthening the transition from middle grades to high school in the Mid-Atlantic region: $D C, D E, M D, N J, P A$. Washington, DC: Author.

Chapman, M.V., \& Sawyer, J. S. (2001). Bridging the gap for students at risk of school failure: a social work-initiated middle to high school transition program. Children \& Schools, 23(4), 235-240. 
Christian, Carol (2012). An Investigation of a Middle-High School System as a Learning Organization during the Implementation of a Grade Eight to Grade Nine Transition Program. Dissertation. University of Louisville, Louisville, Kentucky Cognato, C. A. (1999, October). The effects of transition activities on adolescent selfperception and academic achievement during the progression from eighth to ninth grade. Paper presented at the National Annual Meeting of the National Middle School Association, Orlando.

Cohen, R. (1995). Students Resolving Conflict: Peer Mediation in Schools. Good Year Books, Tucson, Arizona.

Cohen, J., Cohen, P., West, S. G., \& Aiken, L. S. (2003). Applied multiple regression/correlation analysis for the behavioral sciences (3rd ed.). Mahwah, NJ: Lawrence Erlbaum Assoc.

Coleman, J. S. (1974, November). Youth: transition to adulthood. NASSP Bulletin, 58(385), 4-11.

Connell, J. P. \& Wellborn, J.G. (1991. Competence, autonomy and relatedness: A motivational analysis of self-system processes. In M. R. Gunnar \& L. A. Sroufe (Eds.), Self processes in development: Minnesota Symposium on Child Psychology (Vol. 23, pp. 43-77). Chicago: University of Chicago Press.

Cook, T. D., \& Campbell, D.T. (1979). Quasi-experimentation: Design and analysis issues for field settings. Chicago: Rand McNally.

Cousins, B. (1998). Intellectual roots of organizational learning. In K. Leithwood \& K. S. Louis (Eds.). Organizational Learning in Schools, 219-235. Lissem NL: Swets 7 Zeitlinger. 
Creemers, B. (2002). From school effectiveness and school improvement to effective school improvement: Background, theoretical analysis, and outline of the empirical study. Educational Research and Evaluation, 8 (4), 343-362.

Creswell, J. W. (2005). Research design: Quantitative, qualitative \& mixed methods approaches. $2^{\text {nd }}$ ed. Thousand Oaks, CA: Sage.

Datnow, A., Hubbard, L., \& Mehan, H. (1998). Educational reform implementation: A co-constructed process. Technical report, University of California, Santa Cruz: Center for Research on Education, Diversity, and Excellence.

Datnow, A., Park, V. \& Wohlstetter, P. (2007). Achieving with data: How high performance driven school systems use data to improve instruction for elementary school students. Report for New Schools Venture Fund.

Datnow, A., \& Stringfield, S. (2000). Working together for reliable school reform. Journal of Education for Students Placed at Risk, 5(1\&2).

Deal, T. E., Intili, J., Rosaler, J. A., \& Stack-house, A. (1977, May). The early childhood education program: an assessment of its impact and implementation. Sacramento: California State Department of Education.

DeCarlo, L. (1997). On the Meaning and Use of Kurtosis. Psychological Methods, Vol. 2, No. 3, 292-307.

Diemert, A. (1992). A needs assessment of fifth grade students in a middle school. Acton: Author.

Doss, D., \& Holley, F. (1982). A cause for national pause: Title I school wide projects (ORE Publication No. 81.55). Austin, Texas: Office of Research and Evaluation, Austin Independent School District. 
Dutrow, A. M. (1997, April). Transitioning students to the middle school: A case study. Published doctoral dissertation. Virginia Polytechnic Institute and State University. Blacksburg:Virginia.

Eccles, J. S., \& Midgley, C. (1989). Stage-environments fit: developmentally appropriate classrooms for early adolescents. In C. Ames \& R. Ames (Eds.), Research on motivation in education: Vol. 3. Goals and Cognition, 139-186. New York: Academic.

Eccles, J., Midgley, C., \& Adler, T. F. (1984). Grade related changes in the school environment: effects on achievement motivation. In J.G. Nicholls (Ed., Advances in Motivation and Achievement, 3, 228-331. Greenwich: JAI Press.

Edmonds, R. R. (1982, December). Programs of School Improvement: An Overview. Educational Leadership, 1-11.

Fiol, C. M., \& Lyles, M. A. (1985). Organizational Learning. Academy of Management Review. 10(4), 803-813.

Firestone, W. A., \& Herriott, R. E. (December, 1982). Prescriptions for effective elementary schools don’t fit secondary schools. Educational Leadership, 51.

Fullan, M. (1993). Change forces. London: Falmer.

Fullan, M. (1995). The school as learning organization: Distant dreams. Theory into Practice, 34(4), 230-235.

Fullan, M. (2000). The return of large-scale reform. Journal of Educational Change, Vol. $1,1-23$.

George, P., \& McEwin, C. (April, 1999). High schools for a new century: Why is the high school changing? NASSP Bulletin, Vol. 83(606), p. 10-24. 
Gibson, L.T. (2006). Working to reduce ninth-grade failure rates in urban school settings: A multi-case study of ninth-grade transition programs in four urban high schools in Virginia. Unpublished Doctoral Dissertation. The College of William and Mary, Williamsburg, VA.

Giles, C., \& Hargreaves, A. (April, 2003). Daring to be different: The sustainability of schools as learning organizations and professional learning communities during standard-based reform. Paper presented at the annual meeting of the American Education Research Association, Chicago.

Gilligan, C. (1990). Remapping the moral domain: new images of the self in relationship. New York University Press.

Glass, G. V. \& Hopkins, K.D. (1996). Statistical methods in education and psychology. Needham, MA: Allyn \& Bacon.

Green, S. B., Salkind, N. \& Akey, T. (2003). Using SPSS for Windows and Macintosh: Analyzing and Understanding Data (3rd edition), New Jersey: Prentice-Hall.

Greenwood, P., Mann, D., \& McLaughlin, M. (1975). Federal programs supporting education change, Vol. III: The change process. U.S. Office of Education, Department of Health, Education, and Welfare. Rand, Santa Monica, CA.

Grossman, J.B. \& Cooney, S. M. (2009, January). Paving the way for success in high school and beyond: The importance of preparing middle school students for the transition to ninth grade. Public/Private Ventures/Groundwork. Philadelphia, PA.

Gruhn, W. T., \& Douglas, H. R. (1947). The modern junior high school. New York: The Ronald Press Company. 
Haney, W., Madaus, G., Abrams, L., Wheelock, A., Miao, J., \& Gruia, I. (January, 2004). The education pipeline in the United States 1970 - 2000. National Board on Education Testing and Public Policy. Chestnut Hill: Boston College.

Harter, S. (1980). The development of competence motivation in the mastery of cognitive and physical skills: is there a place for joy. Psychology of Motor Behavior and Sport. Page 3-29.

Harter, S. (1981). A new self-report scale of intrinsic versus extrinsic orientation in the classroom: motivational \& informational components. Developmental Psychology 17, No. 3, 300 .

Harter, S. (1986). Processes underlying the construction, maintenance and enhancement of the self-concept in children. Psychological Perspectives on the Self, 3, 137181.

Harter, S. (1996). Historical roots of contemporary issues involving self-concept.

Harter, S. (1988). Manual for the self-perception profile for adolescents. University of Denver.

Hartos, J. L., \& Power, T. G. (1997). Mother's awareness of their early adolescents' stressors: relation between awareness and adolescent adjustment. Journal of Early Adolescence, 17(4), 371-389.

Hertzog, C. J., \& Morgan, P. L. (1999, January-February). Making the transition from middle level to high school. High School Magazine, 6(4), 26-30.

Hertzog, C. J., Morgan, P. L., Diamond, P. A., \& Walker, M. J. (1996). Transition to high school: a look at student perceptions. Becoming, 7(2), 6-8.

Hinton, P.R. (2004). Statistics Explained. $2^{\text {nd }}$ ed. London. Routledge. 
Horner, R., Carr, O., Halle, J., McGee, G., Odom, S., \& Wolery, M. (2005). The use of single-subject research to identify evidence-based practice in special education. Exceptional Children, 71(2), 165-179.

Huberman, A. M. (1973). Understanding change in education: an introduction. United Nations Educational, Scientific and Cultural Organizations. Rolland: Paris. Infinite Campus University Product Knowledge I Training Manual Kentucky (2009). Blaine, MN: Infinite Campus, Inc.

Ingels, S., Scott, L. A., Taylor, J. R., Owings, J. \& Quinn, P. (1998, May). National education longitudinal study of 1988 (NELS:88) base year through second follow up: Final methodology report. National Center for Education Statistics. Washington, D.C.

Innes, R. G. (2009). Examining Kentucky's 'No child left behind' Tier 5 schools. Bluegrass Institute for Public Policy Solutions: Bowling Green.

Isakson, K., \& Jarvis, P. (1999). The adjustments of adolescents during the transition into high school; a short-term longitudinal study. Journal of Youth and Adolescence, 28(1), 1-26.

Iver, M., Abele, M., Kemper, E., \& Stringfield, S (2003). The Baltimore Curriculum Project: Final Report of the Fourteen Year Evaluation Study. Center for Research on the Education of Students Placed At Risk. Baltimore, MD.

Johnston, J. H. (1992). Climate and culture as mediators of school values and collaborative behavior. In Irvin, J. Transforming middle level education: Perspectives and possibilities (pp. 77-92). Needham Heights, MA: Allyn \&Bacon. Journal of College Admissions (Winter, 2009). On realizing its worse than I thought. 
Kennelly, L., \& Monrad, M. (July, 2007). Easing the transition to high school: Research and best practices designed to support high school learning. National High School Center. Retrieved July 10, 2008, from: http://www.betterhighschools.com/docs/NHSC_TransitionReport. pdf.

Kimmel, D.C. \& Weiner, I.B. (1985). Adolescence: A developmental transition. L. Eribaum Associates.

Kinney. D. A. (1993). From nerds to normals: the recovery of identity among adolescents from middle school to high school. Sociology of Education, 66, 21-40.

LaPorte, T., \& Consoline, P. (1991). Working in practice but not in theory: theoretical challenges of high-reliability organizations. Journal of Public Administration Research and Theory, 1(1), 19-48.

Lasky, S., Stringfield, S., Teddlie, C., Kennedy, E., Schaffer, E., Chrispeels, J., Daly, A. J., \& McDonald, D. (2005). Designing and conducting a gold standard effective schools study. Journal for Effective Schools, 27-45.

Lee, J. (2001). Accelerated schools for quality education: Initial experiences of school change. Hong Kong: International Conference on Rejuvenating Schools, Through Partnership.

Lee, V. E., \& Smith J. B. (1995). Effects of high school restructuring and size on early gains in achievement and engagement. Sociology of Education, 68, 241-27.

Lee, V. E., Bryk, A. S., \& Smith, J. B. (1993). The organization of effective secondary schools. In L. Darling-Hammond (Ed.), Review of research in education (pp. 171267). Washington, DC: American Educational Research Association. 
Levitt, B., \& March, J. (1988). Organizational learning. Annual Review of Sociology, 14, 319-340.

Lezotte, L. W. (2007). Effective schools: past, present and future. Effective Schools Products, Ltd: Okemos.

Linver, M. R., \& Silverberg, S. B. (1997). Maternal predictors of early adolescent's achievement- related outcomes: adolescent genders as moderator. Journal of Early Adolescence, 17(3), 294-318.

Louis, K.S. (1994). Beyond managed change: Rethinking how schools improve. School Effectiveness and School Improvement, 5(1), 2-24.

Louis, K. S. (2006). Changing the culture of schools: Professional community, organizational learning, and trust. Journal of School Leadership, 16(5), 477-489.

Mac Iver, D. J. (1990). Meeting the needs of young adolescents: Advisory groups, interdisciplinary teaching teams, and school transition programs. Phi Delta Kappan, 71(6), 458-464. EJ 402385.

Mac Iver, D. J., \& Epstein, J. L. (1991). Responsive practices in the middle grades: Teacher teams, advisory groups, remedial instruction and school transition programs. American Journal of Education, 99(4), 587-622.

Manning, M. L., \& Baruth, L. G. (1995). Students at risk. Needham Heights: Allyn \& Bacon.

Marais, K., Dulac, N., \& Levison, N, (March 24, 2004). Beyond normal accidents and high reliability organizations: The need for an alternative approach to safety in complex systems. MIT. 
Marzan, R.J., \& Waters, T. (2009). District Leadership That Works: Striding the Right Balance. Bloomington, IN: Solution Tree Press.

Maute, J. K. (1991). Transition concerns of eighth-grade students in six Illinois schools as they prepare for high school. Unpublished doctoral dissertation, National-Louis University, Evanston, IL.

McErwin, C. K. (1998). Concepts of continuing importance. In R. David (Ed.), Moving forward from the past: early writing and current reflections of middle school founders. 35-39. Columbus: National Middle School Association \& Pittsburg: Pennsylvania Middle School Association.

McLaughlin, M. W. (1990). The rand change agent study revisited: Macro perspectives and micro realities. Educational Researcher, 19(9), 11-16.

Midgley, C., Anderman, E., \& Hicks, L. (1995). Differences between elementary and middle school teachers and students: a goal theory approach. Journal of Early Adolescence, 15(1), 90-113.

Miles, M.B. (1998). Finding keys to school change: A 40-year odyssey. In A. Hargreaves, International Handbook of Educational Change (p. 37-69). Great Britain: Kluwer Academic Publishers.

Mizelle, N. B. (April, 1995). Transition from middle school to high school. The student perspective. Paper presented at the annual meeting of the American Educational Research Association, San Francisco.

Mizelle, N., \& Irwin, J. (May, 2000). Transition from middle school into high school. Middle School Journal, 31(5). 
Morgan, L. P., \& Hertzog, C. J. (2001). Designing comprehensive transition plans. Principal Leadership, 1(7), 10-18.

Murphy, J. (1992). School effectiveness and school restructuring: contributions to educational improvement. Paper presented at the Annual Meeting of the International Congress for School Effectiveness and Improvement.

National Association of State Boards of Education (2008). Beginning in the middle: Critical steps in early secondary school reform. Arlington, VA: Author.

National Middle School Association. (2006). National Middle School Association’s position statement on the professional preparation of middle level teachers. Retrieved February, 25, 2010.

Newman, F. M., \& Wehlage, G. G. (1995, April). Five standards of authentic instruction. Educational Leadership, 50(7), 8-12.

No Child Left Behind Act of 2001, Pub. L. No. 107-110, 115 Stat. 1425 (2002).

Nunnally, J.C. (1978). Psychometric Theory. NewYork: McGraw-Hill.

Oakes, A. (2009, May). Middle-to-high school transition, practical strategies to consider. The Center for Comprehensive School Reform and Improvement Newsletter.

Oates, J., Flores, R., \& Weishew, N. (1998). Achieving student success in inner-city schools is possible, provided... Research in Middle Level Education Quarterly, 21(3), 51-62.

Paulson, S. E. (1994). Relations of parenting style and parental involvement with ninth grade student's achievement. Journal of Early Adolescence, 14(2), 250-267. 
Paulson, S. E., Marchant, G. J., \& Rothlisberg, B. A. (1998). Early adolescents' perceptions of patterns of parenting, teaching, and school atmosphere: implications for achievement. Journal of Early Adolescence, 18(1), 5-26.

Phelan, P., Yu, H. C., \& Davidson, A. L. (1994). Navigating the psychosocial pressures of adolescence: the voices and experiences of high school youth. American Educational Research Journal, 31(2), 415-447.

Purkey, S. C., \& Smith, M. (1982). Too soon to cheer? Synthesis of Research on Effective Schools.

Purkey, S. C., \& Smith, M. (1983). Effective Schools: A Review. Elementary School Journal, 83(4).

Quinn, D. (2010, November 30). How to Convert EXPLORE Test Scores Into PLAN Test Scores. Retrieved March 5, 2011, from http://www.ehow.com/how_7579554_convert-scores-plan-test-scores.html Renchler, R. (2000). Research Roundup 16, 3 (Spring 2000) Grade Span. ERIC Clearinghouse on Educational Management. OR. (ERIC Document Reproduction Service No. ED 440471) Rourke.

Reynolds, D., \& Stoll, L. (1996). Merging school effectiveness and school improvement: The knowledge bases in Reynolds et al Making good schools: Linking school effectiveness and school improvement. London: Routledge.

Ricks, M.H. (1985). The social transmission of parental behavior. Attachment across generations. Monographs of the Society for Research in Child development. 211227. 
Rockoff, J. E. \& Lockwood, B. B. (2010, Fall). Stuck in the middle: How and why middle schools harm student achievement. Education Next, 10(4).

Ross, S. M. (2001, December). Creating critical mass for restructuring: What we can learn from Memphis. AEL Policy Brief.

Rossi, S., \& Stringfield, S. (1998). Bold plans for school restructuring. Mahwah: Erlbaum.

Rothman, S. (2001). School absence and student background factors: A multilevel analysis. International Education Journal, 2(1).

Rumberger, R., \& Palardy, G. (2005). Test scores, dropout rates, and transfer rates as alternative indicators of high school performance. American Educational Research Journal, 42(1), 3-42.

Sammons, P. (2006, January). School effectiveness and equity: making connections. Embracing Diversity: New challenges for School Improvement in a Global Learning Society International Congress for School Effectiveness and Improvement, Fort Lauderdale Florida.

Sammons, P., Hillman, J., \& Mortimore, P. (1995, April). Key characteristics of effective schools: A review of school effectiveness research. Institute of Education for the Office for Standards in Education: University of London.

Sarason, S. (1990). The predictable failure of educational reform: Can we change course before it's too late? Jossey-Bass Publishers, San Francisco, CA.

Schiller, K. S. (1999, October). Effects on feeder patterns on students' transition to high school. Sociology of Education, 72(4), 216-233. 
Schumacher, D. (1998). The transition to middle school. ERIC Digest. Clearinghouse on Elementary and Early Childhood Education. University of Illinois.

Senge, P. (1990). The Fifth Discipline: The Art and Practice of the Learning Organization. New York: Doubleday.

Shadish, W. R., Cook, T. D., \& Campbell, D. T. (2002). Experimental and quasiexperimental designs for generalized causal inference. Boston, MA: Houghton Mifflin.

Silins, H. C., Mulford, W. R., \& Zarins, S. (2002). Organizational learning and school change. Educational Administration Quarterly, 38, 613-642.

Silins, H. C., \& Mulford, W. R. (2002). Schools as learning organizations. Journal of Educational Administration, 40(5), 425-446.

Skipper, S. (January, 2006). Conceptual Framework for Effective Inclusive Schools. Paper presented at ICSEI: International Congress for School Effectiveness and Improvement, Ft. Lauderdale.

Spender, J., \& Grant, R. M. (1996). Knowledge and the firm: Overview. Strategic Management Journal, 17, 5-10.

Sproull, N. L. (2002). Handbook of research methods: a guide for practitioner's and students in the social sciences (2nd ed.). Lanham, MD: The Scarecrow Press.

Stringfied, S. \& Datnow, A. (1998). Scaling up school restructuring in multicultural, multilingual contexts: Early observations from Sunland County. Center for Research on Education, Diversity \& Excellence, University of California, Santa Cruz: CA. 
Stringfield, S., Reynolds, D., \& Schaffer, E. (2008). Improving secondary students' academic achievement through a focus on reform reliability: 4- and 9-year findings from the High Reliability Schools project. School Effectiveness and School Improvement, 19(4), 409-428

Stringfield, S., \& Teddlie, C. (1991). Observers as predictors of schools' multi-year outlier status. Elementary School Journal, 91(4), 357-375.

Stringfield, S. \& Yonezawa, S. (2000). Special strategies for educating disadvantaged student's follow-up study: Examining the sustainability of research-based school reforms. Baltimore: John Hopkins University CRESPAR.

Teddlie, C., \& Stringfield, S. (1993). School matters: Lessons learned from a 10-year study of school effects. New York: Teachers College Press.

Trisman, D. A., Waller, M. I., \& Wilder, C. (1976). A descriptive and analytic study of compensatory reading programs: Final Report. Vol. 2 (PR 75-26). Princeton, N.J.: Educational Testing Service.

University of Surrey Psychology Department (2007). How do I test the normality of a variable's distribution? Guildford, Surrey. UK: The University of Surrey, Department of Psychology. Retrieved from http://www.psy.surrey.ac.uk/cfs/p8.htm

Vail, K. (2010). Changing the grade. American School Board Journal, 4-8.

Vars, G. F. (1998). You've come a long way, baby! In R. David (Ed.), Moving forward from the past: early writings and current reflections of middle school founders.

Waggoner, Jan E. (1994, October). The relationship between instructional teaming and self-esteem of sixth graders transitioning to a traditional junior high. Paper 
presented at a meeting of the Illinois Association of Teacher Educators, Lisle, IL. ED 379278.

Waggoner, M, \& Blackorby, J. (1996, Spring). Transition from high school to work or college: how special education students fare. Special Education for Students with Disabilities, 6(1).

Weick, K. (1976). Educational organizations as loosely coupled systems. Administrative Science Quarterly, 21 (1-9).

Weiner, B. (1985). An attribution theory of achievement motivation and emotion. Psychological Review, 92, 548-573.

Welck, K. E., Sutciffe, K. M., \& Obstfeld, D. (2000). Organizing for high reliability: processes of collective mindfulness. Research in Organizational Behavior, Vol.1, p. $81-123$.

Wells, M.C. (1996). Literacies lost: when students move from a progressive middle school to a traditional high school. New York: Teachers College Press.

Williamson, R., \& Johnston, J. H. (1999). Challenging orthodoxy: an emerging agenda for middle level reform. Middle School Journal, 30(4), 10-17.

Wise, B. (May 2008). High schools at the tipping point. Educational Leadership, 65(8), 8-13. 


\section{APPENDIX A: HARTER ADOLESCENT SELF-PERCEPTION PROFILE SURVEY \\ WHAT I AM LIKE}

Name Age

Birthday Group

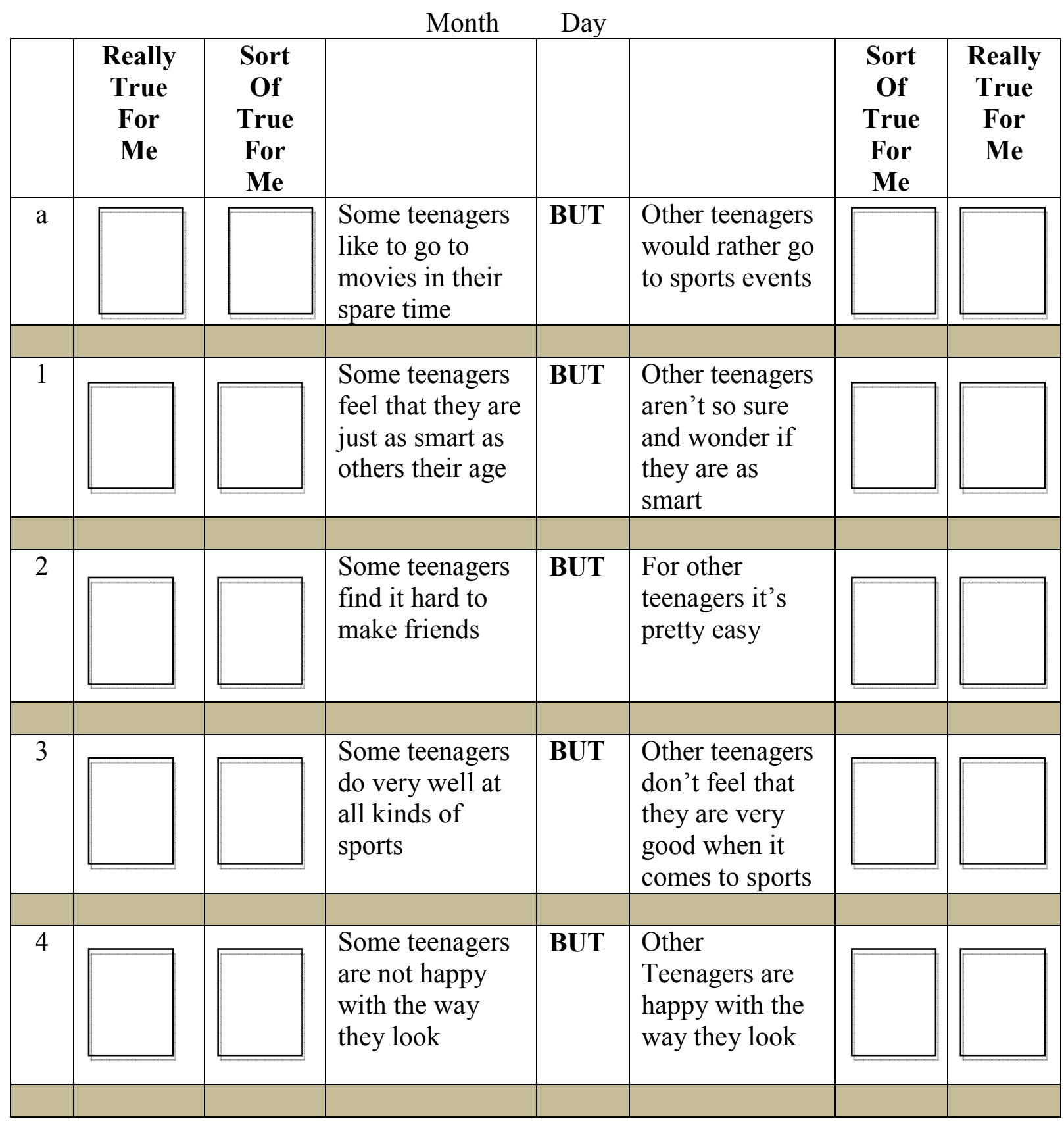




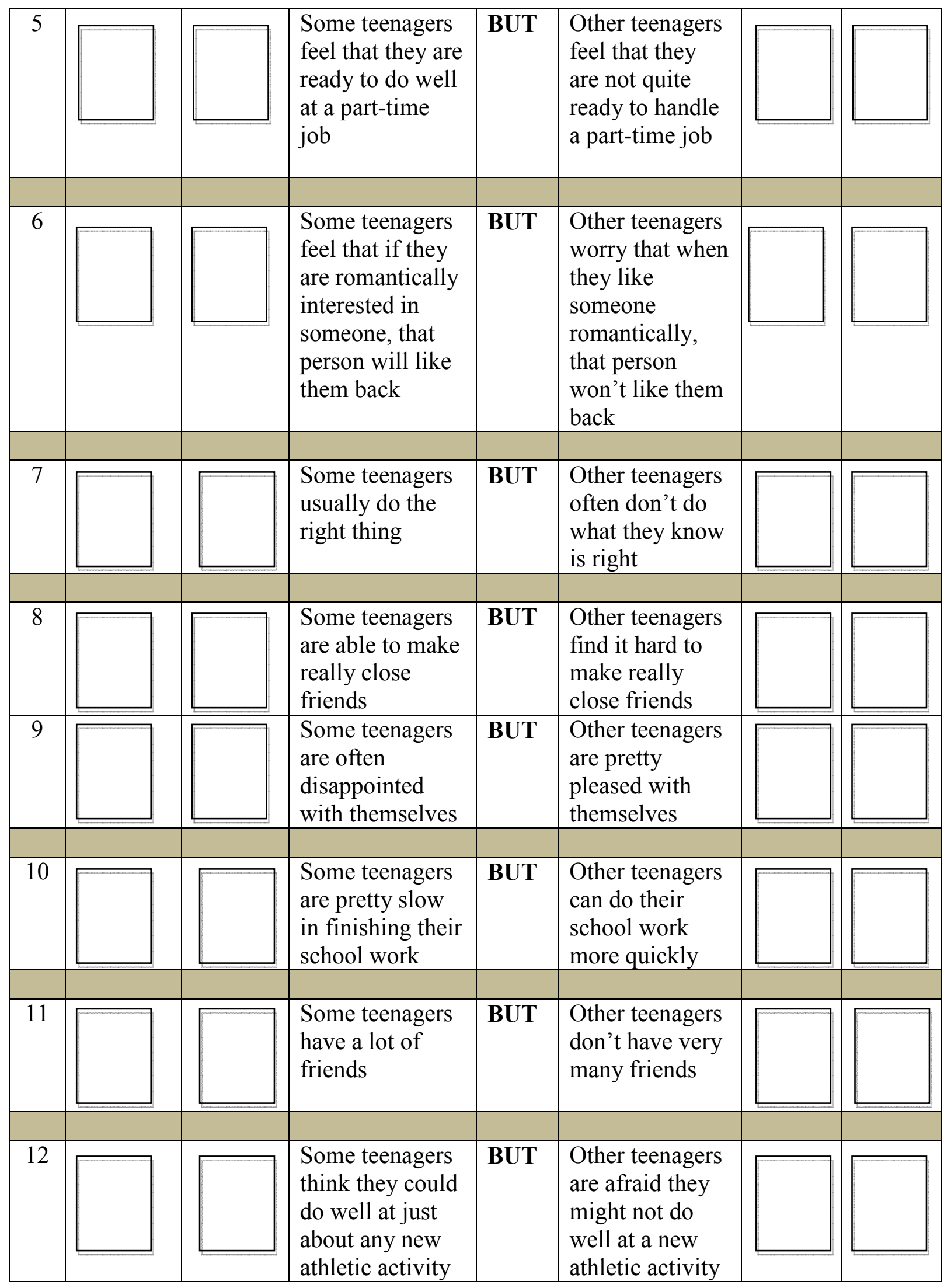




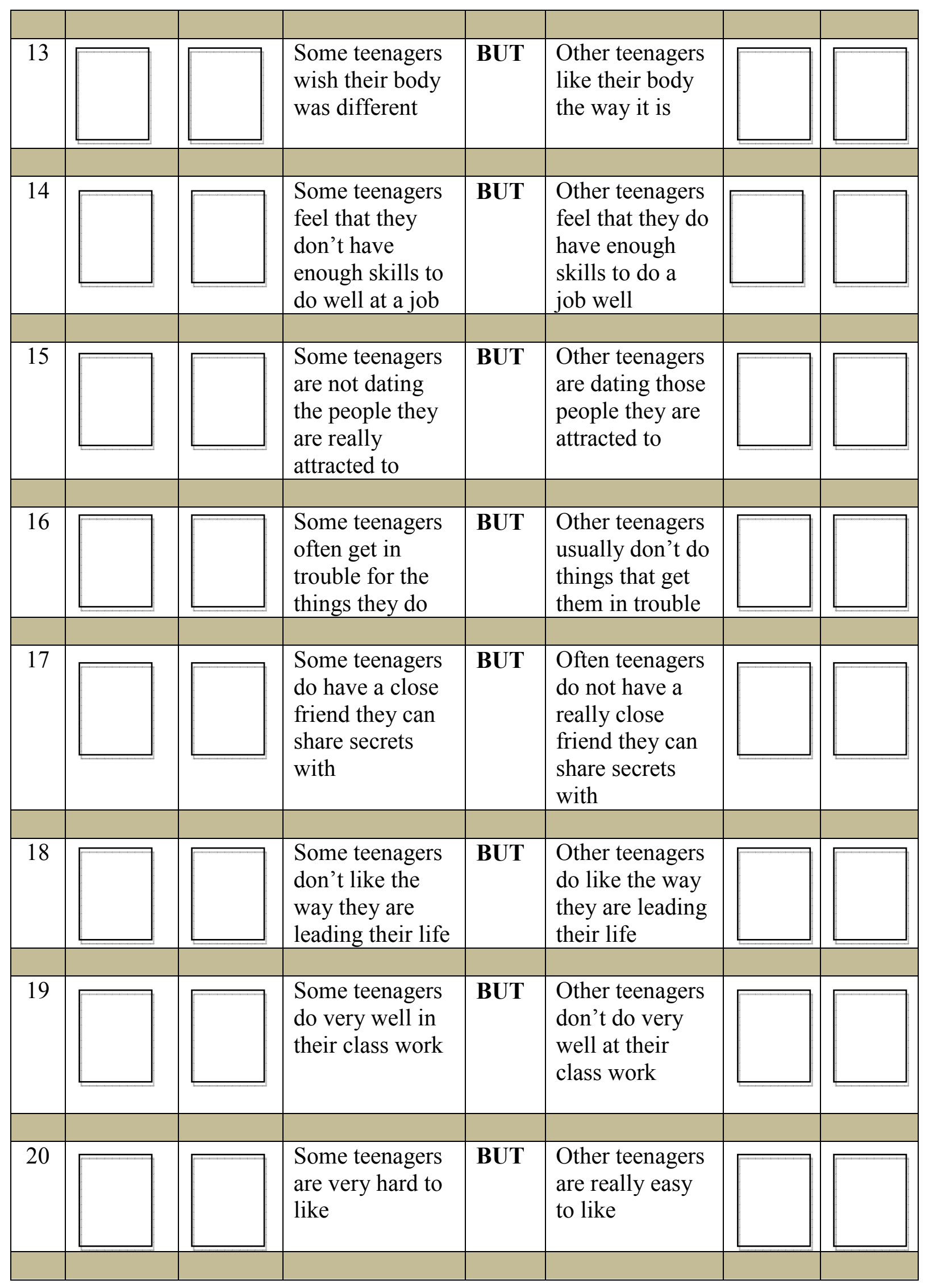




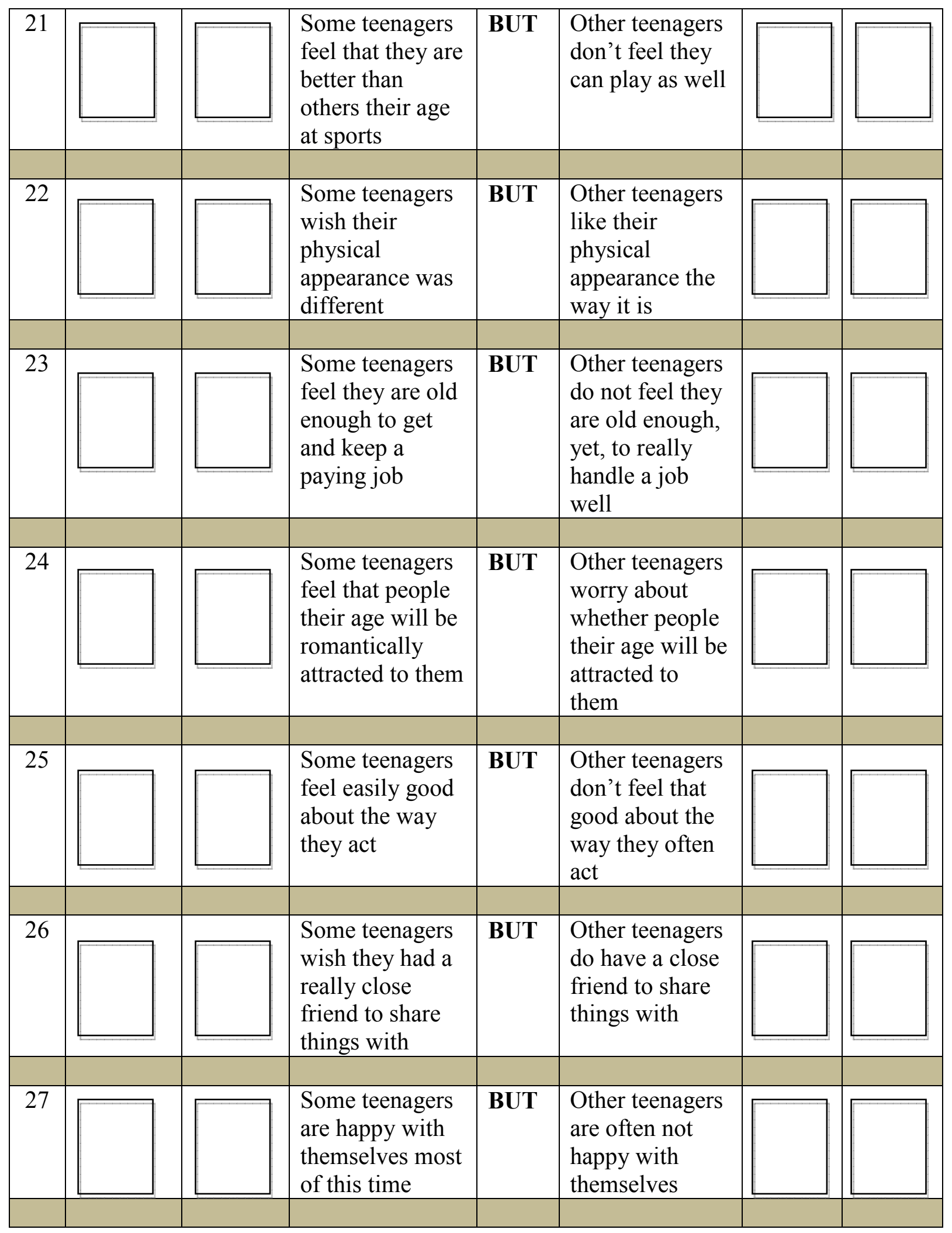




\begin{tabular}{|c|c|c|c|c|c|c|c|}
\hline 28 & & & $\begin{array}{l}\text { Some teenagers } \\
\text { have trouble } \\
\text { figuring out the } \\
\text { answers in } \\
\text { school }\end{array}$ & \begin{tabular}{|l|} 
BUT \\
\end{tabular} & $\begin{array}{l}\text { Other teenagers } \\
\text { almost always } \\
\text { can figure out } \\
\text { the answers }\end{array}$ & & \\
\hline 29 & & & $\begin{array}{l}\text { Some teenagers } \\
\text { are popular with } \\
\text { others their age }\end{array}$ & BUT & $\begin{array}{l}\text { Other teenagers } \\
\text { are not very } \\
\text { popular }\end{array}$ & & \\
\hline 30 & & & \begin{tabular}{|l} 
Some teenagers \\
don't do well at \\
new outdoor \\
games
\end{tabular} & BUT & \begin{tabular}{|l|} 
Other teenagers \\
are good at new \\
games right \\
away
\end{tabular} & & \\
\hline 31 & & & $\begin{array}{l}\text { Some teenagers } \\
\text { think that they } \\
\text { are good looking }\end{array}$ & BUT & $\begin{array}{l}\text { Other teenagers } \\
\text { think that they } \\
\text { are not very } \\
\text { good looking }\end{array}$ & & \\
\hline 32 & & & $\begin{array}{l}\text { Some teenagers } \\
\text { feel like they } \\
\text { could do better } \\
\text { at work they do } \\
\text { for pay }\end{array}$ & BUT & $\begin{array}{l}\text { Other teenagers } \\
\text { feel that they } \\
\text { are doing really } \\
\text { well at work } \\
\text { they do for pay }\end{array}$ & & \\
\hline 33 & & & $\begin{array}{l}\text { Some teenagers } \\
\text { feel that they are } \\
\text { fun and } \\
\text { interesting on a } \\
\text { date }\end{array}$ & BUT & $\begin{array}{l}\text { Other teenagers } \\
\text { wonder about } \\
\text { how fun and } \\
\text { interesting they } \\
\text { are on a date }\end{array}$ & & \\
\hline 34 & & & $\begin{array}{l}\text { Some teenagers } \\
\text { do things they } \\
\text { know they } \\
\text { shouldn't do }\end{array}$ & BUT & $\begin{array}{l}\text { Other teenagers } \\
\text { hardly ever do } \\
\text { things they } \\
\text { know they } \\
\text { shouldn't do }\end{array}$ & & \\
\hline 35 & & & $\begin{array}{l}\text { Some teenagers } \\
\text { find it hard to } \\
\text { make friends } \\
\text { they can really } \\
\text { trust }\end{array}$ & BUT & $\begin{array}{l}\text { Other teenagers } \\
\text { are able to make } \\
\text { close friends } \\
\text { they can really } \\
\text { trust }\end{array}$ & & \\
\hline
\end{tabular}




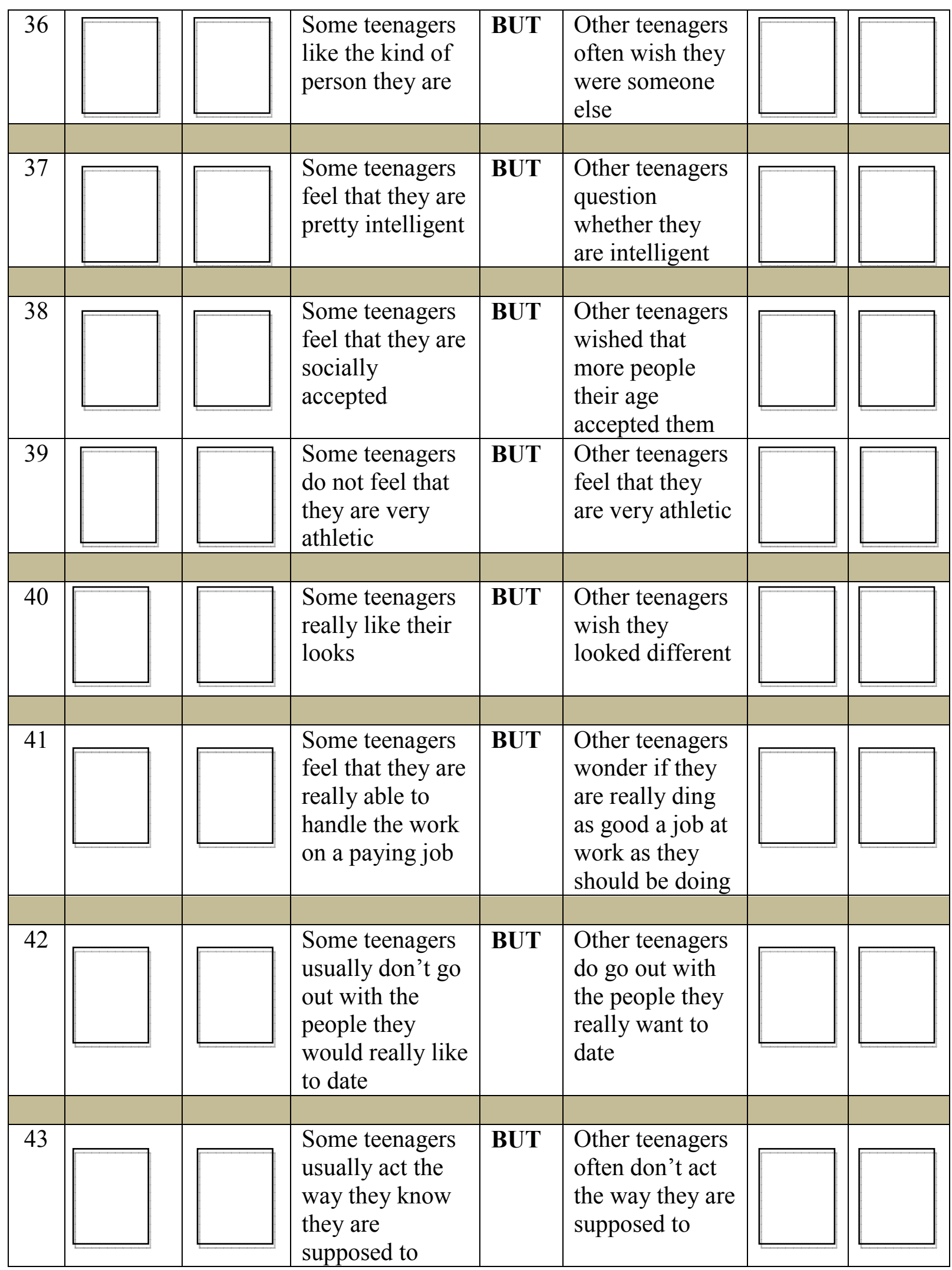




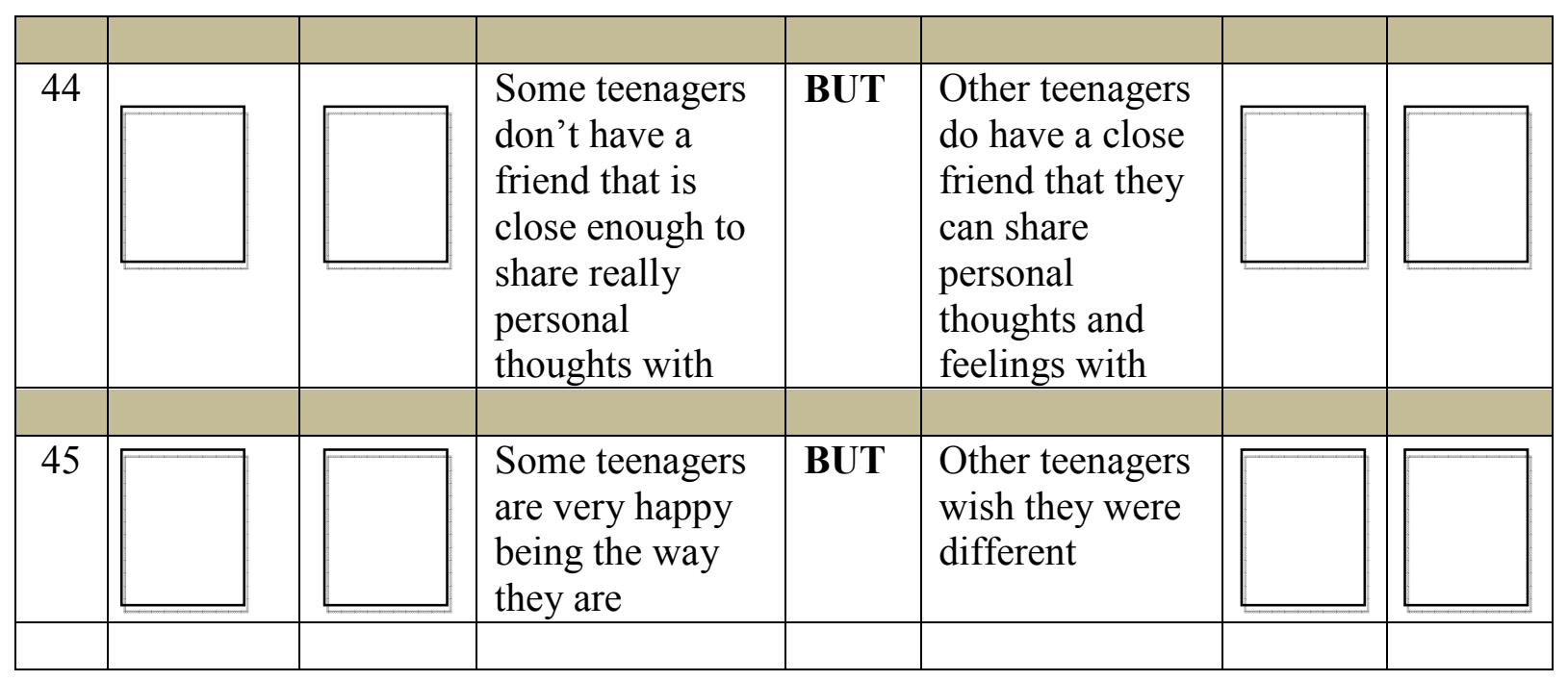




\section{APPENDIX B: HARTER ADOLESCENT SELF-PERCEPTION PROFILE SURVEY}

HOW IMPORTANT ARE EACH OF THESE THINGS TO YOU

Name

Age

Grade

Group

\begin{tabular}{|c|c|c|c|c|c|c|c|}
\hline & $\begin{array}{c}\text { Really } \\
\text { True } \\
\text { For } \\
\text { Me }\end{array}$ & $\begin{array}{l}\text { Sort } \\
\text { Of } \\
\text { True } \\
\text { For } \\
\text { Me }\end{array}$ & & & & $\begin{array}{l}\text { Sort } \\
\text { Of } \\
\text { True } \\
\text { For } \\
\text { Me }\end{array}$ & $\begin{array}{c}\text { Really } \\
\text { True } \\
\text { For } \\
\text { Me }\end{array}$ \\
\hline 1 & & & $\begin{array}{l}\text { Some teenagers } \\
\text { think it is } \\
\text { important to be } \\
\text { intelligent }\end{array}$ & BUT & $\begin{array}{l}\text { Other teenagers } \\
\text { don't think it is } \\
\text { important to be } \\
\text { intelligent }\end{array}$ & & \\
\hline & & & & & & & \\
\hline 2 & & & $\begin{array}{l}\text { Some teenagers } \\
\text { don't think it is } \\
\text { all that } \\
\text { important to } \\
\text { have a lot of } \\
\text { friends }\end{array}$ & BUT & $\begin{array}{l}\text { Other teenagers } \\
\text { think that } \\
\text { having a lot of } \\
\text { friends is } \\
\text { important }\end{array}$ & & \\
\hline 3 & & & $\begin{array}{l}\text { Some teenagers } \\
\text { think it is } \\
\text { important to be } \\
\text { good at sports }\end{array}$ & BUT & $\begin{array}{l}\text { Other teenagers } \\
\text { don't care much } \\
\text { about being } \\
\text { good at sports }\end{array}$ & & \\
\hline & & & & & & & \\
\hline 4 & & & $\begin{array}{l}\text { Some teenagers } \\
\text { don't really } \\
\text { think that their } \\
\text { physical } \\
\text { appearance is all } \\
\text { that important }\end{array}$ & BUT & $\begin{array}{l}\text { Other teenagers } \\
\text { think that their } \\
\text { physical } \\
\text { appearance is } \\
\text { important }\end{array}$ & & \\
\hline 5 & & & $\begin{array}{l}\text { Some teenagers } \\
\text { don't care that } \\
\text { much about how } \\
\text { well they do on } \\
\text { a paying job }\end{array}$ & BUT & $\begin{array}{l}\text { Other teenagers } \\
\text { feel it is } \\
\text { important that } \\
\text { they do well on } \\
\text { a paying job }\end{array}$ & & \\
\hline
\end{tabular}




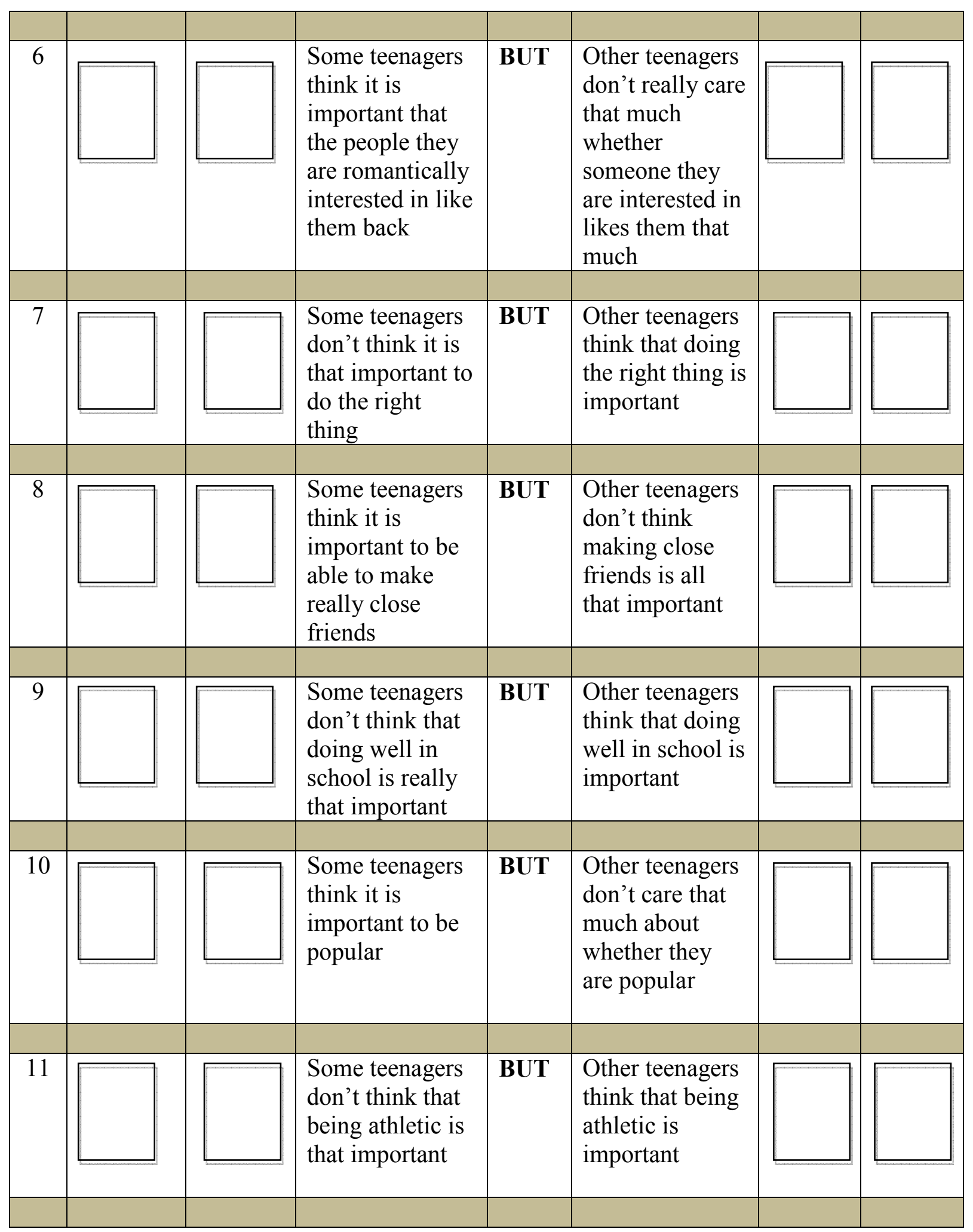




\begin{tabular}{|c|c|c|c|c|c|c|c|}
\hline 12 & Г & & $\begin{array}{l}\text { Some teenagers } \\
\text { think that how } \\
\text { they look is } \\
\text { important }\end{array}$ & BUT & $\begin{array}{l}\text { Other teenagers } \\
\text { don't care that } \\
\text { much about } \\
\text { how they look }\end{array}$ & & \\
\hline 13 & & & $\begin{array}{l}\text { Some teenagers } \\
\text { think it is } \\
\text { important to do } \\
\text { their best on a } \\
\text { paying job }\end{array}$ & BUT & $\begin{array}{l}\text { Other teenagers } \\
\text { don't think that } \\
\text { doing their best } \\
\text { on a job is all } \\
\text { that important }\end{array}$ & & \\
\hline & & & & & & & \\
\hline 14 & & & $\begin{array}{l}\text { Some teenagers } \\
\text { don't care that } \\
\text { much whether } \\
\text { they are dating } \\
\text { someone they } \\
\text { are romantically } \\
\text { interested in } \\
\end{array}$ & BUT & $\begin{array}{l}\text { Other teenagers } \\
\text { thinks it is } \\
\text { important to be } \\
\text { dating someone } \\
\text { they are } \\
\text { interested in }\end{array}$ & & \\
\hline 15 & & & $\begin{array}{l}\text { Some teenagers } \\
\text { think it is } \\
\text { important to act } \\
\text { the way they are } \\
\text { supposed to }\end{array}$ & BUT & $\begin{array}{l}\text { Other teenagers } \\
\text { don't care that } \\
\text { much whether } \\
\text { they are acting } \\
\text { the way they are } \\
\text { supposed to }\end{array}$ & & \\
\hline 16 & & & $\begin{array}{l}\text { Some teenagers } \\
\text { don't care that } \\
\text { much about } \\
\text { having a close } \\
\text { friend they can } \\
\text { trust } \\
\end{array}$ & BUT & $\begin{array}{l}\text { Other teenagers } \\
\text { thinks it is } \\
\text { important to } \\
\text { have a really } \\
\text { close friend you } \\
\text { can trust }\end{array}$ & & \\
\hline & & & & & & & \\
\hline
\end{tabular}




\section{APPENDIX C: ANDERSON STUDENT SURVEY}

Date:

School attended in $8^{\text {th }}$ grade:

Private/Public

Gender: Male

Female

School attended in $9^{\text {th }}$ grade: Private/Public

Ethnicity:

Please fill out the survey below based on your experience in ninth grade. Individual responses will be kept confidential.

\begin{tabular}{|l|c|c|c|c|c|}
\hline \multicolumn{1}{|c|}{ QUESTIONS } & $\begin{array}{c}\text { Strongly } \\
\text { Disagree }\end{array}$ & Disagree & Neutral & Agree & $\begin{array}{c}\text { Strongly } \\
\text { Agree }\end{array}$ \\
\hline $\begin{array}{l}\text { 1. Were you excited about entering school? } \\
\text { 2. Were you looking forward to making new } \\
\text { friends? }\end{array}$ & 1 & 2 & 3 & 4 & 5 \\
\hline $\begin{array}{l}\text { 3. Was the school schedule confusing in } \\
\text { ninth grade? }\end{array}$ & 1 & 2 & 3 & 4 & 5 \\
\hline $\begin{array}{l}\text { 4. Did you feel the academic work load in } \\
\text { high school was different from middle } \\
\text { school? }\end{array}$ & 1 & 2 & 3 & 4 & 5 \\
\hline $\begin{array}{l}\text { 5. Did you ever feel lost? } \\
\text { 6. Did you ever feel like dropping out of } \\
\text { school? }\end{array}$ & 1 & 2 & 3 & 4 & 5 \\
\hline $\begin{array}{l}\text { 7. Were the attendance procedures and } \\
\text { classroom schedules clearly explained at the } \\
\text { beginning of each semester? }\end{array}$ & 1 & 2 & 3 & 4 & 5 \\
\hline $\begin{array}{l}\text { 8. Was the grading policy explained at the } \\
\text { beginning of each semester? }\end{array}$ & 1 & 2 & 3 & 4 & 5 \\
\hline $\begin{array}{l}\text { 9. Was classroom discipline fair, consistent, } \\
\text { and conducive to learning? }\end{array}$ & 1 & 2 & 3 & 4 & 5 \\
\hline
\end{tabular}




\begin{tabular}{|l|c|c|c|c|c|}
\hline $\begin{array}{l}\text { 10. Did you feel that you received support } \\
\text { from school faculty and staff? }\end{array}$ & 1 & 2 & 3 & 4 & 5 \\
\hline $\begin{array}{l}\text { 11. Did you feel that you received support } \\
\text { from your parents/guardians? }\end{array}$ & 1 & 2 & 3 & 4 & 5 \\
\hline $\begin{array}{l}\text { 12. Did you feel your ninth grade teachers } \\
\text { motivated you to succeed? }\end{array}$ & 1 & 2 & 3 & 4 & 5 \\
\hline $\begin{array}{l}\text { 13. Were you satisfied with the academic } \\
\text { support you received in ninth grade? }\end{array}$ & 1 & 2 & 3 & 4 & 5 \\
\hline $\begin{array}{l}\text { 14. Were you satisfied with the procedural } \\
\text { support you received in ninth grade? }\end{array}$ & 1 & 2 & 3 & 4 & 5 \\
\hline $\begin{array}{l}\text { 15. Were you satisfied with the social } \\
\text { support you received in ninth grade? }\end{array}$ & 1 & 2 & 3 & 4 & 5 \\
\hline
\end{tabular}




\section{APPENDIX D: FOCUS GROUP INTERVIEW QUESTIONS}

School:

Date:

1. What were some of the things you missed about middle school (if any)?

(Circle all that apply)
a. Friends that did not attend the same high school.
b. School schedule
c. Particular teacher/staff member
d. Co-curricular activities of middle school

2. What were you looking forward to in high school?

(Circle all that apply)
a. New friends
b. More interesting/challenging classes
c. New schedules
d. More choice in academic classes
e. Co-curricular activities of high school

3. What were the major differences you observed during your transition to high school?

4. What was the easiest transition to high school?

5. What was the most challenging during your transition?

6 What transition activity was the most helpful to you in your transition? 
7. How important is graduating from high school to you?

8. Have you ever thought about leaving school before graduation? If so, what made you stay?

9. Overall, did you feel you had a successful ninth grade school year?

(Anderson, 2008) 


\section{CURRICULUM VITA}

\section{MICHAEL J. HIBBETT}

682 Devonshire

Florence, KY 41042

Tel: (859) 525-7305

E-Mail: michael.hibbett@yahoo.com

\section{EDUCATION BACKGROUND}

Administrative Certificate, Elementary, Middle School, High School, Superintendent, Xavier University. 1986.

Master Degree, Special Education K-12, East Tennessee State University, Johnson City, Tennessee. 1979.

Bachelor Degree, Elementary K-8, Special Education K-12, Northeastern Illinois University. 1977.

\section{PRESENTATIONS}

Hibbett, M. (April, 2014). Lost in Transition: A Grade Nine Transition Program using Articulation Activities and Their Affect On Student Attitudes.

\section{PROFESSIONAL MEMBERSHIPS}

Association for Supervision and Curriculum Development

Kentucky Association of School AdministratorsKentucky Association of School Councils

National/State Middle School Association

National/State Association of Secondary School Principals 


\section{PREVIOUS WORK EXPERIENCE}

Superintendent of Schools, Grant County Schools, Williamstown, KY 2007-2011

Assistant Superintendent of Operations, Boone County Schools, Florence, KY 1999-2007

Principal, Conner Middle School, Hebron, KY 1990-1999

Principal, Hillard Collins Elementary School, Florence, KY 1989-1990

Teacher, Boone County High School, Florence, KY 1986-1989

Teacher, R.A. Jones Middle School, Florence, KY 1982-1986

Teacher, Holmes Junior/Senior High School, Covington, KY 1981-1982

Teacher, Carlisle Elementary School, Covington, KY 1980-1981

Assistant, East Tennessee State University, Jonesboro, TN 1978-1979

Teacher, Greendale Middle School, Lawrence burg, IN 1978 